UNIVERSIDADE DE SÃO PAULO

INSTITUTO DE QUÍMICA DE SÃO CARLOS

\title{
CARACTERIZAÇÃO PARCIAL DOS PRODUTOS DE ELETROOXIDAÇÃO DO DIPIRIDAMOL EM ACETONITRILA E EM MEIO AQUOSO ÁCIDO
}

\section{MICHELLE LIMA}

Dissertação apresentada ao Instituto de Química de São Carlos, como requisito para a obtenção do título de Mestre em

Ciências. Área de Concentração: Química Analítica

Orientador: Prof. Dr. Marcel Tabak

São Carlos - SP

2008 
$O$ valor das coisas não está no tempo que elas duram, mas na intensidade com que acontecem. Por isso existem momentos inesquecíveis, coisas inexplicáveis e pessoas incomparáveis. 

Dedico a todos os meus amigos $e$ familiares que me apoiaram, incentivaram $e$ sempre estiveram ao meu lado nos bons e nos maus momentos. A Dra. Mariana Corrêa, Dra. Nina Mussolino e as funcionárias da Secretaria de pós-graduação do IQSC que não mediram esforços para me ajudar. $E$ principalmente aos médicos e funcionários do Hospital das Clínicas e do UNICOR de São Paulo que possibilitaram a continuidade da minha jornada... 


\section{AGRADECIMENTOS}

Ao meu orientador Prof. Dr. Marcel Tabak por toda a contribuição na minha formação como pesquisadora e pela oportunidade do ingresso em seu laboratório onde conheci pessoas incríveis e maravilhosas.

Ao Prof. Dr. Luiz Henrique Mazo por ter disponibilizado o seu laboratório para o desenvolvimento da pesquisa.

Aos meus amigos do GMEME: Andréa, Marcelão e Robson meus sinceros agradecimentos pela oportunidade de enriquecer os meus conhecimentos sobre eletroquímica e principalmente pela demonstração de carinho e sincera amizade! Adoro vocês!!!

Aos meus amigos do LaPE: Prof. Dr. Nerilso, Prof. Dr. Romeu, Profa Dra. Sônia, Kallyni, Edgar, Rogério, Luli, Adilson, Alexandre, Karina, Adriana, Fábio, Sheila, Patrícia, Laís, Edison (meu padrinho!) e Leonardo (meu pai!) pelo constante apoio, pelas maravilhosas festas, pelos sábios ensinamentos e por sempre estarem ao meu lado nas horas mais tristes... meus amigos do coração! muitas saudades!!!

Às minhas amigas Lidiane e Foca por terem sido as melhores parceiras de república!!! À minha turma de graduação 2000 da Federal de São Carlos!!! Saudades!!! Ao pessoal do CAQUI por toda atenção e carinho.

Ao Prof. Dr. Edson Rodrigues por todos os conselhos e pela paciência!!! Aos meus amigos do laboratório de Lesões em Biomoléculas e ao Prof. Dr. Paolo Di Mascio por todo o profissionalismo, pela prestimosa ajuda, por disponibilizar todos os recursos contribuindo para que o meu trabalho pudesse ser desenvolvido e mais ainda pela amizade e pelas boas risadas!!! 
Ao Prof. Dr. Maurício Baptista por ter disponibilizado o seu laboratório e pelos ensinamentos profissionais.

À Conceição e seus funcionários do Pão de Queijo, pelo carinho, pela preocupação e pelas ótimas risadas!!!

Aos médicos e funcionários do Posto Médico da USP por toda a atenção e ajuda.

Ao cirurgião Dr. Hugo Luz e à fonoaudióloga Thatiana do Hospital das Clínicas por terem cuidado de mim sempre com bom humor, humanidade e carinho.

Às técnicas Bel e Andressa do laboratório de Biofísica Molecular do Departamento de Física da USP de São Carlos por toda atenção, ajuda e disponibilidade.

Aos meus amados amigos e parceiros de laboratório: Alessandra (Líriooo), Aline (Federalll) Angel (E o meu cartão de crédito?), Ézer (Garotãooo), Júlio (Chúuu), Leonardo (Boca Nervosa), Marcos (Harry), Patrícia (Denizeee), Priscila (Kelly Key), Shirley (Festaaa!), Cláudia (Krewdia), Janiciara (Jane) Fran, Érika, Adriano (Chiquinho)... por todo carinho, amizade, apoio, pelas risadas, pelas festas, por todos os "bafões", pelas "chafurdações" e acima de tudo por gostarem de mim... mesmo sendo eu: Bola de Fogo e Boadiceia!!! Adoro todos vocês!!!

E principalmente a minha irmã de laboratório Marilene que além de desenvolver este trabalho junto comigo, sempre me ajudou e esteve ao meu lado, apoiando-me nos bons e maus momentos. Obrigada Mari por ter "quebrado a cabeça" junto comigo, pelas hilárias idas a São Paulo e pelos "bafões" nos Congressos. Não poderia ter tido melhor parceira e professora de laboratório!!! Que a nossa amizade seja para sempre! E finalmente à CNPq pela bolsa fornecida. 


\section{SUMÁRIO}

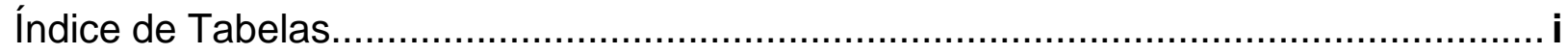

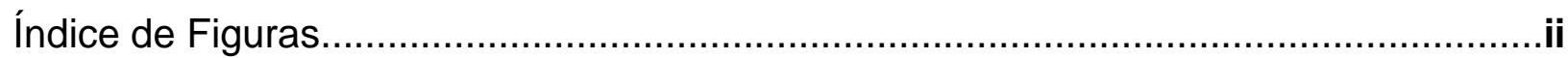

Lista de Símbolos e Abreviações...................................................................................

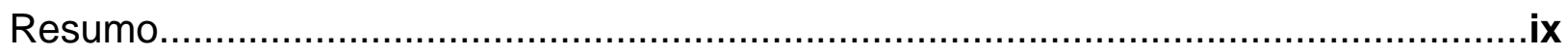

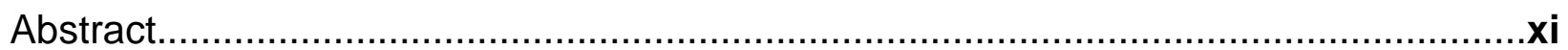

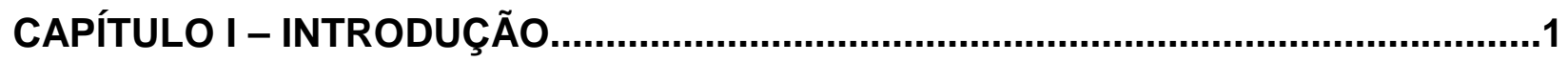

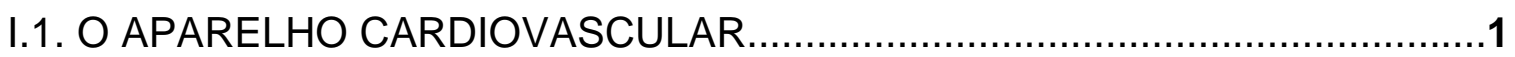

I.2. RADICAIS LIVRES E ESPÉCIES REATIVAS DO METABOLISMO DO

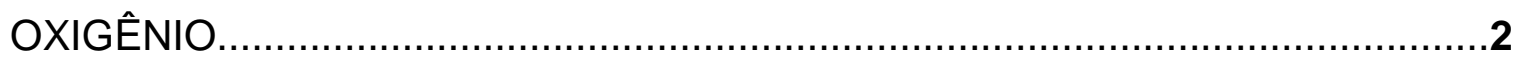

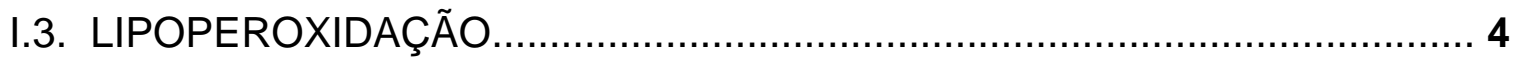

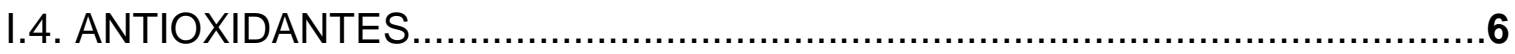

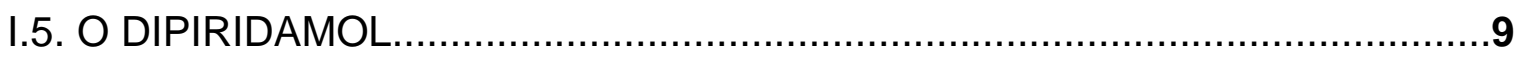

I.5.1. PROPRIEDADES QUÍMICAS DO DIPIRIDAMOL..........................14

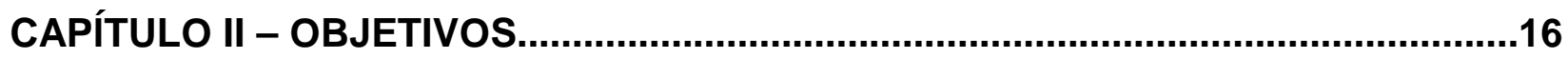

CAPÍTULO III - MATERIAIS E MÉTODOS..........................................................17

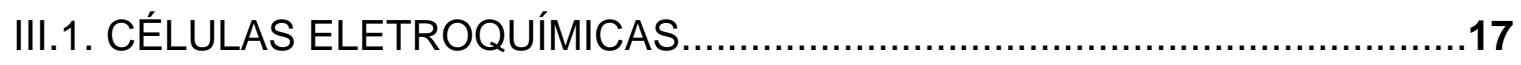

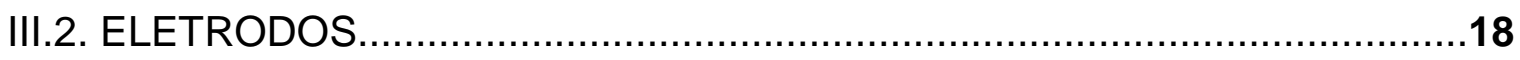




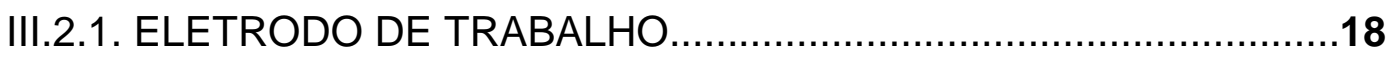

III.2.2. ELETRODO DE REFERÊNCIA ...............................................18

III.2.3. CONTRA ELETRODO.........................................................18

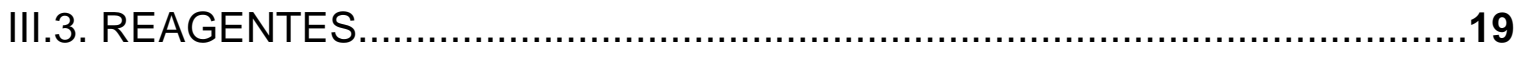

III.4. SOLUÇÕES DE DIP EM ACETONITRILA .............................................19

III.5. SOLUÇÕES DE DIP EM MEIO ÁCIDO ..........................................................

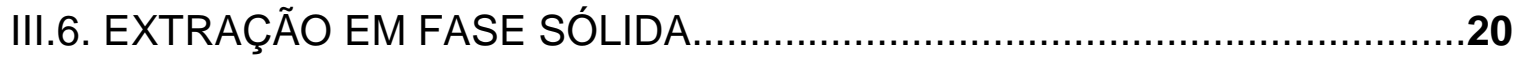

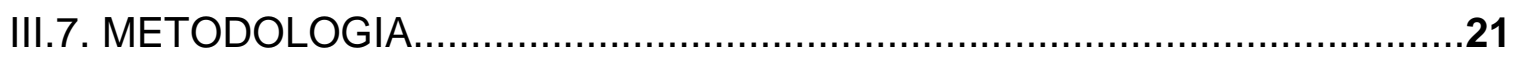

III.7.1. VOLTAMETRIA CÍCLICA...................................................21

III.7.2. ELETRÓLISE A POTENCIAL CONTROLADO.............................22

III.7.3. ESPECTROSCOPIA DE ABSORÇÃO UV-Vis..............................22

III.7.4. ESPECTROSCOPIA DE EMISSÃO DE FLUORESCÊNCIA..........23

III.7.5. EXTRAÇÃO EM FASE SÓLIDA................................................23

III.7.6. CROMATOGRAFIA LÍQUIDA ACOPLADA A ESPECTROMETRIA

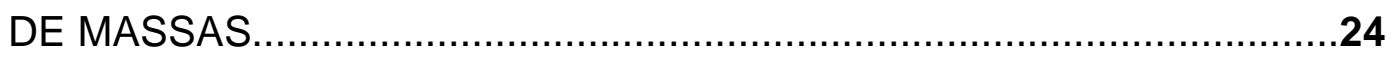

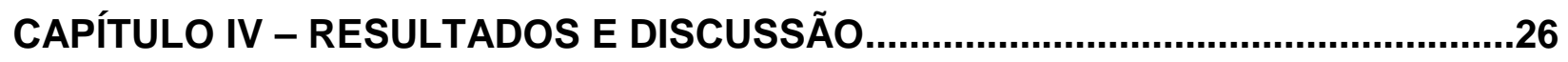

IV.1. ELETROQUÍMICA DO DIPIRIDAMOL EM ACETONITRILA E EM MEIO

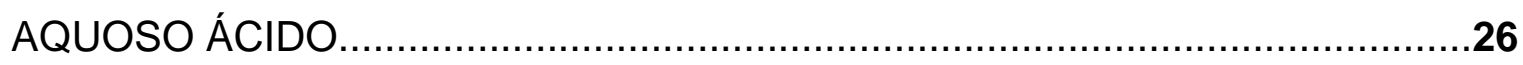

IV.2. ESPECTROSCOPIA ÓTICA DA ELETROOXIDAÇÃO DO DIPIRIDAMOL EM ACETONITRILA E EM MEIO AQUOSO ÁCIDO..........................................30

IV.3. ANÁLISES CROMATOGRÁFICAS E ESPECTROMÉTRICAS DOS PRODUTOS DE ELETROOXIDAÇÃO DO DIPIRIDAMOL..................................39 
IV.3.1. ANÁLISE DOS PRODUTOS DA FRAÇÃO AQUOSA DAS ELETRÓLISES DO DIPIRIDAMOL EM ACETONITRILA NA PRIMEIRA ONDA.

IV.3.2. ANÁLISE DOS PRODUTOS DA FRAÇÃO AQUOSA DAS ELETRÓLISES DO DIPIRIDAMOL EM ACETONITRILA NA SEGUNDA ONDA. 45

IV.3.3. ANÁLISE DOS PRODUTOS DA FRAÇÃO METANÓLICA DAS ELETRÓLISES DO DIPIRIDAMOL EM ACETONITRILA NA PRIMEIRA ONDA.

IV.3.4. ANÁLISE DOS PRODUTOS DA FRAÇÃO METANÓLICA DAS ELETRÓLISES DO DIPIRIDAMOL EM ACETONITRILA NA SEGUNDA ONDA. .53

IV.3.5. ANÁLISE DOS PRODUTOS DAS ELETRÓLISES DO DIPIRIDAMOL EM MEIO AQUOSO ÁCIDO.

V - CONCLUSÕES.

VI - PERSPECTIVAS FUTURAS. .64 


\section{Índice de Tabelas}

Tabela I. procedência e grau de pureza dos reagentes utilizados.

19

Tabela II. Cálculos teóricos dos elétrons envolvidos nas eletrooxidações

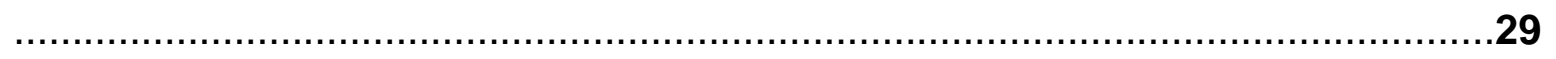

Tabela III. Concentração e porcentagem residual de DIP antes e após a

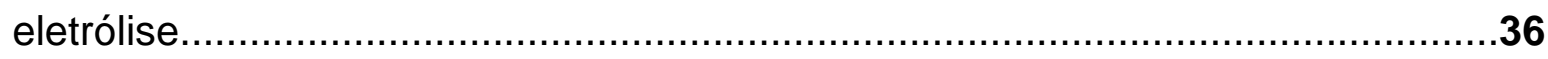




\section{Índice de Figuras}

Figura 1: Estrutura do Dipiridamol e seus derivados.

Figura 2: Voltamogramas cíclicos do DIP $0,5 \mathrm{mM}$ antes e depois das eletrólises;solução eletrolisada: $20 \mathrm{~mL}$ (A) Potencial de primeira onda em ACN; Tempo de eletrólise = 1,0 hora; (B) Potencial de segunda onda em ACN; Tempo de eletrólise $=1,0$ hora e $(\mathrm{C})$ em meio aquoso ácido $\mathrm{pH}=1,0$; Tempo de eletrólise $=$ 2,0 horas.

27

Figura 3: Cronoamperogramas das eletrólises do DIP $0,5 \mathrm{mM}$, volume de solução $20 \mathrm{~mL}(\mathrm{~A})$ em ACN na primeira onda $=+340 \mathrm{mV}$, (B) em ACN na segunda onda $=$ $+680 \mathrm{mV}$ e $(\mathrm{C})$ no meio aquoso ácido $=840$ $\mathrm{mV}$. 28

Figura 4: Espectros de absorção ótica da eletrooxidação do DIP 0,5 mM utilizando cubeta de quartzo de $1 \mathrm{~mm}$ de caminho ótico: (A) eletrolise em ACN na primeira onda, (B) eletrólise em ACN na segunda onda e (C) eletrólise em meio aquoso ácido.

Figura 5: Espectros de absorção ótica da eletrooxidação do DIP 0,5 mM utilizando cubeta de quartzo de $1 \mathrm{~mm}$ de caminho ótico: (A) eletrólise em ACN na primeira onda, (B) eletrólise em ACN na segunda onda e (C) eletrólise em meio aquoso ácido. Espectros apresentados foram extraídos da Figura 4

Figura 6: Espectros de fluorescência antes e depois da eletrólise do DIP 0,5 mM, $\lambda_{\text {exc }}=412 \mathrm{~nm}$, utilizando cubeta de quartzo de $1 \mathrm{~mm}$ de caminho ótico orientada à 45 em relação ao raio de excitação: $(A)$ eletrolise em $A C N$ na primeira onda, (B) eletrólise em $A C N$ na segunda onda e (C) eletrólise em meio aquoso ácido.

Figura 7: Cromatograma das frações em Sep-Pak do material de quatro eletrólises de $20 \mathrm{~mL}$ cada do DIP $0,5 \mathrm{mM}$. Absorbância medida em $\lambda=275 \mathrm{~nm}$ : (A) eletrolise em ACN na primeira onda, (B) eletrólise em ACN na segunda onda e (C) eletrólise em meio aquoso ácido.

Figura 8: Espectros de absorção ótica dos cromatogramas das frações separadas em Sep-Pak do material de duas eletrólises de $20 \mathrm{~mL}$ cada, de DIP 0,5 mM. Foi utilizada cubeta de quartzo de $1 \mathrm{~cm}$ de caminho ótico: (A) eletrólise em $A C N$ na primeira onda e (B) eletrólise em ACN na segunda onda...

Figura 9: Cromatograma do Dipiridamol 0,5 mM, Fase móvel: $\mathrm{NH}_{4} \mathrm{COOH}$ [30 mM] / $\mathrm{MeOH}$;Gradiente de eluição 3-97\% de $\mathrm{MeOH}$ em 30 min; Volume de injeção: $25 \mu \mathrm{L}$; Fluxo de $1 \mathrm{~mL} / \mathrm{min}$. 
Figura 10: Cromatogramas dos produtos da fração aquosa da eletrooxidação do DIP em ACN na primeira onda $(340 \mathrm{mV})$, Fase móvel: $\mathrm{NH}_{4} \mathrm{COOH}$ [30 mM] / $\mathrm{MeOH}$;Gradiente de eluição 3-97\% de $\mathrm{MeOH}$ em 30 min; Volume de injeção: $100 \mu \mathrm{L}$; Fluxo de $1 \mathrm{~mL} / \mathrm{min}$.

Figura 11: Espectros de massas do produto de $t_{r}=8.9 \mathrm{~min}$, fração aquosa da eletrooxidação na primeira onda (A) "fullscan" - ESI/MS no modo positivo, voltagem do cone $40 \mathrm{~V}$, voltagem do capilar $3,6 \mathrm{kV}$. (B) respectivos íonsfragmentos, energia de colisão $30 \mathrm{eV}$.

Figura 12: Proposta de estrutura para o produto da eletrooxidação em meio aquoso ácido [31].

Figura 13: Espectros de massas do produto de $t_{r}=11.7 \mathrm{~min}$, fração aquosa da eletrooxidação na primeira onda (A) "fullscan" - ESI/MS no modo positivo, voltagem do cone $40 \mathrm{~V}$, voltagem do capilar $3,6 \mathrm{kV}$. (B) respectivos íonsfragmentos,energia de colisão $30 \mathrm{eV}$.

Figura 14: Espectros de massas "fullscan" - ESI/MS no modo positivo do produto de $t_{r}=16.0 \mathrm{~min}$, da fração aquosa da eletrooxidação na primeira onda, voltagem do cone $40 \mathrm{~V}$, voltagem do capilar $3,6 \mathrm{kV}$.

Figura 15: Proposta de mecanismo e estrutura final do produto da eletrooxidação (fração metanólica) na primeira e segunda ondas em acetonitrila, $\mathrm{t}_{\mathrm{r}}=16.0 \mathrm{~min} . . .45$

Figura 16: Cromatogramas dos produtos da fração aquosa da eletrooxidação do DIP em ACN na segunda onda $(680 \mathrm{mV})$. Fase móvel: $\mathrm{NH}_{4} \mathrm{COOH}$ [30 mM] / $\mathrm{MeOH}$. Gradiente de eluição: $3-30 \%$ de $\mathrm{MeOH}$ em 30 min; Volume de injeção: $100 \mu \mathrm{L}$; Fluxo de $1 \mathrm{~mL} / \mathrm{min}$.

Figura 17: Espectros de massas do produto de $t_{r}=9.3 \mathrm{~min}$, da fração aquosa da eletrooxidação na segunda onda (A) "fullscan" - ESI/MS no modo positivo, voltagem do cone $40 \mathrm{~V}$, voltagem do capilar $3,6 \mathrm{kV}$. (B) respectivos íonsfragmentos, energia de colisão $30 \mathrm{eV}$.

Figura 18: Espectros de massas do produto de $t_{r}=12.2 \mathrm{~min}$, fração aquosa da eletrooxidação na segunda onda (A) "fullscan" - ESI/MS no modo positivo, voltagem do cone $40 \mathrm{~V}$, voltagem do capilar $3,6 \mathrm{kV}$. (B) respectivos íonsfragmentos, energia de colisão $30 \mathrm{eV}$. 48

Figura 19: Espectros de massas "fullscan" - ESI/MS no modo positivo, do produto de $t_{r}=16.5$ min, fração aquosa da eletrooxidação na segunda onda, voltagem do cone $40 \mathrm{~V}$, voltagem do capilar $3,6 \mathrm{kV}$. 48 
Figura 20: Cromatograma dos produtos da fração metanólica da eletrooxidação na primeira onda $(+350 \mathrm{mV})$ do DIP em acetonitrila. Fase móvel: $\mathrm{NH}_{4} \mathrm{COOH}$ [30 $\mathrm{mM}$ ] / MeOH. Gradiente: $30 \%$ a $97 \%$ de $\mathrm{MeOH}$ em 30 min; Fase estacionária: C18; Volume de injeção: $100 \mu \mathrm{L}$. Com fluxo de 1

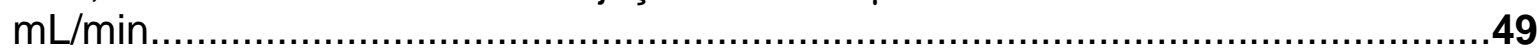

Figura 21: Espectros de massas do produto de $t_{r}=11.9$ min, fração metanólica da eletrooxidação na primeira onda (A) "fullscan" - ESI/MS no modo positivo, voltagem do cone $30 \mathrm{~V}$, voltagem do capilar $3,6 \mathrm{kV}$. (B) respectivos íonsfragmentos, energia de colisão $50 \mathrm{eV}$.

Figura 22: Espectros de massas do produto de $t_{r}=22.0$ min, fração metanólica da eletrooxidação na primeira onda (A) "fullscan" - ESI/MS no modo positivo, voltagem do cone $30 \mathrm{~V}$, voltagem do capilar $3,6 \mathrm{kV}$. (B) respectivos íonsfragmentos, energia de colisão $70 \mathrm{eV}$.

Figura 23: Proposta de mecanismo e estrutura final do produto da eletrooxidação (fração metanólica) na primeira e segunda onda em acetonitrila, $t_{r}=22.0$ $\min$

Figura 24: Espectro de massas do DIP regenerado em solução após a eletrooxidação na primeira onda; $t_{r}=29.1 \mathrm{~min}$ "fullscan" - ESI/MS no modo positivo, voltagem do cone $40 \mathrm{~V}$, voltagem do capilar $3,6 \mathrm{kV}$. .52

Figura 25: Cromatograma dos produtos da fração metanólica da eletrooxidação na segunda onda $(+640 \mathrm{mV})$ do DIP em acetonitrila. Fase móvel: $\mathrm{NH}_{4} \mathrm{COOH}$ [30 $\mathrm{mM}$ ] / MeOH. Gradiente: $30 \%$ a $97 \%$ de $\mathrm{MeOH}$ em 30 min; Fase estacionária: C18; Volume de injeção: $100 \mu \mathrm{L}$. Com fluxo de $1 \mathrm{~mL} / \mathrm{min}$.

Figura 26: Espectros de massas do produto de $t_{r}=6.8$ min, fração metanólica da eletrooxidação na segunda onda (A) "fullscan" - ESI/MS no modo positivo, voltagem do cone $30 \mathrm{~V}$, voltagem do capilar $3,6 \mathrm{kV}$. (B) respectivos íonsfragmentos, energia de colisão $50 \mathrm{eV}$. .54

Figura 27: Espectros de massas do produto de $t_{r}=17.6 \mathrm{~min}$, fração metanólica da eletrooxidação na segunda onda (A) "fullscan" - ESI/MS no modo positivo, voltagem do cone $30 \mathrm{~V}$, voltagem do capilar $3,6 \mathrm{kV}$. (B) respectivos íonsfragmentos, energia de colisão $70 \mathrm{eV}$.

Figura 28: Espectro de massas do DIP regenerado em solução após a eletrooxidação na segunda onda; "fullscan" - ESI/MS no modo positivo, $t_{r}=24.0$ min voltagem do cone $40 \mathrm{~V}$, voltagem do capilar $3,6 \mathrm{kV}$... 
Figura 29: Cromatogramas dos produtos da eletrólise do DIP em meio ácido. Fase móvel $\mathrm{NH}_{4} \mathrm{COOH}[30 \mathrm{mM}] / \mathrm{MeOH}$. Gradiente de eluição: 3-97\% de $\mathrm{MeOH}$ em 30 min. Fase estacionária: C18; Volume de injeção: 100 $\mu \mathrm{L}$. com fluxo de 1 $\mathrm{mL} / \mathrm{min}$

Figura 30: Espectros de massas do produto de $t_{r}=8.9 \mathrm{~min}(A), t_{r}=11.7 \mathrm{~min}(C), t_{r}$ = $12 \mathrm{~min}(\mathrm{E})$, da eletrooxidação do Dipiridamol em meio aquoso ácido. "Fullscan" ESI/MS no modo positivo, voltagem do cone $20 \mathrm{~V}$, voltagem do capilar $3,6 \mathrm{kV}$. (B, $\mathrm{D}, \mathrm{F})$ respectivos íons-fragmentos, energia de colisão $30 \mathrm{eV}$.

Figura 31: Espectros de massas dos produtos de $t_{r}=29.7(A), 14.4(B)$ e $21.1 \mathrm{~min}$ (C), da eletrooxidação do Dipiridamol em meio aquoso ácido. (A, B, C) "fullscan" ESI/MS no modo positivo, voltagem do cone $20 \mathrm{~V}$, voltagem do capilar 3,6 $\mathrm{kV}$. .58

Figura 32: Espectros de massas dos produtos de $t_{r}=15.1 \mathrm{~min}$, da eletrooxidação do Dipiridamol em meio aquoso ácido. "fullscan" - ESI/MS no modo positivo, voltagem do cone $20 \mathrm{~V}$, voltagem do capilar $3,6 \mathrm{kV}$ 59

Figura 33: Espectros de massas dos produtos de $t_{r}=26.9 \mathrm{~min}$, da eletrooxidação do Dipiridamol em meio aquoso ácido. "fullscan" - ESI/MS no modo positivo, voltagem do cone $20 \mathrm{~V}$, voltagem do capilar $3,6 \mathrm{kV}$. 60 


\section{Lista de Símbolos e Abreviações}

$\lambda=$ Comprimento de Onda

$\phi=$ Diâmetro

$\mu \mathbf{A}=$ Microampere

$[\mathrm{M}+\mathbf{2 H}]^{+}=$ĺon Duplamente Carregado

$[\mathrm{M}+\mathrm{H}]^{+}=$Íon Monocarregado

$\mathbf{A C N}=$ Acetonitrila

$\mathbf{A g C l}=$ Cloreto de Prata

$\mathrm{AgNO}_{3}=$ Nitrato de Prata

C18 $=$ Fase Octadecilsilano

DIP = Dipiridamol

DIP $^{*+}=$ Cátion Radical do Dipiridamol

DIP $^{2+}=$ Dicátion do Dipiridamol

$\mathbf{E}=$ Potencial

EPR = Ressonância Paramagnética Eletrônica

ERMO = Espécies Reativas do Metabolismo do Oxigênio

$\mathrm{ESI}^{+} / \mathbf{M S}=$ Espectrometria de Massas com lonização por Eletronspray no Modo Positivo

$\mathrm{eV}=$ Eletrovolts

$\mathbf{F e}=$ Ferro

$\mathbf{h}=$ Horas

$\mathrm{H}_{2} \mathrm{O}=$ Água

$\mathrm{H}_{2} \mathrm{O}_{2}=$ Peróxido de Hidrogênio 
$\mathrm{HCl}=$ Ácido Clorídrico

HPLC = Cromatografia Líquida de Alta Eficiência

$\mathbf{I}=$ Corrente

$\mathbf{k} \mathbf{V}=$ kilovolts

L = Lipídeo

$\mathbf{L}^{\bullet}=$ Radical Lipídico

LC-MS = Espectrometria de Massas Acoplada a Cromatografia Líquida

$\mathrm{LiClO}_{4}=$ Perclorato de Lítio

$\mathrm{LO}^{\circ}=$ Radical Alcoxila

LOO $^{\circ}=$ Radical Peroxila

LOOH = Hidroperóxidos Lipídicos

$\boldsymbol{m} / \mathbf{z}=$ Relação Carga Massa

$\mathrm{MeOH}=$ Metanol

$\min =\operatorname{mintos}$

MS = Espectrometria de Massas

$\mathbf{m V}=$ Milivolts

$\mathbf{n A}=$ Nanoampere

$\mathrm{NH}_{4} \mathrm{COOH}=$ Formiato de Amônio

$\mathbf{n m}=$ Nanômetros

$\mathrm{O}_{2}=$ Oxigênio no Estado Fundamental

$\mathrm{O}_{2}^{-}=$Radical Superóxido

$\mathrm{OH}^{\bullet}=$ Radical Hidroxila

PA = Pureza Analítica 
$\mathbf{P t}=$ Platina

RMN = Ressonância Magnética Nuclear

$\mathbf{s}=$ Segundos

SPE $=$ Extração em Fase Sólida

$\mathbf{t}_{\mathbf{r}}=$ Tempo de Retenção

UV = Ultravioleta Visível 


\section{RESUMO}

Neste trabalho foram estudados os produtos gerados pela eletrooxidação do 2,6bis(dietanolamina)-4,8-dipiperidinapirimida-[5,4-d] pirimidina, Dipiridamol. Atualmente o Dipiridamol é um dos fármacos que induzem vasodilatação coronariana mais utilizados em Cardiologia Nuclear em diferentes técnicas aplicadas na aquisição e processamento de imagens (cintilografia miocárdica de perfusão, cintilografia de necrose miorcárdica, ressonância magnética do coração, ventriculografia e angiocardiografia radio-isotópica). Na prática clínica, o emprego do dipiridamol baseia-se na diminuição da agregação plaquetária, elevação dos níveis de adenosina e na potencialização dos efeitos da Aspirina $^{\circledR}$.

A eletrooxidação do Dipiridamol em acetonitrila é caracterizada por dois processos consecutivos envolvendo a perda de um elétron em cada etapa de oxidação. Diferentemente do meio aprótico, a eletrooxidação do Dipiridamol em meio aquoso ácido, apresenta apenas uma única etapa de oxidação que corresponde à perda de dois elétrons.

A eletrooxidação foi realizada em condições de potencial controlado para a retirada de um ou de dois elétrons. Espectros de Absorção Ótica e de Fluorescência foram obtidos após as eletrooxidações para o acompanhamento da estabilização e caracterização parcial dos produtos de oxidação eletroquímica nos diferentes meios.

Após a estabilização dos produtos utilizou-se a técnica de Extração em Fase Sólida para a retirada do sal eletrolítico, obtendo-se dois tipos de frações, uma aquosa e outra metanólica, na eletrooxidação em acetonitrila. Essas frações foram estudadas 
por meio de Espectrometria de Massas acoplada à Cromatografia Líquida de Alta Eficiência (LC-MS).

Não foi utilizada Extração em Fase Sólida para os compostos obtidos pela eletrólise em meio aquoso ácido, os quais, foram analisados diretamente por LC-MS.

Os produtos obtidos das eletrooxidações do Dipiridamol foram parcialmente caracterizados. Todas as eletrólises levaram à formação de isômeros com $\mathrm{m} / \mathrm{z}$ de 472 $[\mathrm{M}+\mathrm{H}]^{+}, 269[\mathrm{M}+\mathrm{H}]^{+}, 519[\mathrm{M}+\mathrm{H}]^{+}$e $505[\mathrm{M}+\mathrm{H}]^{+}$. A elucidação estrutural completa destes produtos não foi possível devido à instabilidade e à baixa concentração dos mesmos o que impossibilitou a realização de estudos mais detalhados de caracterização estrutural. 


\section{ABSTRACT}

In this work the products obtained in the eletrooxidation reactions of 2,6bis(diethanolamino)-4,8-dipiperidinopyrimido-[5,4-d] pyrimidine (Dipyridamole) were studied. Dipyridamole is a drug that induce the coronary vasodilatation mostly used in Nuclear Cardiology in different techniques based on acquisition and image processing ( perfusion heart cintilography, heart necrosis cintilography, heart magnetic resonance, ventriclegraphy and radio-isotopic coronary angioplasty). In clinical medicine, Dipyridamole is used for decreasing platelet aggregation, increasing the adenosine levels and co-activating Aspirine ${ }^{\circledR}$ effects.

The eletrooxidation of the Dipyridamole in acetonitrile is characterized by two consecutives processes involving the release of one electron in each stage of oxidation. Differently from aprotic medium, the electrooxidation of Dipyridamole in acid aqueous media shows a single oxidation stage corresponding to the release of two electrons.

Electrooxidation was performed in Controlled Potential Conditions using a potential necessary to remove one or two electrons. Optical Absorption and Fluorescence Emission Spectra were obtained after the electrooxidation to monitor the electrochemical oxidation products stabilization in different media.

After allowing the products stabilization Solid Phase Extraction tecnique was used to remove the electrolytical salt, and, two different fractions were obtained, an aqueous one and a methanolic one upon the electrooxidation in acetonitrile. These fractions were studied by Mass Spectrometry combined with High Performance Liquid Chromatography. (LC-MS). Solid Phase Extraction was not used for the products 
obtained in acid aqueous medium eletrolysis, and they were directly analyzed by LCMS.

The products obtained from Dipiridamol eletrooxidations were partially characterized. Every electrooxidation formed isomers with $\mathrm{m} / \mathrm{z}$ de $472[\mathrm{M}+\mathrm{H}]^{+}, 269$ $[\mathrm{M}+\mathrm{H}]^{+}, 519[\mathrm{M}+\mathrm{H}]^{+}$and $505[\mathrm{M}+\mathrm{H}]^{+}$. The complete structural elucidation of these products was not possible due to their instability and the low concentration obtained in the purification, which was insufficient for futher detailed studies such as nuclear magnetic resonance analysis. 


\section{CAPÍTULO I - INTRODUÇÃO}

\section{I.1 O APARELHO CARDIOVASCULAR}

O Aparelho Cardiovascular funciona para fornecer e manter contínuo o fluxo sangüíneo aos diversos tecidos do organismo, segundo suas necessidades metabólicas, para o desempenho das funções que devem cumprir, diante das diversas exigências funcionais a que o organismo está sujeito.

Apesar da evolução tecnológica e dos grandes conhecimentos e dos estudos realizados nos últimos anos, a insuficiência cardíaca é uma síndrome com alta mortalidade nas formas avançadas atingindo $50 \%$ dos pacientes por ano. Com a descoberta e o estudo dos fatores fisiopatológicos envolvidos na insuficiência cardíaca, ingressamos numa nova forma de analisar e tratarmos pessoas doentes, deixando num passado não muito distante, o tratamento básico das alterações hemodinâmicas com inotrópicos e diuréticos, que apenas tratava sintomas sem efeitos sobre a alta mortalidade.

A descoberta de dois grupos de substâncias neuro-hormonais estimulados na insuficiência cardíaca foi de fundamental importância. Os hormônios vasoconstritores (noradrenalina, sistema renina-angiotensina-aldoterona-SRAA e arginina-vasopressina) que são antinatriuréticos, antidiuréticos e geralmente têm propriedades de promover hipertrofia, enquanto que, o grupo de vasodilatadores (fator atrial natriurético, prostoglandinas, sistema calicreína e cinina) são diuréticos e têm efeitos antimitogênicos. 
O desenvolvimento dos estudos da fisiopatologia da insuficiência cardíaca possibilitou o uso de fármacos que não só melhoram a sintomatologia, mas modificam significativamente a morbidade e a mortalidade aumentando a sobrevida dos pacientes [1].

Os principais sintomas da insuficiência cardíaca são dispnéia, fadiga e diminuição de força muscular. Esses sintomas podem limitar a tolerância ao esforço físico, levando à congestão pulmonar e ao edema periférico. No entanto, uma das hipóteses para a diminuição de força muscular é o aumento do dano oxidativo, promovido por hipoxemia relacionada à redução do aporte sangüíneo, [2] uma vez que a estrutura e a função das membranas celulares são afetadas, resultando em disfunção celular, e assim, aumentando a lipoperoxidação e diminuindo a atividade de enzimas antioxidantes, culminando numa situação de estresse oxidativo pela geração excessiva de radicais livres [3].

Entre os radicais livres que causam mais danos às membranas celulares encontram-se as espécies reativas do metabolismo do oxigênio (ERMO) que ocorrem em todos os sistemas biológicos.

\section{I.2 RADICAIS LIVRES E ESPÉCIES REATIVAS DO METABOLISMO DO OXIGÊNIO}

Radical livre é qualquer espécie química capaz de existir independentemente, que contenha um ou mais elétrons não pareados ocupando orbitais atômicos ou moleculares. Em geral, estas espécies são instáveis, têm uma meia-vida muita curta 
(podendo variar desde nanosegundos a alguns minutos), e reagem rapidamente com diversos compostos e alvos celulares.

Os radicais livres podem ser formados pela perda ou adição de um único elétron a um composto não radicalar. $\mathrm{Na}$ natureza existem substâncias que são radicais livres, como o oxigênio no estado fundamental $\left(\mathrm{O}_{2}\right)$ e o óxido nítrico $\left(\mathrm{NO}^{\circ}\right)$, que ocorre como poluente atmosférico, mas que também é sintetizado em diversas células do organismo, sendo, atualmente, identificado como o fator de relaxamento dependente do endotélio (EDRF).

Pelo fato da molécula de oxigênio ser um bi-radical (possuir dois elétrons livres nos orbitais $\pi$ antiligantes), o oxigênio só pode reagir com moléculas com configuração eletrônica semelhante. Como a maioria das biomoléculas não são biradicais, o oxigênio fica impedido (por restrição de spin) de reagir com as mesmas, evitando assim que alvos celulares importantes sejam lesados. No entanto, o oxigênio pode dar origem a diversas espécies reativas, seja por absorção de energia ou por transferência de elétrons.

Assim, quando o oxigênio no estado fundamental absorve energia formam-se as espécies eletronicamente excitadas denominadas oxigênio singlete $\left({ }^{1} \mathrm{O}_{2}\right)$, delta e sigma (respectivamente, 22,4 Kcal e 37,5 Kcal a mais que o oxigênio no estado fundamental). Nessas formas de oxigênio singlete a restrição de spin desaparece, o que lhes confere um maior poder oxidante.

Uma outra via de formação de espécies reativas do metabolismo do oxigênio (ERMO) consiste na redução unieletrônica do oxigênio à água, na qual a entrada de quatro elétrons na molécula de oxigênio (em quatro etapas de um elétron) promove o aparecimento do radical superóxido $\left(\mathrm{O}_{2}^{-}\right)$, do peróxido de hidrogênio $\left(\mathrm{H}_{2} \mathrm{O}_{2}\right)$ e do radical hidroxila $\left(\mathrm{OH}^{\bullet}\right)$, conforme a equação 1: 


\section{$\mathrm{O}_{2} \stackrel{\mathrm{e}^{-}}{\longrightarrow} \mathrm{O}_{2}^{-} \stackrel{\mathrm{e}^{-}}{\mathrm{H}^{+}} \mathrm{H}_{2} \mathrm{O}_{2} \stackrel{\mathrm{e}^{-}}{\mathrm{H}^{+}} \mathrm{OH} \stackrel{\mathrm{H}^{-}}{\stackrel{\mathrm{e}^{-}}{\longrightarrow}} \mathrm{H}_{2} \mathrm{O} \quad$ Equação 1}

Portanto, a toxicidade do oxigênio decorre da formação destas espécies reativas que podem interagir com diversas biomoléculas e lesar diferentes estruturas celulares. Em condições normais, a concentração destas espécies dentro das células é extremamente baixa pelo fato de existirem enzimas antioxidantes que as removem, ou impedem a sua formação [4].

\section{I.3 LIPOPEROXIDAÇÃO}

Todos os componentes celulares são suscetíveis à ação das ERMO, porém, a membrana é um dos alvos mais atingidos em decorrência da peroxidação lipídica, que acarreta alterações na estrutura e na permeabilidade das membranas celulares [5]. Conseqüentemente, há perda da seletividade na troca iônica e liberação do conteúdo de organelas, como as enzimas hidrolíticas dos lisossomas, e formação de produtos citotóxicos (como o malonaldeído), culminando com a morte celular [6].

A lipoperoxidação também pode estar associada aos mecanismos de envelhecimento, de câncer e à exacerbação da toxicidade de xenobióticos [7]. Assim como na formação das ERMO, nem sempre os processos de lipoperoxidação são prejudiciais, pois seus produtos são importantes na reação em cascata a partir do 
ácido aracdônico (formação de prostaglandinas) e, portanto, na resposta inflamatória. Todavia, o excesso de tais produtos pode ser lesivo [8].

A lipoperoxidação é uma reação em cadeia, representada pelas etapas de iniciação, propagação e terminação. Estas etapas estão apresentadas nas equações 2, 3, 4, 5 e 6 onde L representa o lipídio [8]:

Iniciação $\quad \mathrm{LH}+\mathrm{OH}^{\circ}$ (ou LO') $\rightarrow \mathrm{L}^{\bullet}+\mathrm{H}_{2} \mathrm{O}$ (ou LOH) (Equação 2)

Propagação $\mathrm{L}^{\bullet}+\mathrm{O}_{2} \rightarrow \mathrm{LOO}^{\circ}$

(Equação 3)

Propagação $\mathrm{LH}+\mathrm{LOO}^{\bullet} \rightarrow \mathrm{L}^{\bullet}+\mathrm{LOOH}$

(Equação 4)

Terminação $\mathrm{LOO}^{\bullet}+\mathrm{L}^{\bullet} \rightarrow \mathrm{LOOL}$

(Equação 5)

Terminação $\mathrm{LOO}^{\circ}+\mathrm{LOO}^{\circ} \rightarrow \mathrm{LOOL}+\mathrm{O}_{2}$

(Equação 6)

As reações acima iniciam-se com o seqüestro do hidrogênio do ácido graxo polinsaturado (LH) da membrana celular. Tal seqüestro pode ser realizado pelo $\mathrm{OH}^{\circ}$ ou pelo $\mathrm{LO}^{\bullet}$ (radical alcoxila), com conseqüente formação do $\mathrm{L}^{\bullet}$ (radical lipídico). $\mathrm{Na}$ primeira reação de propagação, $\circ \mathrm{L}^{\bullet}$ reage rapidamente com $\circ \mathrm{O}_{2}$, resultando em LOO` (radical peroxila), que, por sua vez, seqüestra novo hidrogênio do ácido graxo polinsaturado, formando novamente $\circ L^{\bullet}$ na segunda reação de propagação. $O$ 
término da lipoperoxidação ocorre quando os radicais ( $\mathrm{L}^{\bullet}$ e $\left.\mathrm{LOO}^{\circ}\right)$ produzidos nas etapas anteriores propagam-se até destruirem-se a si próprios.

A lipoperoxidação pode ser catalisada por íons ferro, por conversão de hidroperóxidos lipídicos $(\mathrm{LOOH})$ em radicais altamente reativos (alcoxila, LO e peroxila, $\mathrm{LOO}^{\circ}$ ), que, por sua vez, iniciam nova cadeia de reações, denominada ramificação. Essas reações, que podem ser rápidas (Equação 7) ou lentas (Equação 8), dependem da valência do ferro, a saber [9]:

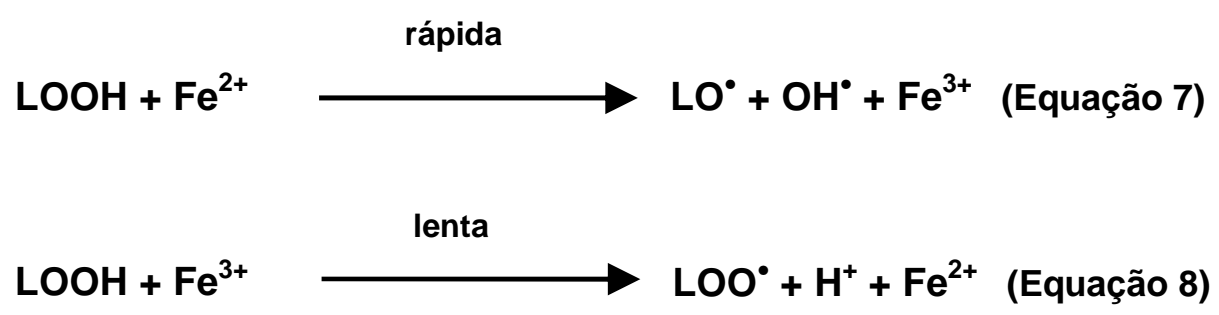

O radical hidroxila $\left(\mathrm{OH}^{*}\right)$ é freqüentemente reconhecido como a espécie iniciadora e a mais importante da lipoperoxidação. Entretanto, estudos recentes indicam que o ferro também desempenha papel determinante na iniciação deste processo, sendo necessária uma relação equimolar $\mathrm{Fe}^{3+}: \mathrm{Fe}^{2+}$ no meio, para que ocorra a lipoperoxidação [10].

\section{I.4 ANTIOXIDANTES}

Atualmente existe um grande interesse no estudo dos antioxidantes devido, principalmente, às descobertas sobre o efeito dos radicais livres no organismo. 
A oxidação é parte fundamental da vida aeróbica e do nosso metabolismo e, assim, os radicais livres são produzidos naturalmente ou por alguma disfunção biológica. No organismo, encontram-se envolvidos na produção de energia, fagocitose, regulação do crescimento celular, sinalização intercelular e síntese de substâncias biológicas importantes.

No entanto, seu excesso apresenta efeitos prejudiciais, tais como a peroxidação dos lipídios de membrana e agressão às proteínas dos tecidos e das membranas, às enzimas, carboidratos e DNA [11]. Dessa forma, encontram-se relacionados com várias patologias, tais como: aterosclerose, artrite, choque hemorrágico, doenças do coração, catarata, disfunções cognitivas, câncer, AIDS, etc [12].

O excesso de radicais livres no organismo é combatido por antioxidantes produzidos pelo corpo ou absorvidos da dieta. De acordo com Halliwell "Antioxidante é qualquer substância que, quando presente em baixa concentração comparada à do substrato oxidável, regenera o substrato ou previne significativamente a oxidação do mesmo" [12].

Do ponto de vista biológico, pode-se definir antioxidantes como compostos que protegem sistemas biológicos contra os efeitos potencialmente danosos de processos ou reações que promovem a oxidação de macromoléculas ou estruturas celulares. Nesse conceito mais amplo, entende-se que o sistema de defesa antioxidante do organismo compreende uma gama variada de substâncias que atuam em diferentes níveis [4].

O sistema de defesa primário é constituído de uma primeira linha de defesa, formada por substâncias que impedem a geração de espécies reativas, ou seqüestram-nas, de forma a impedir sua interação com alvos celulares, ou seja, 
bloqueiam a etapa de iniciação da cadeia radicalar. Neste sistema encontram-se a) enzimas antioxidantes, b) quelantes e proteínas, como a transferrina e a ceruloplasmina, que transportam ferro e cobre, respectivamente, impedindo que estes metais sejam liberados e catalisem a formação de espécies antioxidantes e c) substância enzimática como o urato, ascorbato, albumina, bilirrubina e carotenóides que seqüestram radicais superóxidos e hidroxila, ou suprimem oxigênio singlete. $O$ sistema de defesa secundário é formado geralmente por compostos fenólicos ou aminas aromáticas, que atuam bloqueando a etapa de propagação da cadeia radicalar, seqüestrando radicais intermediários (como o peroxil e o alcoxil). Encontram-se nesta classe os tocoferóis (vitamina E), tocotrienóis, flavonóides e vários antioxidantes sintéticos. Uma terceira linha de defesa antioxidante é constituída pelo sistema de reparo do DNA, por proteases e fosfolipases, as quais atuam removendo as lesões oxidativas do DNA, proteínas e lipídeos, respectivamente [4].

O desequilíbrio entre a formação e a remoção dos radicais livres no organismo, decorrente da diminuição dos antioxidantes endógenos, devido à menor formação ou ao maior consumo, ou aumento da geração de oxidantes, gera um estado pró-oxidante que favorece a ocorrência de lesões oxidativas em macromoléculas e estruturas celulares, podendo resultar inclusive na morte celular $[4]$.

Nesse sentido, o interesse em drogas sintéticas ou naturais que apresentam efeito antioxidante em nível biológico vem crescendo muito nos últimos anos, estando diretamente relacionado com a melhoria de qualidade de vida, principalmente na terceira idade, relacionada à proteção em relação ao envelhecimento, bem como, na prevenção de uma gama de doenças [12]. 


\section{I.5 O DIPIRIDAMOL}

O Dipiridamol (DIP), 2,6-bis(dietanolamina)-4,8-dipiperidinapirimida-[5,4-d] pirimidina, cuja estrutura está apresentada na Figura 1, utilizado em cardiologia desde 1959, era um fármaco bastante utilizado no tratamento de doenças cardiovasculares sendo utilizado no tratamento e profilaxia da angina do peito, no tratamento e profilaxia do reinfarto do miocárdio $[13,14]$.

A estimulação dos receptores $A_{2 a}$ da adenosina sobre as células musculares lisas produz relaxamento vascular, com vasodilatação arteriolar máxima (redução máxima da resistência coronariana), fazendo com que o fluxo sanguíneo coronariano aumente a níveis máximos [15,16]. O Dipiridamol bloqueia o retransporte intracelular de adenosina e inibe a adenosina-deaminase, responsável pela degradação intracelular da adenosina. Portanto, o Dipiridamol age como um vasodilatador coronariano indireto, aumentando as concentrações intracelulares e intersticiais de adenosina $[15,16,17]$.

Atualmente é uma das drogas mais utilizadas em Cardiologia Nuclear em diferentes técnicas aplicadas na aquisição e processamento de imagens (cintilografia miocárdica de perfusão, cintilografia de necrose miocárdica, ressonância magnética do coração, ventriculografia e angiocardiografia radioisotópica) onde, é de particular interesse, a realização de exames em pacientes com limitações físicas, na vigência de drogas que impeçam a elevação adequada da freqüência cardíaca ou em pacientes diabéticos com doença vascular periférica, com ampla margem de segurança ao mesmo [18].

Além de seu efeito vasodilatador, o emprego do dipiridamol na prática clínica baseia-se na diminuição da agregação plaquetária, com mecanismo de ação que 
inclui a inibição da fosfodiesterase, elevação nos níveis de adenosina e potencialização dos efeitos da Aspirina ${ }^{\circledR}[18]$.

O aumento do fluxo nas artérias coronárias normais após Dipiridamol é de três a cinco vezes maior que os valores obtidos em repouso, em artérias sem obstrução significativa. Em regiões supridas por artérias coronárias com lesões obstrutivas, verifica-se menor variação de fluxo durante a vasodilatação (até o limite de dobrarse o valor em repouso) [18].

Administrado por via intravenosa, na dose convencional de $0,56 \mathrm{mg} / \mathrm{kg}$ no tempo de 4 minutos, é distribuído em 15 minutos, apresentando meia-vida biológica variável (45 a 136 minutos). Administrado por via oral requer uma dose de 200 mg/dia. O Dipiridamol é encontrado nos níveis plasmáticos com uma concentração em torno de 4,0 $\mu \mathrm{M}$ onde ocorre os vários mecanismos de ação desta droga [18].

O Dipiridamol além das importantes aplicações já estabelecidas em medicina apresenta uma ação antioxidante em sistemas biológicos bastante acentuada, conforme demonstrada nos estudos de luliano et al. [19] e Pedulli et al. [20] referentes à neutralização de radicais peroxilas, responsáveis pela peroxidação lipídica. No entanto estes trabalhos são discordantes no que se refere ao mecanismo de ação antioxidante.

Enquanto luliano et al. [19] propõe um mecanismo que envolve a transferência de um átomo de hidrogênio para o radical peroxila, e que aparentemente ocorre em compostos fenólicos, Pedulli et al. [20] concluem que a ação antioxidante resulta da reação de transferência direta de um elétron do Dipiridamol para o radical peroxila onde seu mecanismo de ação poderia ser exemplificado da seguinte maneira: 


\section{$\mathrm{LOO}^{\circ}+\mathrm{DIP} \leftrightarrow \mathrm{LOO}^{\circ}+\mathrm{DIP}^{\circ+} \quad$ (Equação 9)}

A atividade antioxidante provavelmente deve estar relacionada à capacidade do Dipiridamol de participar em reações redox no organismo e os seus efeitos a nível clínico podem estar também associados à facilidade de participar nessas reações.

Devido à importância do emprego do Dipiridamol em medicina, métodos cromatográficos têm sido utilizados para a sua determinação no sangue e na urina com detecção eletroquímica, mas sem a preocupação com um detalhamento maior dos processos eletroquímicos envolvidos [21].

Trabalhos reportados na literatura mostraram que a polarografia pode ser também utilizada como método analítico com sucesso, sendo que os autores novamente não mostraram uma maior preocupação com as etapas do mecanismo de redução do composto $[22,23]$.

Neste sentido o Dipiridamol, vem sendo estudado em nosso Laboratório com abordagens tanto eletroquímica e espectroscópica, resultando em trabalhos publicados que incluem o estudo da eletrooxidação em meio não aquoso (acetonitrila e etanol), onde verificamos que o mecanismo de oxidação ocorre via duas etapas referentes à perda consecutiva reversível de um elétron por etapa, com a formação do radical cátion $\mathrm{DIP}^{+\bullet}$ no primeiro processo [24], um trabalho em meio aquoso ácido, onde a protonação da droga altera o mecanismo de oxidação para um processo único de dois elétrons [25], e um trabalho em soluções contendo micelas de surfactantes, que mimetizam, ainda que de forma muito simplificada, o ambiente fisiológico da membrana, onde foi avaliado o efeito da interação do Dipiridamol com micelas catiônicas, aniônicas e neutras na oxidação eletroquímica [26]. Neste 
trabalho mostrou-se que em micelas aniônicas a formação do cátion radical é observada. Além disso, a interação da droga com o eletrodo é controlada pela difusão da mesma juntamente com a micela caracterizando a forte associação Dipiridamol-micela.

Diferenças significativas na atividade biológica dos derivados do DIP, denominados RA25, RA47, RA14 e RA143 foram observadas quando estudado o poder antioxidante relativo a peroxidação lipídica em mitocôndrias [27]. Neste trabalho mostrou-se que a atividade varia de um fator 100 comparando o Dipiridamol com o derivado RA25.

O Dipiridamol e seus derivados mostraram uma sequência decrescente de atividade biológica antioxidante na ordem DIP $\geq$ RA14 > RA47 > RA25, sendo que esta mesma sequência descreve a hidrofobicidade destes compostos, assim como a sua localização nas micelas e suas constantes de associação observadas com micelas de surfactantes [28]. À maior atividade e hidrofobicidade correlacionam-se com uma maior constante de associação e localização mais profunda na interface micelar.

A atividade antioxidante do Dipiridamol e do RA25, também foi avaliada na peroxidação lipídica e hemólise em células vermelhas do sangue, sendo o derivado de menor hidrofobicidade, foi o que apresentou menor proteção quanto a peroxidação lipídica, ou seja, menor ação antioxidante [29], o que é totalmente similar às observações em mitocôndrias [27]. 

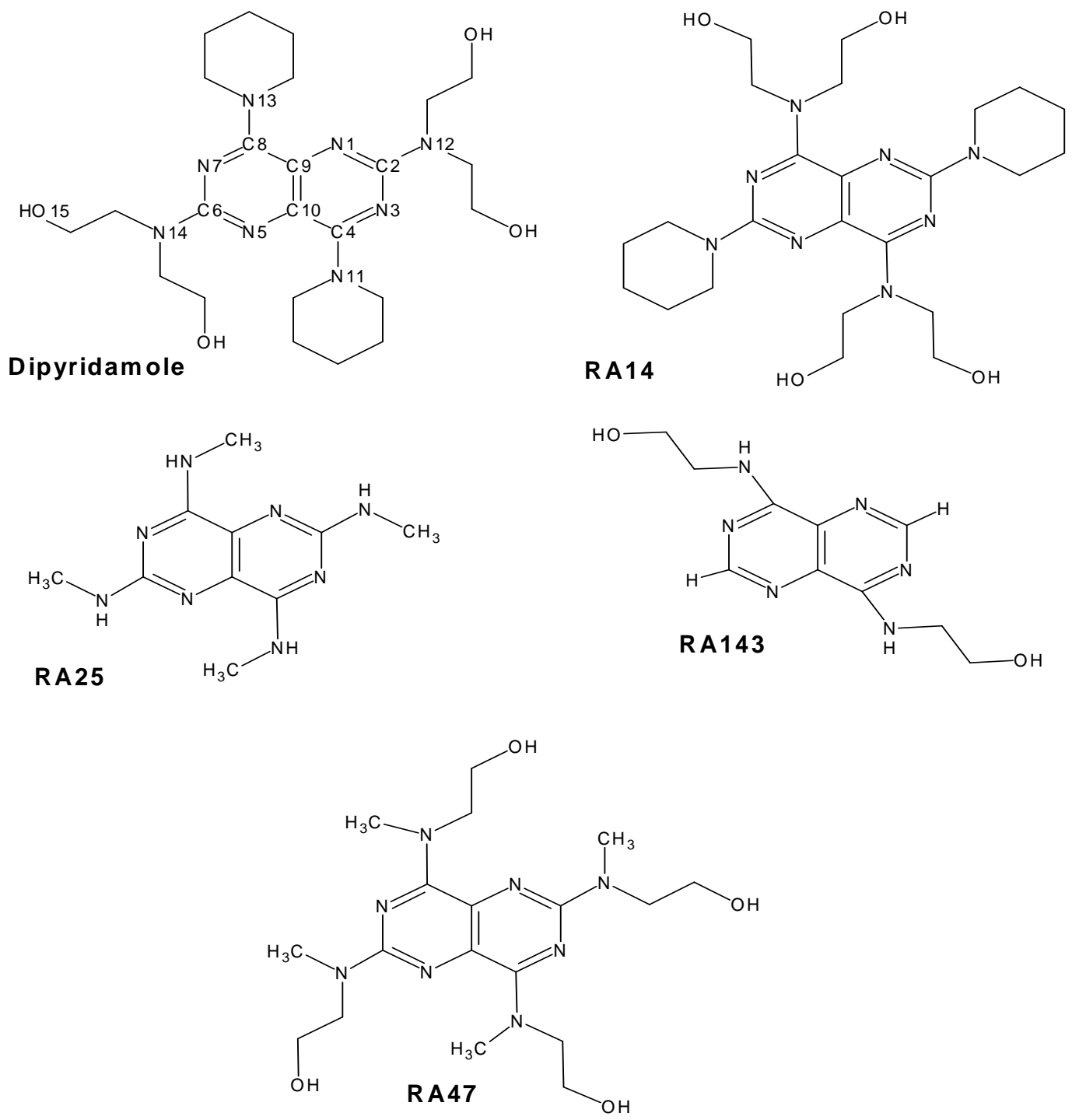

Figura 1. Estrutura do Dipiridamol e seus derivados

Em outro trabalho de luliano et. al. [30] são apresentados resultados com dipiridamol e derivados sendo que foi proposto que todos os nitrogênios do anel pirimido-pirimidino devem estar necessariamente substituídos para o composto apresentar atividade biológica antioxidante, visto que, a ausência de um grupo piperidino causa a perda da atividade antioxidante no derivado RA25. 
Estudos eletroquímicos fizeram parte da tese de doutorado de Adaíla M. P. Almeida onde foi demonstrado que os produtos da eletrooxidação do Dipiridamol possuem características espectroscópicas diferentes, quando comparados ao Dipiridamol, como o desaparecimento da intensidade da fluorescência e da banda de absorção em torno de $400 \mathrm{~nm}$ [31], sendo que a estabilização dos produtos finais de reação deve ser do tipo EC, reação eletroquímica seguida de extensa reação química [32, 36].

A fragmentação do Dipiridamol e de alguns dos seus derivados foi estudada nos modos positivo e negativo utilizando Espectrometria de Massas no modo de ionização electrospray (ESI) combinada a decomposição ativada por colisão (CAD) e, no qual, foi possivel sugerir que a fragmentação ocorre preferencialmente nos grupos etanolaminas [31, 33].

\section{I.5.1 PROPRIEDADES QUÍMICAS DO DIPIRIDAMOL}

O Dipiridamol é um fármaco comercializado com os nomes de Persantin ${ }^{\circledR}$, Pradio $^{\circledR}$, Dipyridan ${ }^{\circledR}$, apresenta-se como um pó cristalino amarelo, de sabor amargo, muito solúvel em etanol, metanol e clorofórmio, porém de baixa solubilidade em água. Em solução aquosa neutra a solubilidade é de 15,0 $\mathrm{molL}^{-1}$ [28].

Já em meio ácido a solubilidade aumenta sensivelmente, sendo de 170,0 $\mu \mathrm{molL}^{-1}$ em $\mathrm{pH}=5,0$, passando para $700,0 \mu \mathrm{molL}^{-1}$ em $\mathrm{pH}=3,0$, e em $\mathrm{pH}=1,0$ a solubilidade é significativamente maior, $16 \times 10^{4} \mu \mathrm{molL}^{-1}$ [28].

$\mathrm{Na}$ literatura são reportados os valores de pka de 5,8 e 12,5 para o Dipiridamol. O pka de 5,8, deve estar associado à protonação dos nitrogênios dos 
substituintes do anel (bis-etanolamina e piperidino), uma vez que o pka dos nitrogênios do anel pirimido-pirimidino deve ser extremamente baixo (menor que 2) e a formação de pontes de hidrogênio intramolecular com substituinte bis-etanolamina deve diminuir ainda mais este valor tornando-o não observável por técnicas convencionais.

O pka de 12,5 não está muito bem definido, pois como a determinação destas constantes foi realizada espectroscopicamente via fluorescência do Dipiridamol, este valor pode estar associado à supressão de fluorescência do Dipiridamol pelos íons hidroxilas da solução.

A estrutura do Dipiridamol apresenta um núcleo pirimido-pirimidino responsável pela transição das moléculas de Dipiridamol da forma neutra para a forma protonada, dentro do intervalo de $\mathrm{pH}$ fisiológico. Devido ao envolvimento de todos os nitrogênios na conjugação $\pi$ da molécula, o sítio de protonação não está bem definido.

Os anéis aromáticos são responsáveis pelas propriedades de fluorescência, as quais variam com o estado de protonação da droga e com o meio na qual se encontra, apresentando uma intensa fluorescência centrada em aproximadamente $500 \mathrm{~nm}[34]$.

O Dipiridamol caracteriza-se espectroscopicamente por bandas de absorção na região de $400 \mathrm{~nm}$ e $280 \mathrm{~nm}$, devido às transições $\pi \rightarrow \pi^{*}$ no ciclo heteroaromático [35]. 


\section{CAPÍTULO II - OBJETIVOS}

Considerando que algumas correlações entre a atividade antioxidante e os potenciais de oxidação podem ser estabelecidos, como tem sido demonstrado na literatura, é objetivo da presente dissertação o estudo dos produtos de eletrooxidação do Dipiridamol em Acetonitrila e em Meio Aquoso Ácido baseados nos resultados obtidos anteriormente nas teses de doutorado de Marilza Castilho [36] e de Adaíla M. P. Almeida. [31]

E assim dessa forma, obter bases para o melhor entendimento do processo de oxidação do Dipiridamol, da sua atividade antioxidante, das propriedades químicas do composto e por conseqüência o mecanismo de atuação desta substância. 


\section{CAPÍTULO III - MATERIAIS E MÉTODOS}

O trabalho experimental foi realizado empregando-se as técnicas de Voltametria Cíclica, Eletrólise a Potencial Controlado, Espectroscopia de Absorção UV-Vis, Emissão de Fluorescência, Extração em Fase Sólida e Cromatografia Líquida Acoplada a Espectrometria de Massas.

\section{III.1 CÉLULAS ELETROQUÍMICAS}

Para a realização dos experimentos de voltametria cíclica, utilizou-se uma célula de vidro Pyrex ${ }^{\circledR}$, com capacidade de $10 \mathrm{~mL}$, equipada com uma tampa Teflon $\AA$ contendo orifícios, para posicionamento dos eletrodos de referência e de trabalho

Para os experimentos de eletrólise a potencial controlado, utilizou-se um célula de três compartimentos com capacidade para $40 \mathrm{~mL}$ de solução, separados por placas de vidro sinterizado, de porosidade média. Equipada com uma tampa Teflon ${ }^{\circledR}$ contendo orifícios, para posicionamento dos eletrodos de referência, de trabalho e contraeletrodo. 


\section{III.2 ELETRODOS}

\section{III.2.1. ELETRODO DE TRABALHO}

Para as medidas de voltametria cíclica foi utilizado um ultramicroeletrodo de $\mathrm{Pt}$ ( $\phi=25 \mathrm{~mm}$ ) confeccionado no laboratório GMEME (Grupo de Materiais Eletroquímicos e Métodos Eletroanalíticos), utilizando-se fios metálicos de procedência Goodfelow Metals Ltd. 99,9\% de pureza com $25 \mu \mathrm{m}$ de diâmetro e isolado em capilar de vidro.

O eletrodo de trabalho utilizado nos experimentos de eletrólise a potencial controlado, consistiu de uma placa de Pt de $4,2 \mathrm{~cm}^{2}$ de área.

\section{III.2.2 ELETRODO DE REFERÊNCIA}

O eletrodo de referência utilizado nos experimentos em acetonitrila e no meio ácido consistiu em um fio de prata anodizado imerso em solução de $0,01 \mathrm{molL}^{-1}$ de $\mathrm{AgNO}_{3}$ com o eletrólito suporte utilizado em cada experimento de eletrooxidação.

\section{III.2.3 CONTRA ELETRODO}

Utilizou-se como contra eletrodo uma placa de platina de $4,2 \mathrm{~cm}^{2}$ de área para os experimentos de eletrólise a potencial controlado. 


\section{III.3 REAGENTES}

Todos os reagentes utilizados nos experimentos são de pureza analítica (PA) ou de grau HPLC e a procedência destes é relacionada na Tabela I.

Tabela I - procedência e grau de pureza dos reagentes utilizados

\begin{tabular}{|l|l|l|l|}
\hline MATERIAL & $\begin{array}{l}\text { FÓRMULA } \\
\text { QUÍMICA }\end{array}$ & PROCEDÊNCIA & GRAU \\
\hline Dipiridamol & $\mathrm{C}_{24} \mathrm{H}_{40} \mathrm{~N}_{8} \mathrm{O}_{4}$ & Sigma & PA \\
\hline Acetonitrila & $\mathrm{CH}_{3} \mathrm{CN}$ & Mallinckrodt & HPLC \\
\hline Perclorato de Lítio (Anidro) & $\mathrm{LiClO}_{4}$ & Alfa Aesar & PA \\
\hline Nitrato de Prata & $\mathrm{AgNO}_{3}$ & Merck & PA \\
\hline Ácido Clorídrico & $\mathrm{HCl}$ & Merck & PA \\
\hline Metanol & $\mathrm{CH}_{3} \mathrm{OH}$ & Mallinckrodt & HPLC \\
\hline Formiato de amônio & $\mathrm{NH}_{4} \mathrm{COOH}$ & Spectrum & PA \\
\hline
\end{tabular}

\section{III.4 SOLUÇÕES DE DIP EM ACETONITRILA}

As soluções de dipiridamol foram preparadas numa concentração de $0,5 \mathrm{mmolL}^{-1}$ em acetonitrila. Foi adicionado a estas soluções $\mathrm{LiClO}_{4}$ na concentração de 0,1 molL ${ }^{-1}$ como eletrólito suporte para se obter um meio suficientemente condutor. A ponte salina foi preparada com uma solução de $\mathrm{LiClO}_{4} 0,1 \mathrm{molL}^{-1}$ em acetonitrila. As soluções foram 
eletrooxidadas nos potenciais de $+340 \mathrm{mV}$ (potencial de primeira onda de oxidação do dipiridamol em acetonitrila) e $+680 \mathrm{mV}$ (potencial de segunda onda de oxidação do dipiridamol em acetonitrila) [36].

\section{III.5 SOLUÇÕES DE DIP EM MEIO ÁCIDO}

As soluções em meio aquoso acidificado $(\mathrm{pH}=1,0)$ foram preparadas numa concentração de $0,5 \mathrm{mmolL}^{-1}$ de dipiridamol em uma solução de ácido clorídrico na concentração de $0,1 \mathrm{molL}^{-1}$. O eletrólito suporte nestas soluções foi o próprio ácido clorídrico que em pH 1,0 é um meio suficientemente condutor e tem a mesma força iônica que o $\mathrm{LiClO}_{4}$ utilizado neste trabalho. A ponte salina foi preparada com uma solução de ácido clorídrico $0,1 \mathrm{molL}^{-1}$. As soluções foram eletrooxidadas no potencial de + $850 \mathrm{mV}$ (processo único de oxidação do dipiridamol em meio ácido) [36].

\section{III.6 EXTRAÇÃO EM FASE SÓLIDA}

Foram utilizados cartuchos da marca Waters modelo Sep-Pak® Vac (2g) com fase sólida C18. As amostras obtidas nas eletrólises em acetonitrila foram liofilizadas e ressuspendidas em $1 \mathrm{~mL}$ de $\mathrm{MeOH}$, em seguida foram aplicadas no cartucho após a ativação do mesmo. Foram aplicados $40 \mathrm{~mL}$ de $\mathrm{H}_{2} \mathrm{O}$ e depois $40 \mathrm{~mL}$ de $\mathrm{MeOH}$ sendo que, durante todo esse processo, foram recolhidas alíquotas de $1 \mathrm{~mL}$ cada. Espectros de UV-Vis foram obtidos para determinar as alíquotas que apresentavam absorção 
ótica e, assim, reuní-las em um único grupo de acordo com suas polaridades. As alíquotas foram divididas em dois grupos (fração aquosa e fração metanólica), liofilizadas novamente e depois analisadas por LC-MS.

As soluções obtidas eletrólises em meio aquoso ácido foram liofilizadas e ressuspendidas em $1 \mathrm{~mL}$ de água Milli-Q e analisadas diretamente no LC-MS.

Todas as amostras foram congeladas após o período de 24 horas depois das eletrólises e também, depois da extração em fase sólida.

\section{III.7 METODOLOGIA}

\section{III.7.1 VOLTAMETRIA CÍCLICA}

A técnica de voltametria cíclica foi empregada para analisar os mecanismos das reações de oxidação do dipiridamol e assim, otimizar os potenciais para a eletrooxidação do mesmo, tanto em acetonitrila como em meio ácido. Estes experimentos foram registrados em um intervalo de faixa de potencial de $-200 \mathrm{mV}$ a $1000 \mathrm{mV}$, com baixa velocidade de varredura $\left(20 \mathrm{mV} . \mathrm{s}^{-1}\right)$ e corrente de $10 \mathrm{nA}$. Utilizouse para estes registros um ultramicroeletrodo de $\mathrm{Pt}(\phi=25 \mu \mathrm{m})$ como eletrodo de trabalho e $\mathrm{Ag}^{0} / \mathrm{Ag}^{+}\left(0,01 \mathrm{~mol} \mathrm{~L}^{-1} \mathrm{Ag}^{+}\right)$como eletrodo de referência. Utilizou-se um Polarógrafo EG\&G PARC Modelo 174-A conectado a um computador IBM-PC. 


\section{III.7.2 ELETRÓLISE A POTENCIAL CONTROLADO}

Esta técnica foi empregada para a realização dos experimentos de eletrólise oxidativa, e com isso, obteve-se os produtos de eletrooxidação do dipiridamol para posterior caracterização.

Neste trabalho as eletrólises foram realizadas em condições especiais de potencial controlado para a retirada de um elétron (potencial na primeira onda de oxidação em acetonitrila) e de dois elétrons (potencial na segunda onda de oxidação em acetonitrila e em um único processo em meio aquoso acidificado).

As eletrólises foram realizadas em uma célula de três compartimentos com capacidade para $40 \mathrm{~mL}$, como ânodo foi utilizado uma placa de Pt de $4,2 \mathrm{~cm}^{2}$ de área, para o cátodo uma placa de mesmo material e tamanho, como eletrodo de referência o $\mathrm{Ag}^{0} / \mathrm{Ag}^{+}[36]$.

A instrumentação utilizada constou de um Potenciostato/Galvanostato EG\&G PARC Modelo 283 conectado a um microcomputador IBM-PC.

Todos os experimentos de eletroquímica foram realizados em colaboração com a Dra. Andréa Renata Malagutti no Grupo de Materiais Eletroquímicos e Métodos Eletroanalíticos (GMEME) do Instituto de Química, USP, São Carlos.

\section{III.7.3 ESPECTROSCOPIA DE ABSORÇÃO UV-VIS}

Espectros de absorção foram utilizados para caracterizar o consumo do dipiridamol em solução e a formação de novas espécies pela atribuição do 
aparecimento e desaparecimento de bandas no espectro óptico. Estes registros foram obtidos retirando-se alíquotas das soluções antes e depois da eletrólise, e realizando medições de hora em hora até a estabilização dos produtos de eletrooxidação (até 24 horas após a eletrólise). As medidas foram efetuadas utilizando-se um espectrofotômetro UV-1601PC Shimadzu, sendo monitoradas na região do visível. Cubetas de quartzo de $1 \mathrm{~mm}$ de caminho óptico foram utilizadas para tal registro.

\section{III.7.4 ESPECTROSCOPIA DE EMISSÃO DE FLUORESCÊNCIA}

Espectros de emissão de fluorescência foram obtidos retirando-se alíquotas das soluções de dipiridamol antes da eletrólise, logo após a eletrólise e com 24 horas após a eletrólise, visto que, os anéis aromáticos encontrados na estrutura do DIP são responsáveis pelas propriedades de absorção e emissão de fluorescência. As medidas foram efetuadas no espectrofluorímetro da HITACHI modelo F-4500, utilizando-se cubetas de quartzo de $1 \mathrm{~cm}$ de caminho óptico e com as quatro faces polidas e de $1 \mathrm{~mm}$ de caminho óptico orientada à $45^{\circ}$ em relação ao fei xe de excitação.

\section{III.7.5 EXTRAÇÃO EM FASE SÓLIDA}

Esta técnica foi empregada para a eliminação do sal eletrolítico das soluções de dipiridamol eletrooxidadas, bem como, para a separação dos analitos das amostras de acordo com suas polaridades, obtendo-se assim dois tipos de frações (uma metanólica e outra aquosa) para as eletrólises em acetonitrila. Para tanto foram utilizados cartuchos da marca Waters modelo Sep-Pak® Vac (2g) com fase sólida C18. 


\section{III.7.6 CROMATOGRAFIA LÍQUIDA ACOPLADA A ESPECTROMETRIA DE MASSAS}

A cromatografia líquida associada à espectrometria de massa (LC-MS) é uma técnica analítica adequada para a análise de misturas complexas. Análises das frações aquosa e metanólica das eletrooxidações do dipiridamol em acetonitrila e da eletrooxidação no meio aquoso ácido foram efetuadas no intuito de elucidar as estruturas dos produtos formados nessas eletrólises.

Análises cromatográficas foram realizadas utilizando uma coluna analítica de fase reversa C18 $(5 \mu \mathrm{m}, 250 \times 4,6 \mathrm{~mm})$ da marca Luna (fabricante: Phenomenex) como fase estacionária e como fase móvel uma solução de formiato de amônio $30 \mathrm{mM} /$ $\mathrm{MeOH}$. Para as frações metanólicas utilizou-se um gradiente de eluição de 30-97\% de $\mathrm{MeOH}$ em 30 min e para as frações aquosas um gradiente de eluição de 3-30\% de $\mathrm{MeOH}$ em 30 min. Para os produtos obtidos na eletrooxidação em meio aquoso ácido utilizou-se um gradiente de eluição de $3-95 \%$ de $\mathrm{MeOH}$ em 30 min. Foi utilizado um HPLC da Shimadzu com fluxo de $1 \mathrm{~mL} / \mathrm{min}$, sendo que este fluxo é dividido para o acoplamento com o MS.

Os dados foram coletados no LC/ESI-MSMS com um fluxo de $70 \mu \mathrm{l} \mathrm{min}{ }^{-1}$, do cromatógrafo para dentro do espectrômetro. As análises de ionização por electrospray (ESI) e decomposição ativada por colisão (CAD) foram feitas em um triplo-quadrupolo QuattroLC com uma fonte de ionização de Z-spray da Micromass. As temperaturas de desolvatação e da fonte de ionização foram de 120 e $140^{\circ} \mathrm{C}$, respectivamente. $\mathrm{N}_{2}$ foi utilizado como gás de nebulização $\left(20 / \mathrm{h}^{-1}\right)$ e gás de desolvatação $\left(350 \mid \mathrm{h}^{-1}\right)$. As 
voltagens aplicadas foram de $3.6 \mathrm{kV}$ para o capilar, 30 ou $50 \mathrm{~V}$ para o cone da amostra e $8 \mathrm{~V}$ para o cone extrator. Os experimentos de espectrometria de massas Tandem, foram realizados adicionando Ar na célula de colisão para produzir uma pressão de $2 \mathrm{x}$ $10^{-3}$ mbar para o CAD. A energia de colisão usada para a decomposição dos íons gerados dos compostos $[\mathrm{M}+\mathrm{H}]^{+}$foi de 30 ou $70 \mathrm{eV}$.

Essas análises foram realizadas em colaboração com o Prof. Dr. Paolo di Mascio e a doutoranda Fernanda M. Prado do Laboratório de Estudo de Lesões em Biomoléculas do Departamento de Bioquímica, Instituto de Química, USP, São Paulo. 


\section{CAPÍTULO IV - RESULTADOS E DISCUSSÃO}

\section{IV.1 ELETROQUÍMICA DO DIPIRIDAMOL EM ACETONITRILA E EM MEIO AQUOSO ÁCIDO}

A Figura 2 apresenta os voltamogramas cíclicos do DIP antes e depois das eletrólises tanto em acetonitrila como no meio aquoso ácido. Nos voltamogramas $\mathrm{A}$ e B pode ser observado que o DIP possui duas ondas de oxidação em acetonitrila. A primeira onda anódica refere-se à oxidação do DIP pela perda de um elétron gerando o radical-cátion DIP*+ $^{\bullet}$. Já a segunda onda está associada com a subsequente oxidação deste radical catiônico, levando a formação do DIP²+.

$$
\begin{array}{llll}
\text { DIP } \leftrightarrow \mathrm{DIP}^{+\bullet}+1 \mathrm{e}^{-} & (\mathrm{E}=+340 \mathrm{mV}) & (\text { Equação 10) } \\
\mathrm{DIP} \leftrightarrow \mathrm{DIP}^{2+}+2 \mathrm{e}^{-} & (\mathrm{E}=+650 \mathrm{mV}) & \text { (Equação 11) }
\end{array}
$$

No voltamograma C, correspondente ao DIP em meio ácido, observa-se a presença de uma única onda de oxidação, referente à perda direta de dois elétrons:

$$
\mathrm{DIPH}^{+} \rightarrow \mathrm{A}^{2+}+\mathrm{H}^{+}+2 \mathrm{e}^{-} \quad(\mathrm{E}=+850 \mathrm{mV})
$$

(Equação 12)

Um estudo envolvendo cálculos teóricos da estrutura do DIP mostrou que a protonação da molécula em um único nitrogênio N1 (ou N5) é energeticamente a mais favorável. Este trabalho também mostrou que a remoção de um e dois elétrons 
leva a mudanças significativas na densidade eletrônica dos nitrogênios, especialmente nos átomos de nitrogênios N11, N12, N13 e N14 [37].
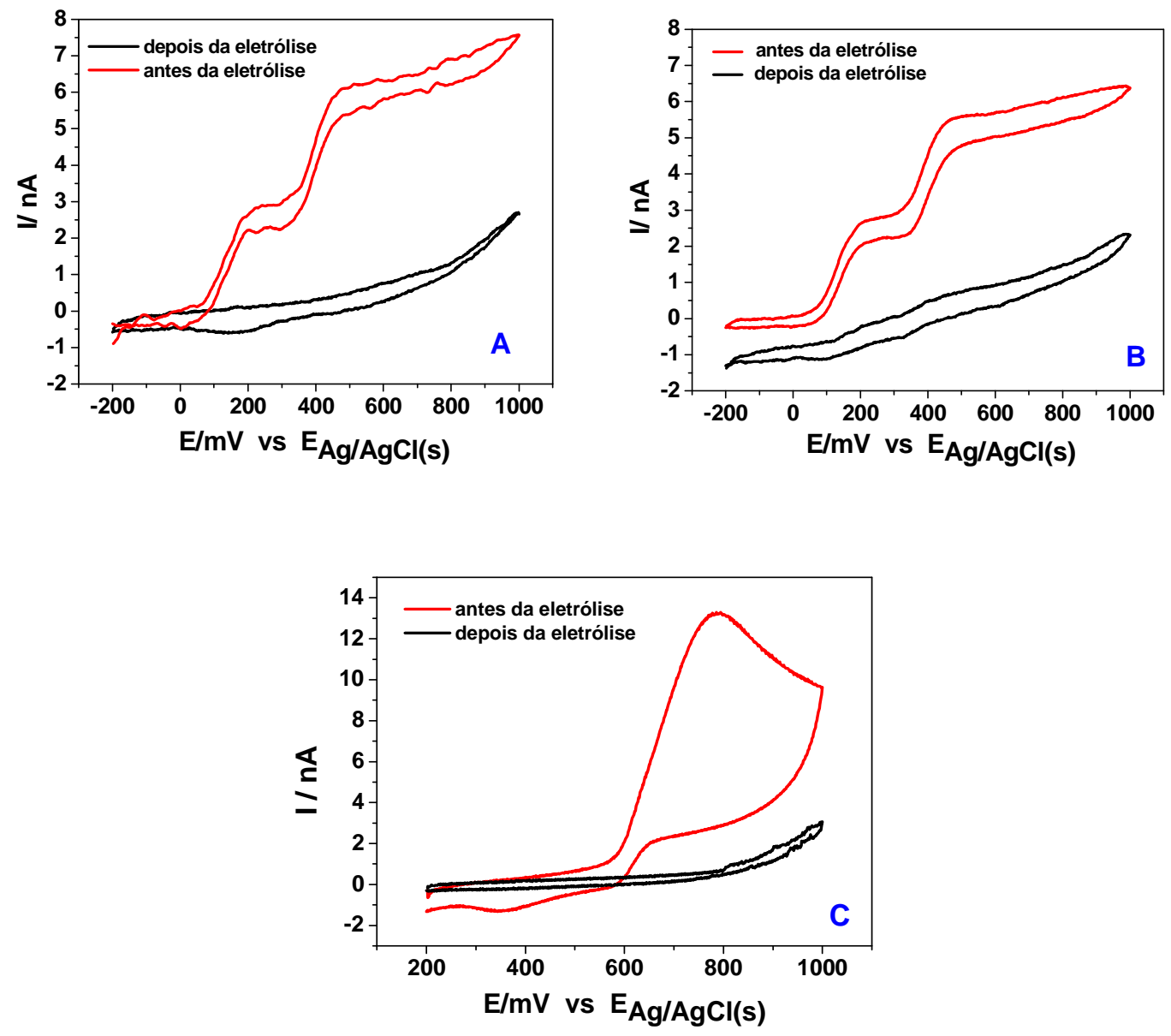

FIGURA 2: Voltamogramas cíclicos do DIP 0,5 mM antes e depois das eletrólises; solução eletrolisada 20mL (A) Potencial de primeira onda em ACN; Tempo de eletrólise = 1,0 hora (B) Potencial de segunda onda em ACN; Tempo de eletrólise $=1,0$ hora e (C) em meio aquoso ácido $\mathrm{pH}=1,0 ;$ Tempo de eletrólise $=2,0$ horas.

O radical cátion formado pela oxidação de um elétron, está associado a remoção do elétron desses nitrogênios, visto pela forte delocalização do mesmo no anel pirimido-pirimidino, observada no espectro de EPR em que não aparece a 
estrutura hiperfina dos nitrogênios. A remoção do segundo elétron também parece estar associada a perda da densidade eletrônica destes mesmos nitrogênios [24].

Observa-se pelos voltamogramas após a eletrólise que uma grande quantidade do DIP foi consumido em solução devido ao decaimento da corrente anódica, o que, também pode ser observado nos respectivos cronoamperogramas (Figura 3).
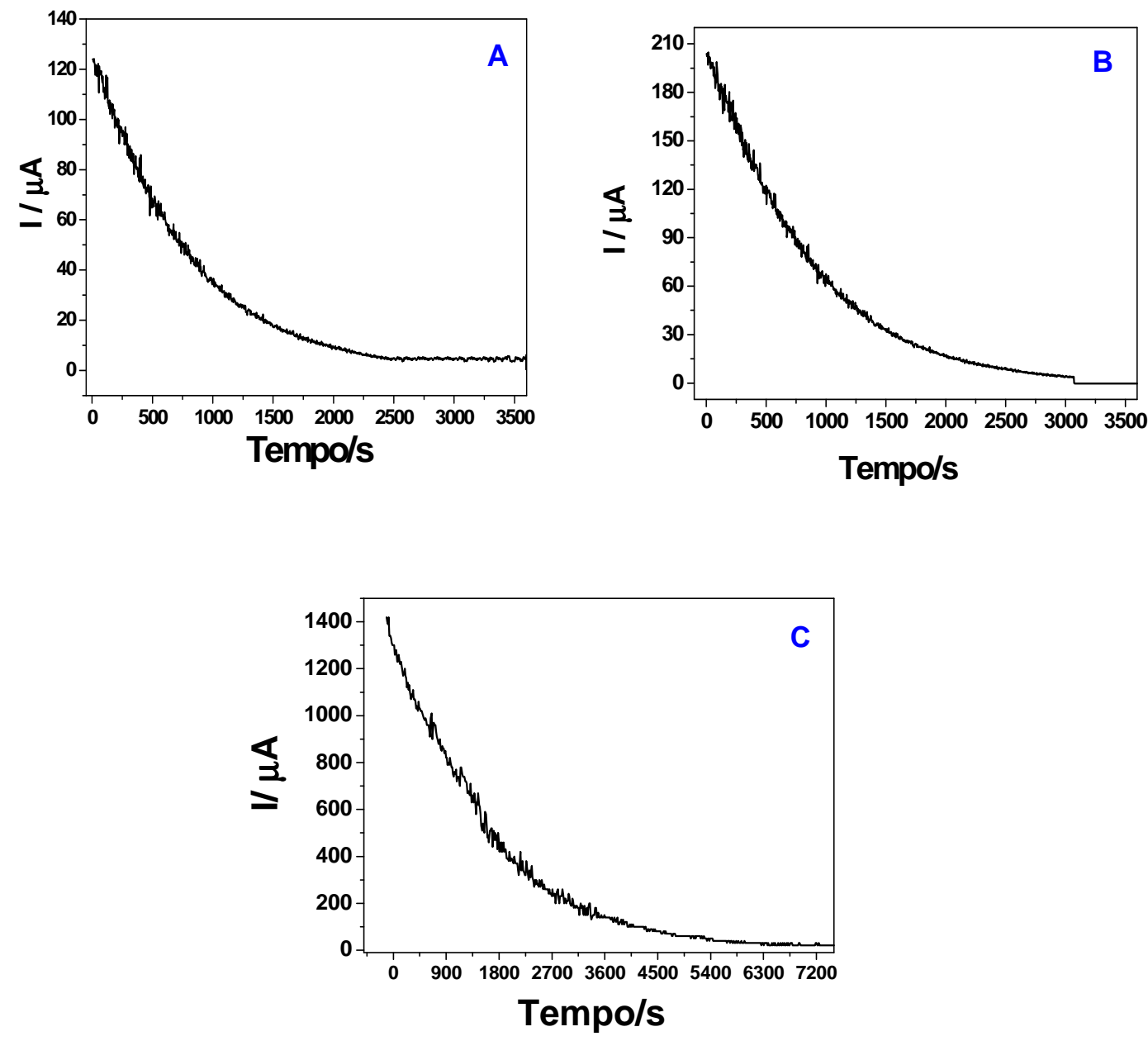

Figura 3: Cronoamperogramas das eletrólises do DIP 0,5 mM, volume de solução: $20 \mathrm{~mL}$, (A) em ACN na primeira onda $=340 \mathrm{mV}$, (B) em $A C N$ na segunda onda $=680 \mathrm{mV}$ e (C) no meio aquoso ácido $=840 \mathrm{mV}$. 
A eletrólise a potencial controlado é uma técnica muito utilizada em eletroquímica orgânica na determinação do número global de elétrons envolvidos num processo de eletrodo [38]. A Análise Coulométrica permite a determinação do número de elétrons envolvidos no processo eletródico pela quantidade de eletricidade consumida na eletrólise. Esta quantidade pode ser obtida utilizando-se a lei de Faraday:

\section{$Q=n F N_{0}$}

(Equação 13)

Onde $\boldsymbol{Q}$ representa a quantidade de eletricidade consumida na eletrólise (em Coulombs), $\boldsymbol{n}$ é o número de elétrons, $\boldsymbol{F}$ a constante de Faraday e $\boldsymbol{N}_{\boldsymbol{0}}$ representa o número total de mols da espécie eletroativa. Em eletrólises exaustivas, onde ocorre uma eficiência de corrente de $100 \%$ a Lei de Faraday pode ser usada para o cálculo do número de elétrons envolvidos numa eletrólise [38].

Cálculos teóricos permitiram obter o número de elétrons envolvidos baseados no voltamograma e no cronoamperograma de ambas as eletrólises, que como esperado, segundo a tese de Marilza Castilho [36], envolvem um elétron na eletrooxidação do DIP em acetonitrila na primeira onda e dois elétrons no potencial de segunda onda em acetonitrila e na eletrólise em meio ácido.

Tabela II: Cálculos teóricos dos elétrons envolvidos nas eletrólises

\begin{tabular}{|c|c|c|}
\hline ELETRÓLISE & $\mathbf{Q}=\int_{0}^{t} i d t$ & $\boldsymbol{n}_{\text {teórico }}$ \\
\hline ACN 1a ONDA & $0,907200 \mathrm{C}$ & 0,94 \\
\hline ACN 2 & & \\
\hline MEIO ONDA & $1,687572 \mathrm{C}$ & 1,75 \\
\hline
\end{tabular}




\section{IV.2 ESPECTROSCOPIA ÓTICA DA ELETROOXIDAÇÃO DO DIPIRIDAMOL EM ACETONITRILA E EM MEIO AQUOSO ÁCIDO}

Os produtos de eletrooxidação do DIP foram monitorados por meio de UV-vis, de hora em hora, por até 24 horas de repouso da amostra após a eletrólise (Figura 4). O Espectro do DIP apresentado na Figura 4 é caracterizado por bandas de absorção nas regiões de 280 e $400 \mathrm{~nm}$, associadas às transições $\pi \rightarrow \pi^{\star}$ no ciclo central heteroaromático.

No espectro de absorção 4A, referente a eletrooxidação do DIP na primeira onda $(E=340 \mathrm{mV})$, notam-se mudanças espectrais bem acentuadas, sendo que os espectros apresentam novas bandas centradas em $\lambda=361$ e $\lambda=508 \mathrm{~nm}$ (bem larga) logo após a eletrooxidação.

Essas bandas são bandas características do cátion-radical DIP*+, o qual, permanece em solução por até 3 horas, como pode ser visto nestes espectros. Após cinco horas em repouso não ocorre mais mudanças significativas.

O espectro final dos produtos apresenta três bandas centradas em $\lambda=232$, 284 e $410 \mathrm{~nm}$, sendo que estes produtos não possuem as características originais da solução antes da eletrólise, ou seja, não se assemelham ao DIP, indicando que ocorreu o consumo do mesmo após a eletrólise, como pode ser visto na Figura 5A. 

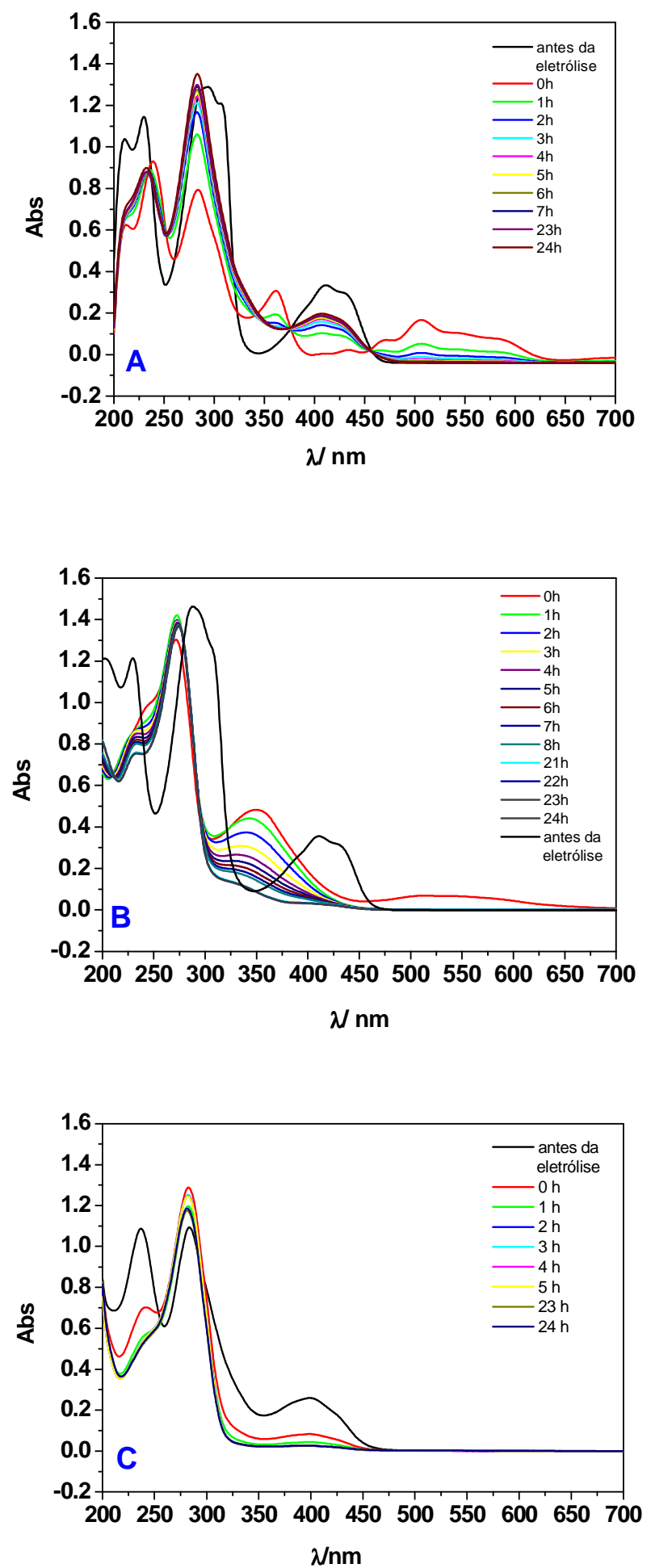

Figura 4: Espectros de absorção ótica da eletrooxidação do DIP 0,5 mM utilizando cubeta de quartzo de $1 \mathrm{~mm}$ de caminho ótico: (A) eletrolise em ACN na primeira onda, (B) eletrólise em ACN na segunda onda e (C) eletrólise em meio aquoso ácido. 
Analisando-se os espectros de absorção óptica da amostra eletrolisada no potencial de segunda onda $(E=680 \mathrm{mV})$, representado no espectro $4 \mathrm{~B}$, verificamos que ao final da reação de eletrólise, há duas bandas intensas em $\lambda=275$ e $350 \mathrm{~nm}$ e uma banda, pouco intensa, centrada em $\lambda=520 \mathrm{~nm}$, e não mais se observam as bandas características do DIP. Porém, após 24 horas de repouso, há um completo desaparecimento da banda centrada em $\lambda=520 \mathrm{~nm}$, uma diminuição na intensidade da banda em $\lambda=350 \mathrm{~nm}$ e um ligeiro aumento da banda em $\lambda=275 \mathrm{~nm}$ como pode ser visto na Figura 5B. Pelos espectros de absorção da Figura 4B observa-se que não ocorrem mudanças após 21 horas de repouso o qual denota ser tempo suficiente para a estabilização dos produtos finais da reação.

Através dos espectros da Figura $4 \mathrm{C}$ da amostra eletrolisada no potencial de $\mathrm{E}$ $=850 \mathrm{mV}$, apresentados na Figura 4, verificamos que ao final da reação de eletrólise ocorre o decaimento de duas bandas características do DIP em meio ácido. Entretanto, também se observa um ligeiro aumento da banda centrada em $\lambda=281$ nm. Após 2 horas de repouso, há uma diminuição intensa das bandas centradas em $\lambda=235$ e $400 \mathrm{~nm}$. Pelos espectros de absorção observa-se que não ocorrem mudanças após 2 horas de repouso, tempo este suficiente para a estabilização dos produtos finais da reação e seu espectro final pode ser melhor observado na Figura 5C. As soluções do DIP em acetonitrila possuem uma coloração original esverdeada, e com a sua eletrooxidação, são produzidos produtos que apresentam uma coloração violeta intensa. Já as soluções do DIP em meio ácido possuem uma coloração amarela, sendo que após a eletrólise a solução adquire uma coloração marrom avermelhado. Ambas as soluções eletrooxidadas após 6 horas em repouso em temperatura ambiente perdem a coloração violeta/marrom gerando uma solução de coloração levemente amarelada. 

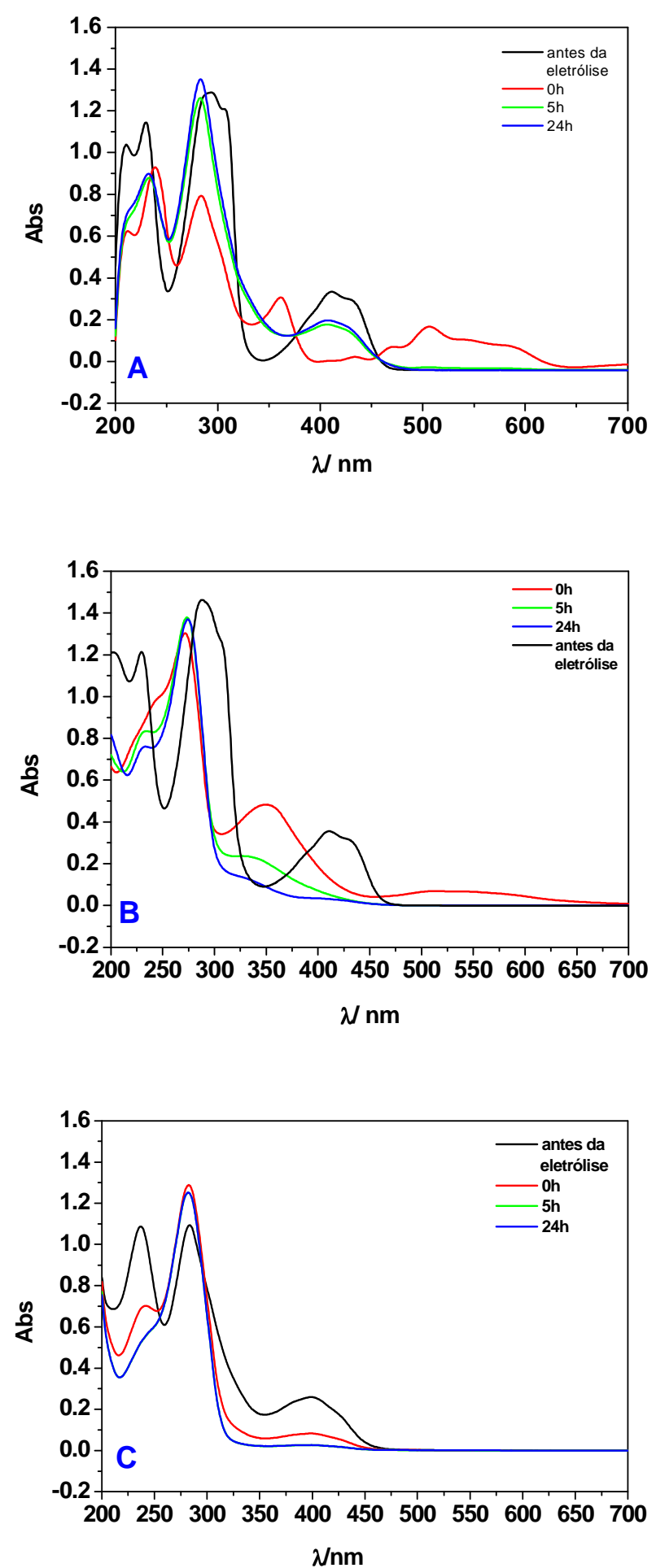

Figura 5: Espectros de absorção ótica da eletrooxidação do DIP 0,5 mM utilizando cubeta de quartzo de $1 \mathrm{~mm}$ de caminho ótico: (A) eletrólise em ACN na primeira onda, (B) eletrólise em ACN na segunda onda e (C) eletrólise em meio aquoso ácido. Espectros apresentados foram extraídos da Figura 4. 
O DIP apresenta uma banda larga de intensa emissão de fluorescência em torno de $\lambda=480 \mathrm{~nm}$ em acetonitrila, como pode ser visto na Figura 6 nos espectros A e B antes da oxidação. Após a eletrólise, ocorre o decaimento desta banda devido à eletrooxidação do DIP, sugerindo o rompimento do anel pirimido-pirimidino, o qual é responsável pela intensa fluorescência.
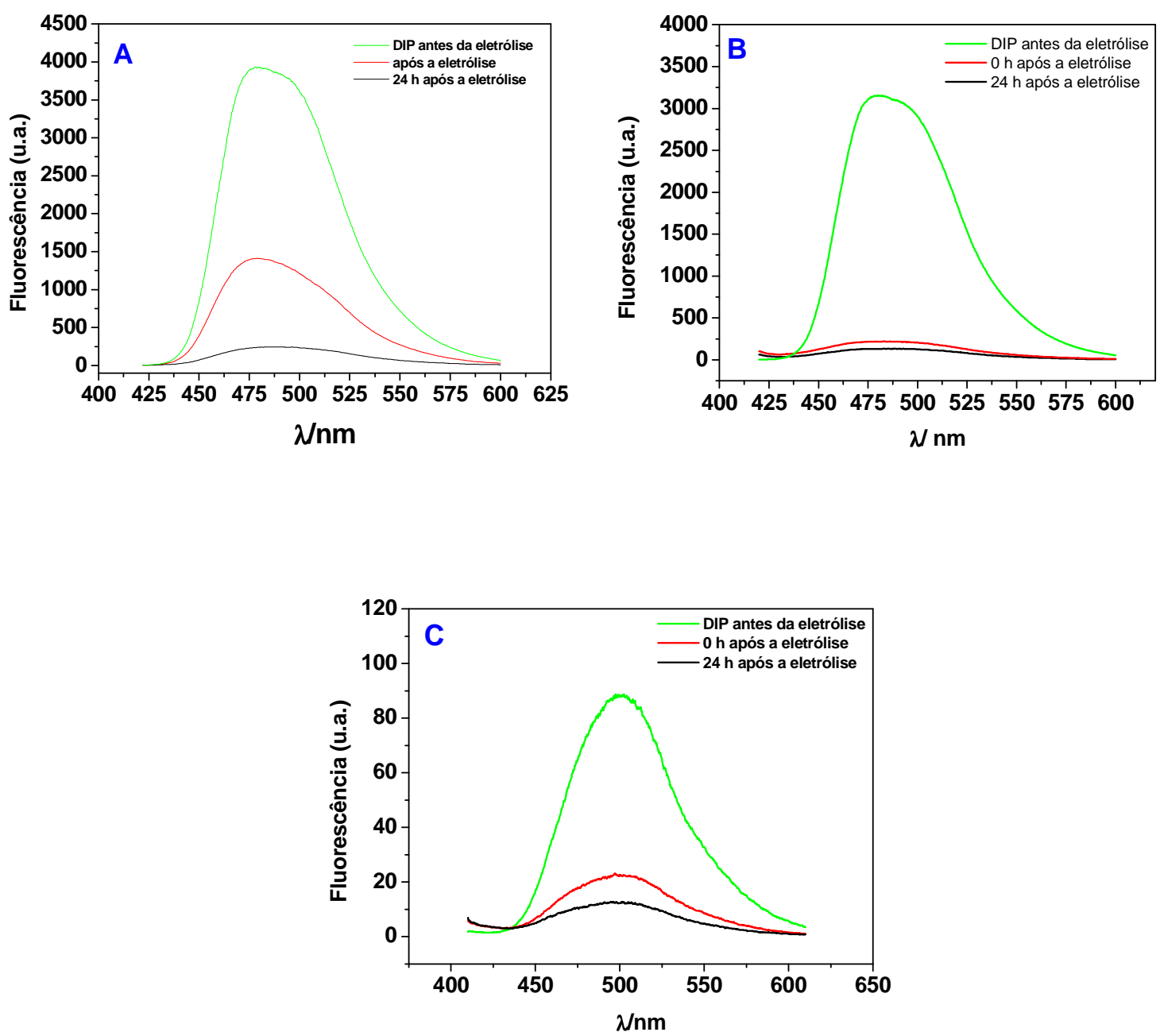

Figura 6: Espectros de fluorescência antes e depois da eletrólise do DIP 0,5 mM, $\lambda_{\text {exc }}=412$ $\mathrm{nm}$, utilizando cubeta de quartzo de $1 \mathrm{~mm}$ de caminho ótico orientada à $45^{\circ}$ em relação ao feixe de excitação: (A) eletrólise em $A C N$ na primeira onda, (B) eletrólise em ACN na segunda onda e $(C)$ eletrólise em meio aquoso ácido. 
Entretanto, no meio ácido (espectro C), o DIP devido à sua protonação apresenta fluorescência quase nula (a intensidade cai por um fator em torno de 40 comparado com DIP em acetonitrila). Pode-se notar que os produtos de eletrooxidação também não são fluorescentes assim como na eletrooxidação em acetonitrila.

Baseados nos cálculos das integrais correspondentes às áreas dos espetros de emissão de fluorescência, antes e depois da eletrólise, como apresentado na Tabela III, verifica-se que ocorreu uma diminuição da fluorescência do DIP em aproximadamente $82 \%$ na eletrooxidação do DIP em acetonitrila na primeira onda. Observa-se também uma diminuição na intensidade depois de 24 horas de repouso demonstrando que o(s) produto(s) formado(s) realmente são muito pouco fluorescentes.

Já para a eletrólise do DIP em acetonitrila na segunda onda verifica-se que ocorreu uma diminuição da fluorescência do DIP em aproximadamente 95\%. Observa-se também uma pequena diminuição na intensidade depois de 24 horas de repouso demonstrando que o(s) produto(s) formado(s) são praticamente não fluorescentes.

Mesmo não apresentando fluorescência significativa, os mesmo cálculos foram feitos para a eletrólise em meio ácido onde ocorreu uma diminuição da fluorescência do DIP em aproximadamente $80 \%$ como apresentado na Tabela III. 
Tabela III. Concentração e porcentagem residual de DIP antes e após a eletrólise.

\begin{tabular}{|c|c|c|c|}
\hline & $\begin{array}{c}\text { ANTES DA } \\
\text { ELETRÓLISE }\end{array}$ & $\begin{array}{l}0 \text { HORAS APÓS A } \\
\text { ELETRÓLISE }\end{array}$ & $\begin{array}{l}24 \text { HORAS APÓS } \\
\text { A ELETRÓLISE }\end{array}$ \\
\hline \multicolumn{4}{|l|}{ ACN $1{ }^{\mathrm{a}}$ ONDA } \\
\hline$A ́ R E A$ & 282366 & 102784 & 20089 \\
\hline DIP EM SOLUÇÃO & $100 \%$ & $18 \%$ & $7 \%$ \\
\hline \multicolumn{4}{|l|}{ ACN $2^{\mathrm{a}}$ ONDA } \\
\hline ÁREA & 226586 & 20388 & 12398 \\
\hline DIP EM SOLUÇÃO & $100 \%$ & $9 \%$ & $6 \%$ \\
\hline \multicolumn{4}{|l|}{ MEIO ÁCIDO } \\
\hline$\hat{A} R E A$ & 7197 & 2040 & 1426 \\
\hline DIP EM SOLUCÃO & $100 \%$ & $28 \%$ & $20 \%$ \\
\hline
\end{tabular}

A redução da fluorescência do DIP em acetonitrila é quase total depois de 24 horas de repouso, e nota-se pela Tabela III que resta ainda 18\% de DIP em solução, o que poderia ser explicado pela seguinte reação de desproporcionamento mencionada por Marilza Castilho [36]

$$
\mathrm{DIP}^{*+}+\mathrm{DIP}^{*+} \rightarrow \mathrm{DIP}+\mathrm{DIP}^{2+}
$$

Este fenômeno é nitidamente observado nos espectros de absorção mostrados na Figura 4A onde após a eletrólise a banda do DIP centrada em torno de $415 \mathrm{~nm}$ reaparece com o tempo, sugerindo a regeneração parcial do DIP.

A fluorescência final obtida depois do tempo de estabilização dos produtos, representa uma pequena porcentagem, quase negligenciável, da fluorescência original, o que concorda com os dados obtidos nos espectros de absorção. A fluorescência do DIP não foi regenerada depois de 24 horas, indicando que o processo de oxidação leva à formação de espécies não fluorescentes. 
Para a eliminação do sal eletrolítico na eletrooxidação do DIP em acenotrila utilizou-se a técnica de extração em fase sólida. Com isto foram obtidos dois tipos de frações, uma metanólica e outra aquosa, nas quais conseguiu-se uma separação dos analitos da mistura original de acordo com suas polaridades, como pode ser visto na Figura 7. Os cartuchos utilizados foram da marca Waters modelo Sep-Pak ${ }^{\circledR}$ Vac (2 g) fase sólida C18. Através dos espectros de absorção da Figura 8, adotou-se o monitoramento das alíquotas obtidas durante o processo de extração em fase sólida no comprimento de onda em $270 \mathrm{~nm}$, visto que os produtos apresentam absorção nessa região. Com base no cromatograma da Figura 7A juntou-se as frações de 11 a 38 (fração aquosa) e as frações de 40 a 65 (fração metanólica) da eletrooxidação na primeira onda, e com base no cromatograma da Figura 7B juntouse as frações 12 a 39 (fração aquosa) e as frações 44 a 60 (fração metanólica) da eletrooxidação na segunda onda em acetonitrila. Essas frações, aquosa e metanólica, foram utilizadas em análises posteriores de LC-MS.
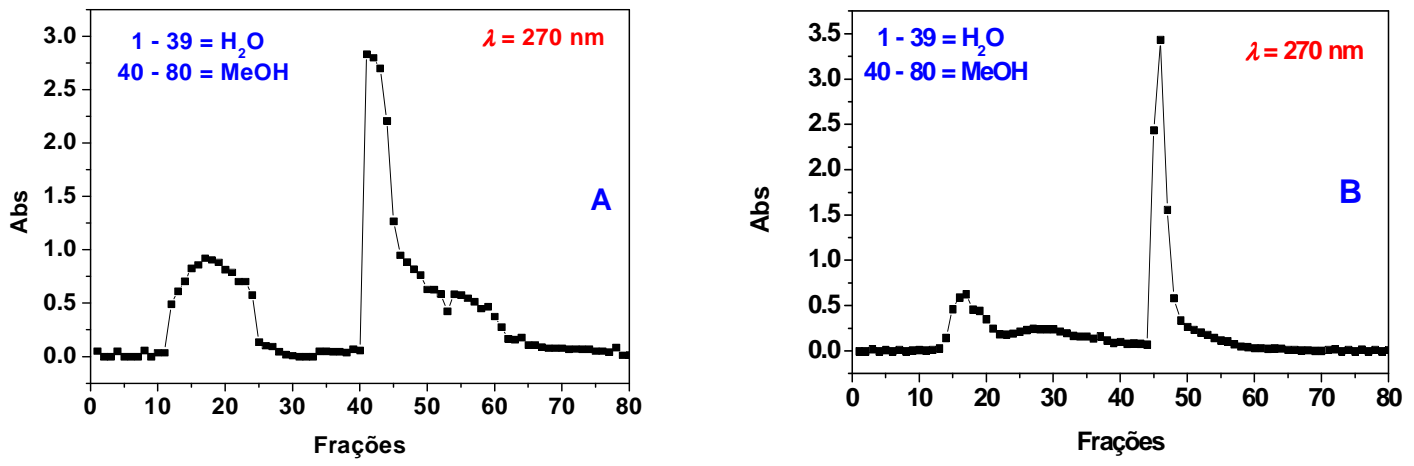

Figura 7 Cromatogramas das frações separadas em Sep-Pak do material de quatro eletrólises de $20 \mathrm{~mL}$ cada, do DIP 0,5 mM ; A absorbância foi medida em $\lambda=275 \mathrm{~nm}$ : (A) eletrólise em ACN na primeira onda, (B) eletrólise em ACN na segunda onda. 

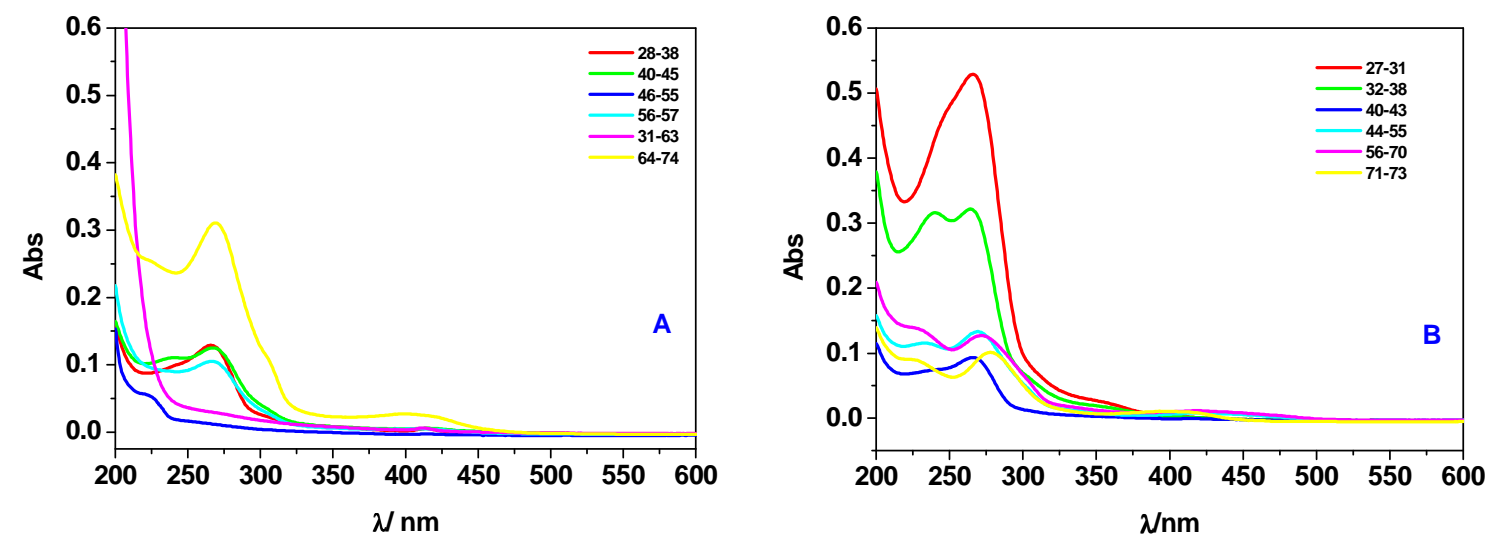

Figura 8: Espectros de absorção ótica dos cromatogramas das frações separadas em SepPak do material de duas eletrólises de $20 \mathrm{~mL}$ cada, de DIP 0,5 mM. Foi utilizada cubeta de quartzo de $1 \mathrm{~cm}$ de caminho ótico: $(A)$ eletrólise em $A C N$ na primeira onda e (B) eletrólise em ACN na segunda onda. 


\section{IV.3 ANÁLISES CROMATOGRÁFICAS E ESPECTROMÉTRICAS DOS PRODUTOS DE ELETROOXIDAÇÃO DO DIPIRIDAMOL}

A Figura 9 mostra o cromatograma do DIP $0,5 \mathrm{mM}$ utilizando como fase móvel: $\mathrm{NH}_{4} \mathrm{COOH}$ [30 mM] / MeOH em um gradiente de eluição 3-95\% de $\mathrm{MeOH}$ em 30 min. Nestas condições o Dipiridamol possui tempo de retenção de $29 \mathrm{~min}$, medido no comprimento de $270 \mathrm{~nm}$.

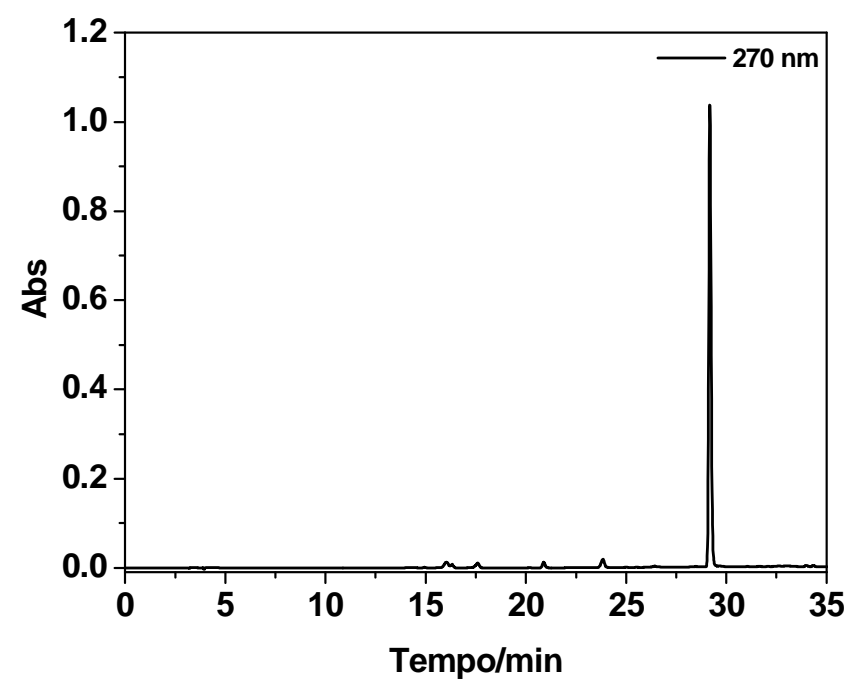

Figura 9: Cromatograma do Dipiridamol 0,5 mM, Fase móvel: $\mathrm{NH}_{4} \mathrm{COOH}$ [30 mM] / $\mathrm{MeOH}$;Gradiente de eluição 3-97\% de MeOH em 30 min; Volume de injeção: 25 $\mu$ L; Fluxo de $1 \mathrm{~mL} / \mathrm{min}$.

\section{IV.3.1 ANÁLISE DOS PRODUTOS DA FRAÇÃO AQUOSA DAS} ELETRÓLISES DO DIPIRIDAMOL EM ACETONITRILA NA PRIMEIRA ONDA

A Figura 10 apresenta os cromatogramas da fração aquosa da primeira onda de eletrooxidação $(340 \mathrm{mV})$ em acetonitrila. Dois picos majoritários com tempos de 
retenção de 8.9 e 11.7 min foram detectados e um pico de menor intensidade com tempo de retenção de 16.0 min. As absorbâncias utilizadas foram 270 nm e 290 nm. Aparentemente os compostos com tempos de retenção 8.9 e 11.7 min absorvem mais em $270 \mathrm{~nm}$ enquanto que o produto com tempo de retenção 16 min absorvem mais em $290 \mathrm{~nm}$.
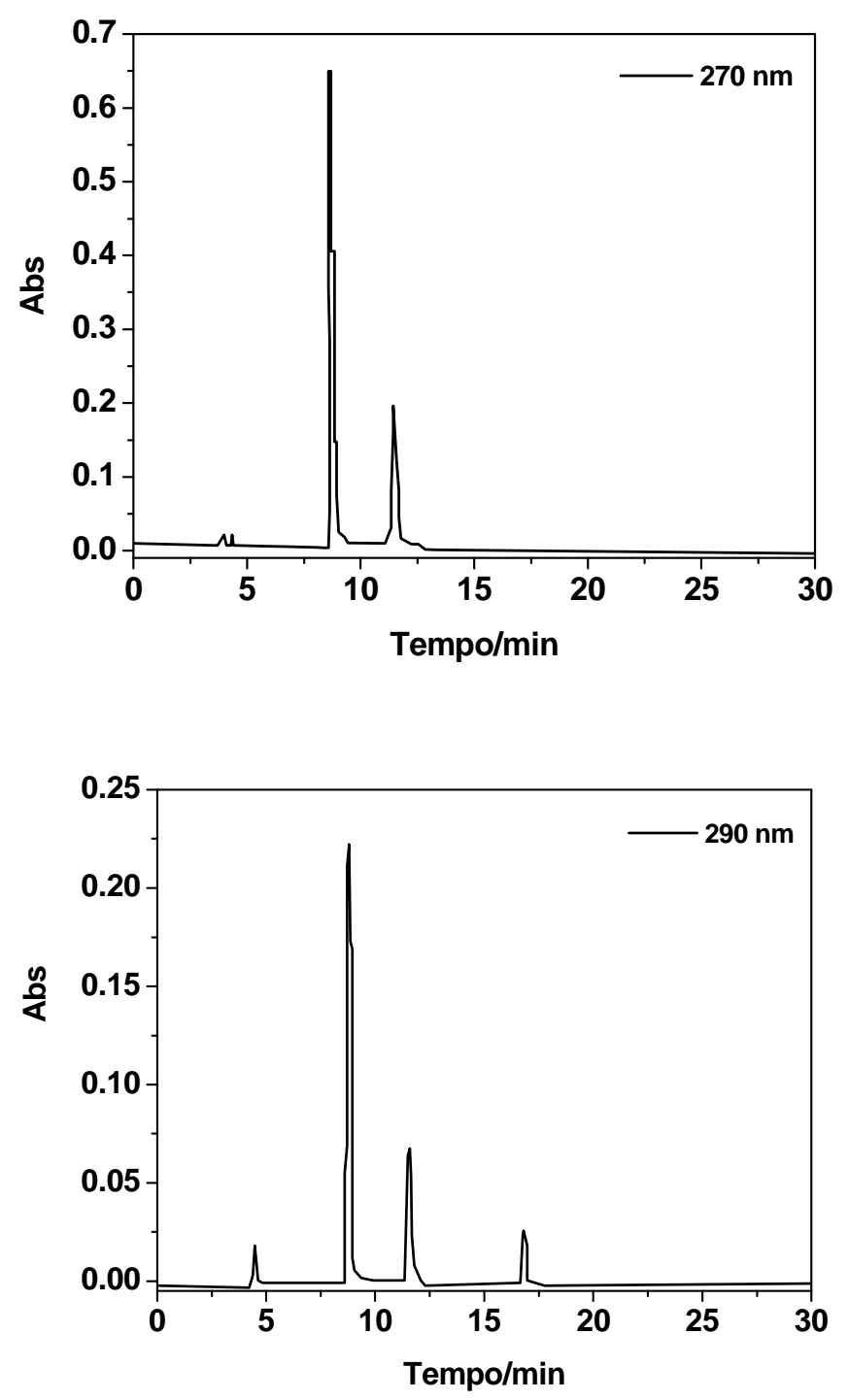

Figura 10: Cromatogramas dos produtos da fração aquosa da eletrooxidação do DIP em ACN na primeira onda (340 mV), Fase móvel: $\mathrm{NH}_{4} \mathrm{COOH}$ [30 mM] / MeOH;Gradiente de eluição 3-30\% de $\mathrm{MeOH}$ em $30 \mathrm{~min}$; Volume de injeção: 100 $\mu \mathrm{L}$; Fluxo de $1 \mathrm{~mL} / \mathrm{min}$. 
O espectro de massas do produto de eletrooxidação com tempo de retenção em 8.9 min possui como íon molecular o $\mathrm{m} / \mathrm{z} 472[\mathrm{M}+\mathrm{H}]^{+}$, como pode ser observado na Figura $11 \mathrm{~A}$. Foram analisados os íons fragmentos deste íon molecular (Figura 11 B) onde obtém-se a comprovação que o íon de $m / z 253[\mathrm{M}+\mathrm{H}]^{+}$é filho do íon de $\mathrm{m} / \mathrm{z}$ $472[\mathrm{M}+\mathrm{H}]^{+}$.

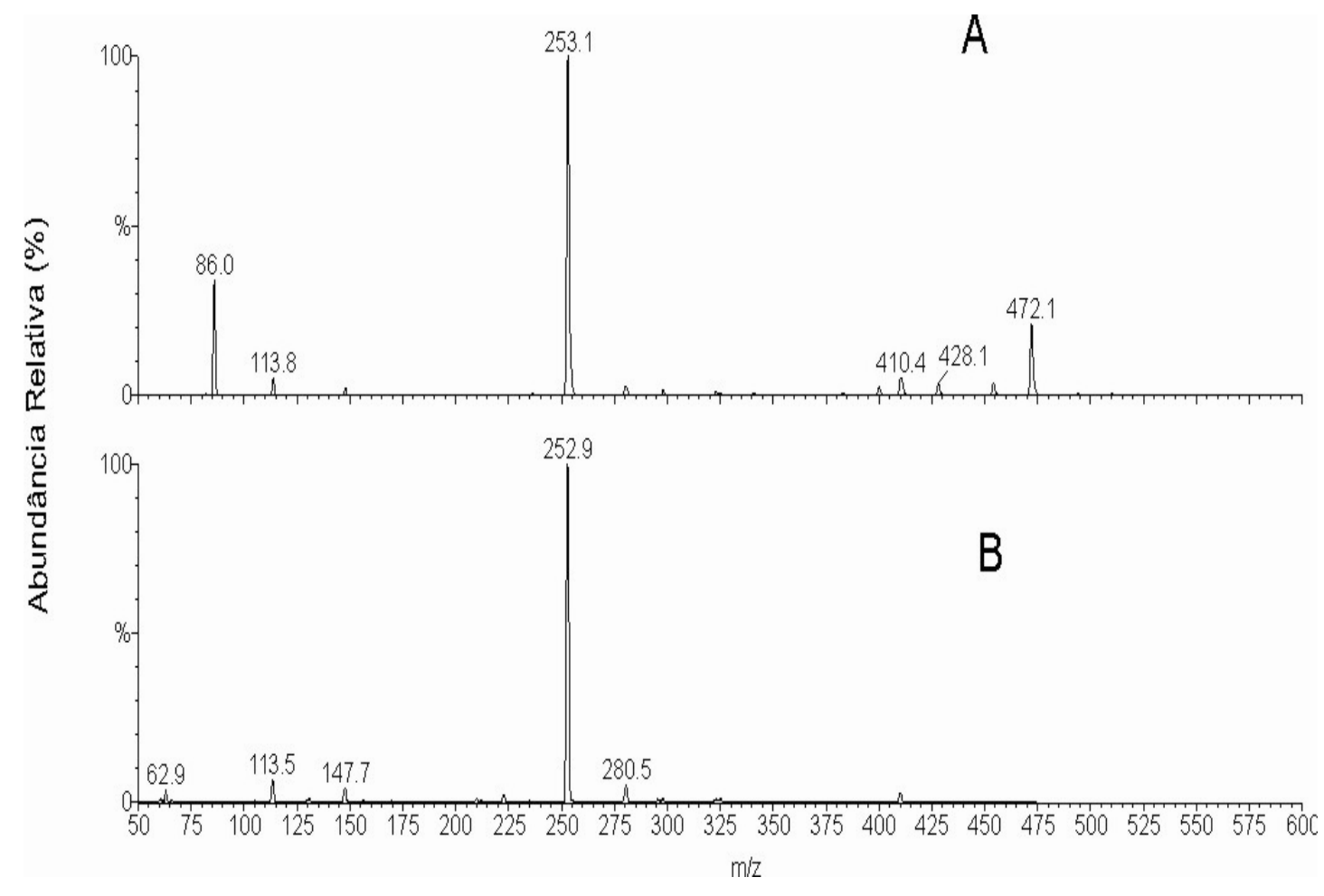

Figura 11: Espectros de massas do produto de $t_{r}=8.9 \mathrm{~min}$, fração aquosa da eletrooxidação na primeira onda (A) "fullscan" - ESI/MS no modo positivo, voltagem do cone $40 \mathrm{~V}$, voltagem do capilar 3,6 kV. (B) respectivos íons-fragmentos, energia de colisão $30 \mathrm{eV}$.

Foi relatado na tese de Adaíla M. P. A. Brasileiro [31] que compostos com $\mathrm{m} / \mathrm{z}$ $473[\mathrm{M}+\mathrm{H}]^{+}$e $\mathrm{m} / \mathrm{z} 253[\mathrm{M}+\mathrm{H}]^{+}$são produtos da eletrooxidação em meio aquoso ácido. Neste trabalho, a estrutura proposta para o íon de $\mathrm{m} / \mathrm{z} 473[\mathrm{M}+\mathrm{H}]^{+}$, está apresentada na Figura. 12 sendo consistente com a perda de 32 Da referente ao grupo $-\mathrm{CH}_{2} \mathrm{OH}$. 
O outro pico com $\mathrm{m} / \mathrm{z}$ de $472[\mathrm{M}+\mathrm{H}]^{+}$com tempo de retenção em 11.7 min é um isômero deste composto. No mesmo trabalho [31] é relatada a presença de outros íons com $\mathrm{m} / \mathrm{z}$ de 473.

A diferença de uma unidade de massa, em relação ao íon encontrado anteriormente, pode estar relacionada a mudanças nas condições experimentais, tais como resolução e voltagem do cone.

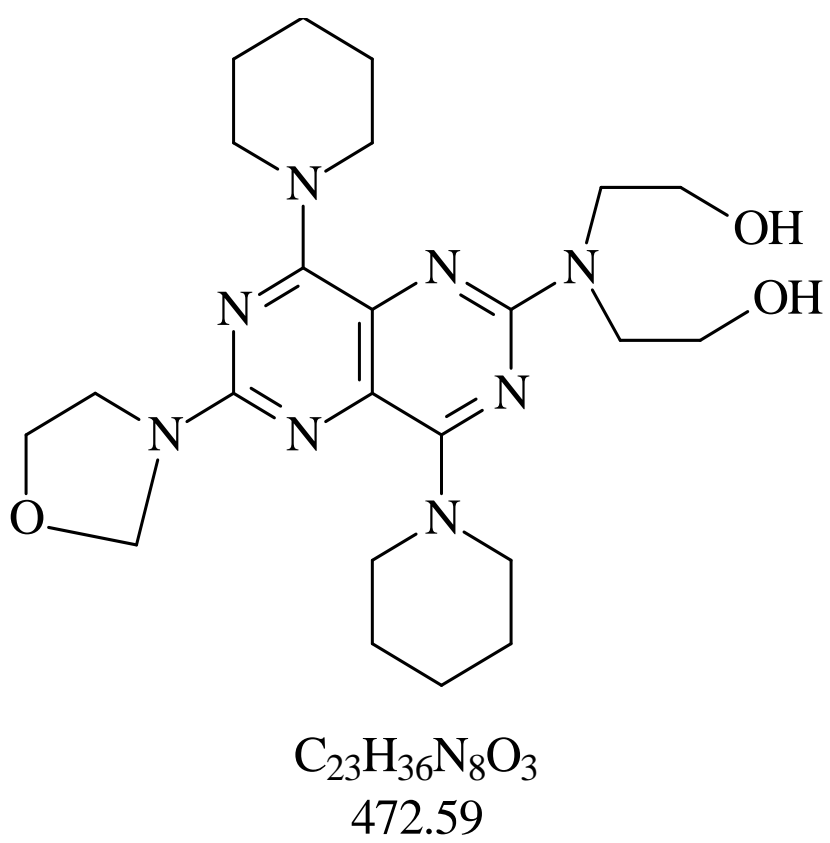

Figura 12: Proposta de estrutura para o produto da eletrooxidação em meio aquoso ácido [31].

A Figura 13 apresenta o espectro de massas e os respectivos íons fragmentos para o composto com tempo de retenção em 11,7 min. Este composto é um isômero do primeiro composto detectado na eletrooxidação em acetonitrila com $m / z 472[\mathrm{M}+\mathrm{H}]^{+}$. 


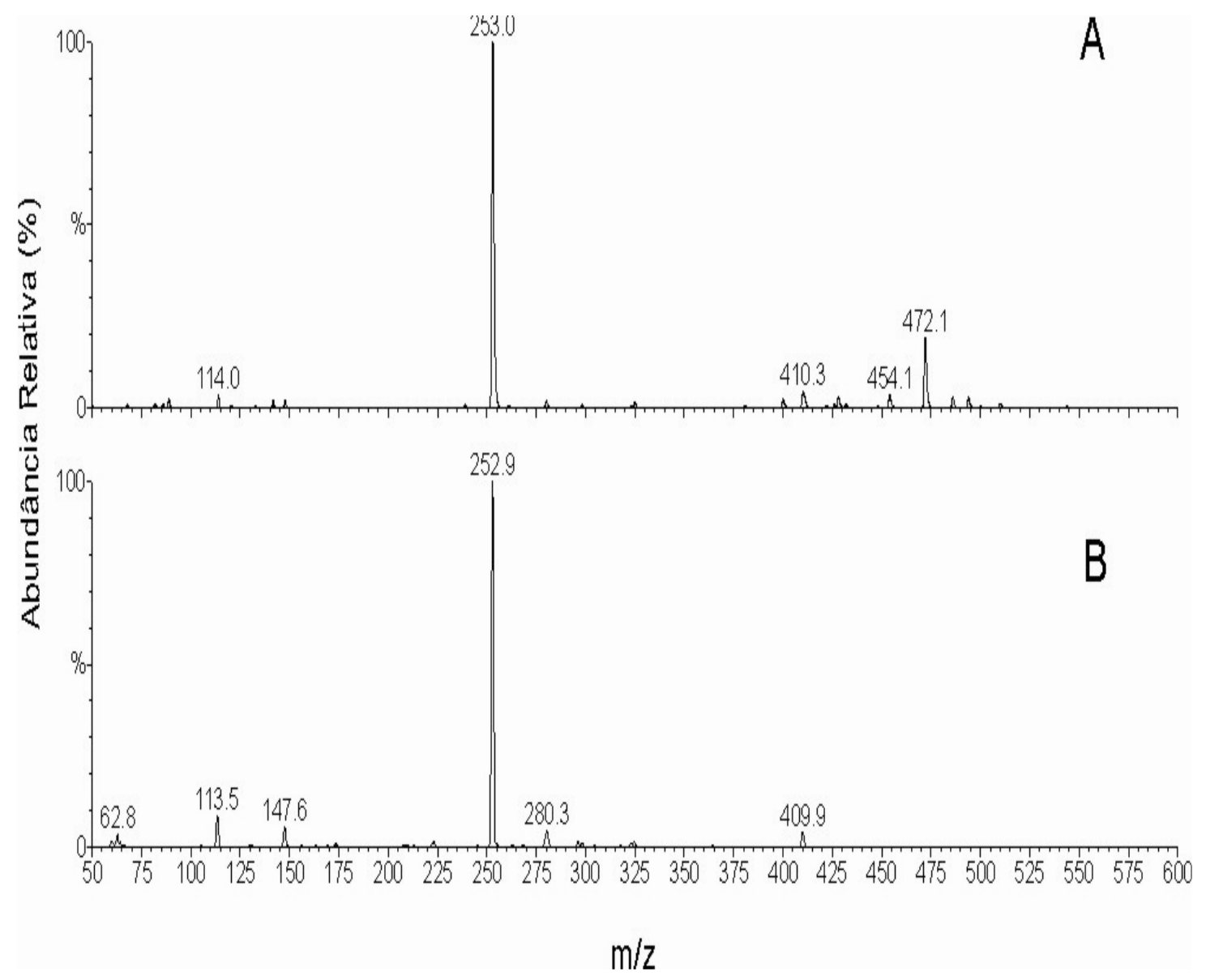

Figura 13: Espectros de massas do produto de $t_{r}=11.7 \mathrm{~min}$, fração aquosa da eletrooxidação na primeira onda (A) "fullscan" - ESI/MS no modo positivo, voltagem do cone $40 \mathrm{~V}$, voltagem do capilar $3,6 \mathrm{kV}$. (B) respectivos íons-fragmentos, energia de colisão $30 \mathrm{eV}$.

Um outro pico com tempo de retenção de $16 \mathrm{~min}$ foi detectado com $\mathrm{m} / \mathrm{z}$ de $269[\mathrm{M}+\mathrm{H}]^{+}$e a Figura 14 apresenta o espectro de massas (fullscan) para este composto.

O íon molecular com $\mathrm{m} / \mathrm{z} 269[\mathrm{M}+\mathrm{H}]^{+}$pode ser constituído pela metade da molécula do DIP com a adição de um oxigênio, ou ainda, poderia estar associado à molécula do DIP com a incorporação de dois oxigênios e duplamente carregado $\mathrm{m} / \mathrm{z}$ $537[\mathrm{M}+2 \mathrm{H}]^{+}$. 


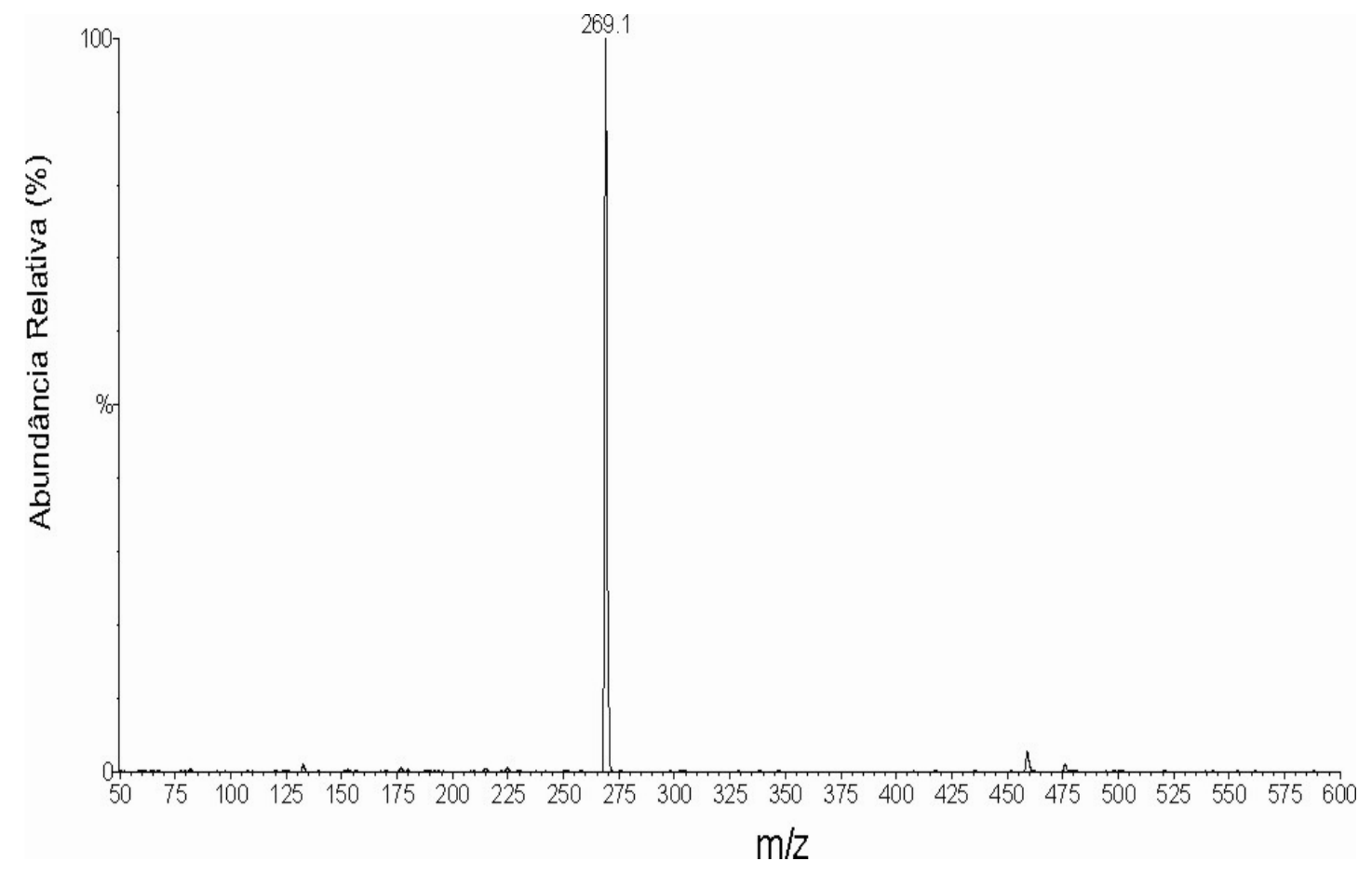

Figura 14: Espectros de massas "fullscan" - ESI/MS no modo positivo do produto de $t_{r}=$ $16.0 \mathrm{~min}$, da fração aquosa da eletrooxidação na primeira onda, voltagem do cone 40V, voltagem do capilar $3,6 \mathrm{kV}$.

A Figura 15 apresenta uma proposta para este composto. De acordo com a equação 10, o cátion radical é formado pela oxidação de um elétron, o que está associado a remoção do elétron do anel pirimido-pirimidino, consistente com o espectro de EPR [24]. Este radical formado em solução poderia reagir com o oxigênio dissolvido no solvente ou no ambiente, e formar o intermediário dioxetano apresentado na Figura 15, que por sua vez poderia sofrer rearranjos formando o produto final.

Este mesmo composto é observado na fração metanólica da eletrooxidação na segunda onda. 


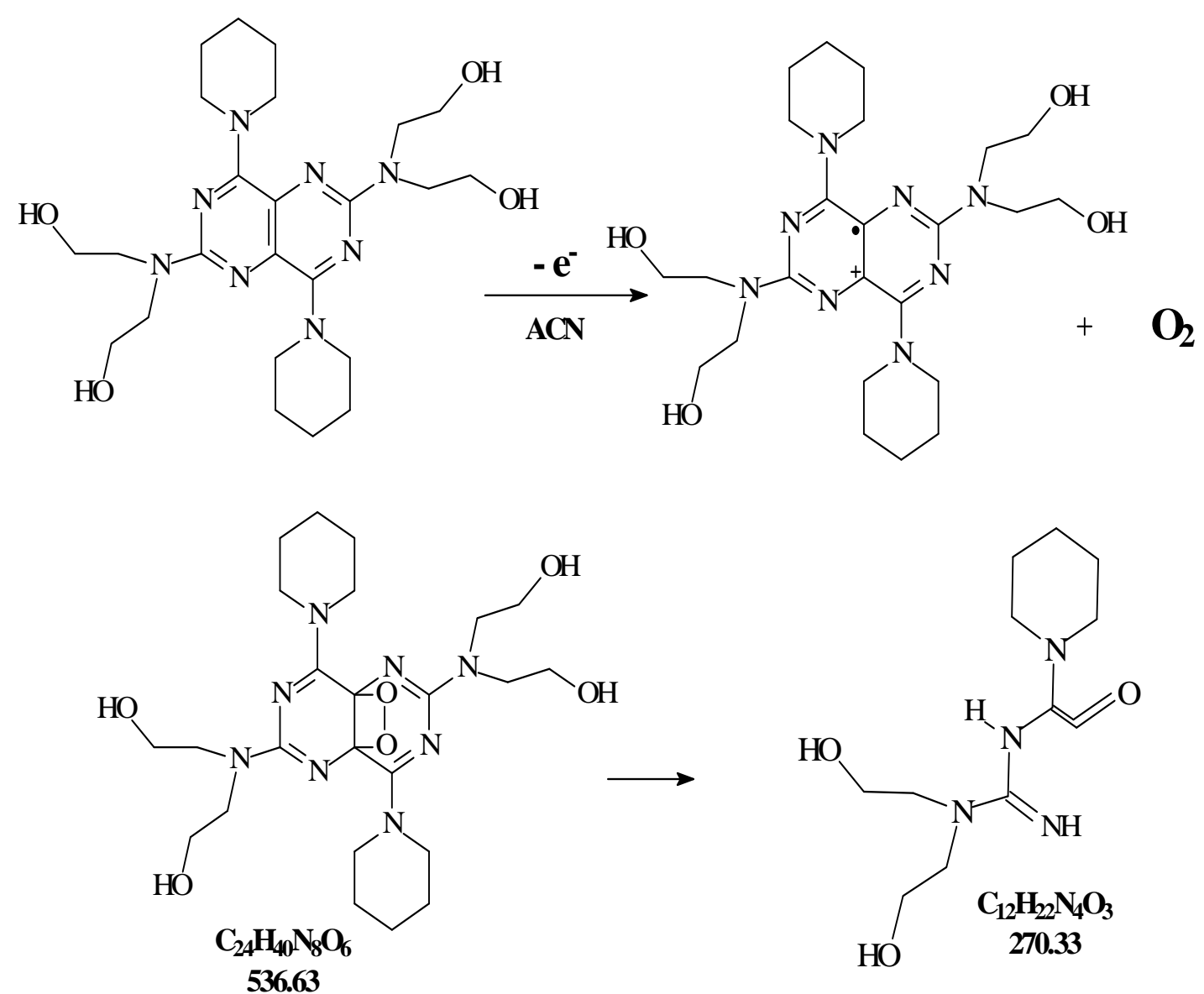

Figura 15: Proposta de mecanismo e estrutura final do produto da eletrooxidação (fração metanólica) na primeira e segunda ondas em acetonitrila, $t_{r}=16.0 \mathrm{~min}$.

\section{IV.3.2 ANÁLISE DOS PRODUTOS DA FRAÇÃO AQUOSA DAS ELETRÓLISES DO DIPIRIDAMOL EM ACETONITRILA NA SEGUNDA ONDA.}

Os resultados cromatográficos e espectrométricos dos produtos da fração aquosa da eletrooxidação do dipiridamol em acetonitrila na segunda onda são semelhantes aos obtidos para os produtos da fração aquosa na primeira onda de oxidação como pode ser observado na Figura 16. 

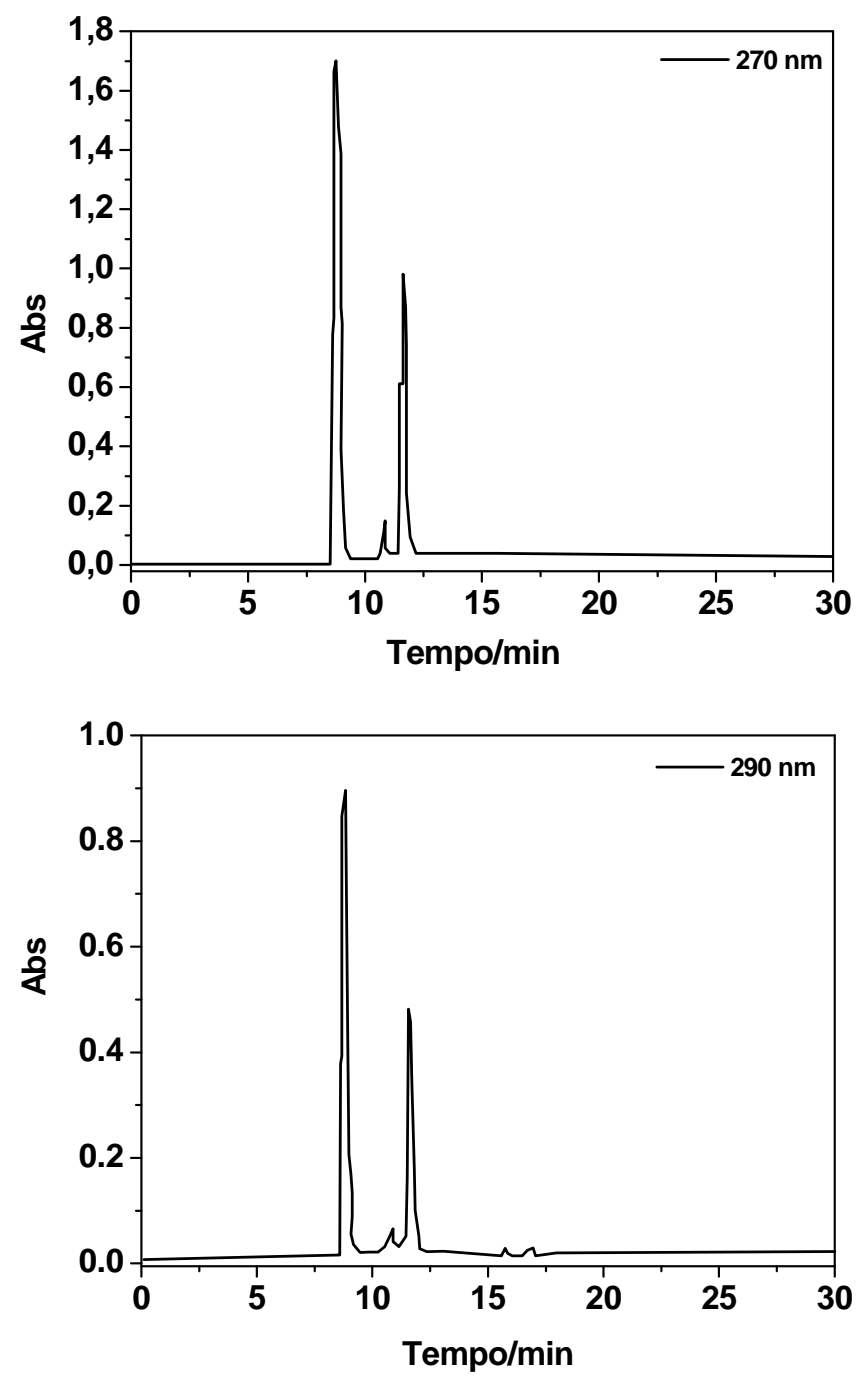

Figura 16: Cromatogramas dos produtos da fração aquosa da eletrooxidação do DIP em ACN na segunda onda (680 mV). Fase móvel: $\mathrm{NH}_{4} \mathrm{COOH}$ [30 mM] / MeOH. Gradiente de

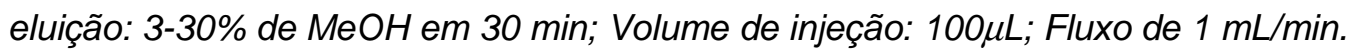

Pode-se observar a presença de dois picos majoritários com tempos de retenção em 9.3 e 12.2 min. O procedimento de análise foi o mesmo realizado para a eletrooxidação na primeira onda, sendo que, neste caso, podemos observar que ocorre a formação de uma quantidade maior de produtos devido às intensidades dos picos obtidos no HPLC. Os produtos associados aos dois picos absorvem mais em $270 \mathrm{~nm}$, assim como observado nos produtos obtidos da eletrooxidação do DIP em acetonitrila na primeira onda. A Figura 17 apresenta os espectros de massas do produto de eletrooxidação com tempo de retenção em 9.3 min. 


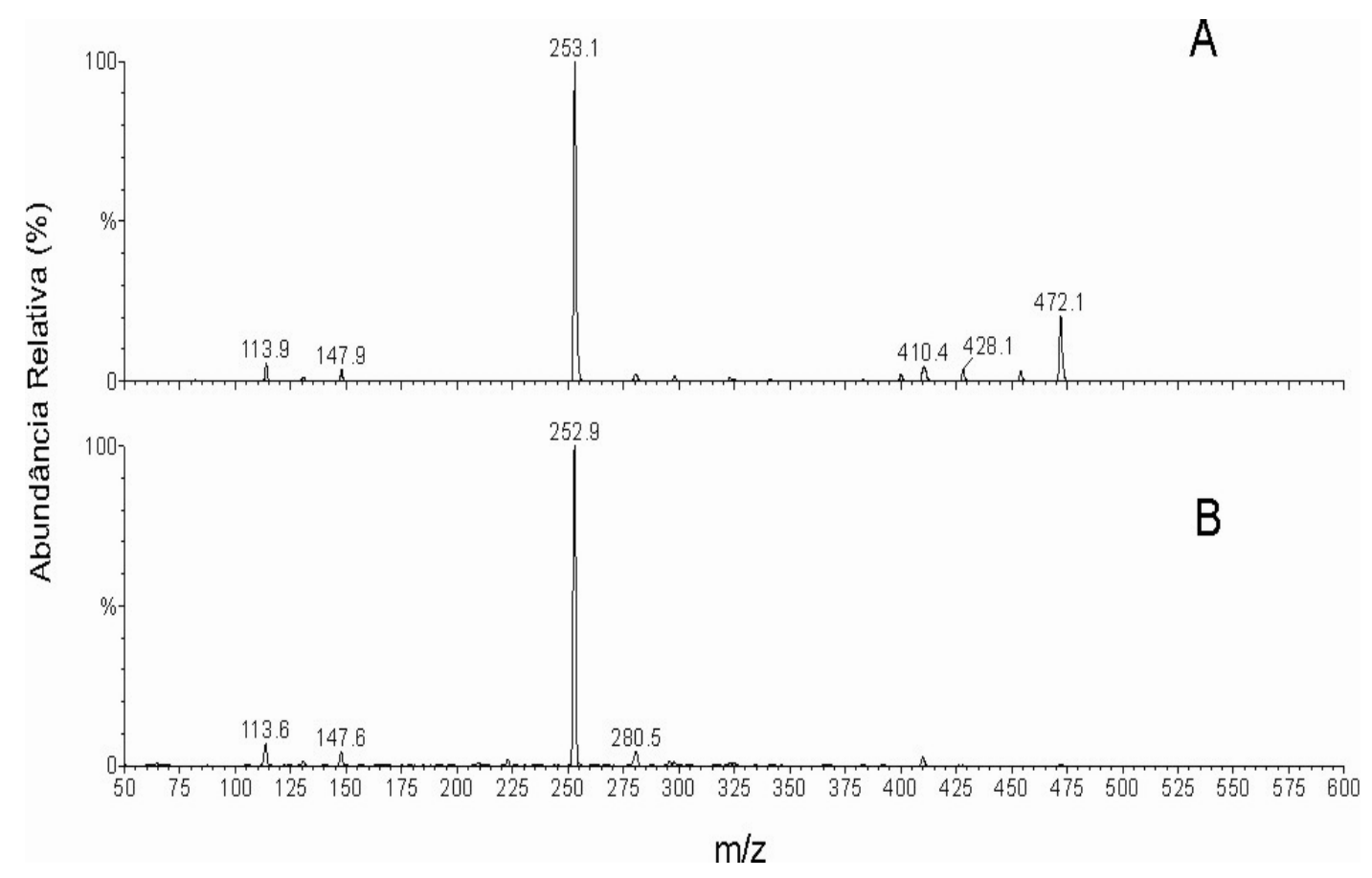

Figura 17: Espectros de massas do produto de $t_{r}=9.3 \mathrm{~min}$, da fração aquosa da eletrooxidação na segunda onda (A) "fullscan" - ESI/MS no modo positivo, voltagem do cone $40 \mathrm{~V}$, voltagem do capilar $3,6 \mathrm{kV}$. (B) respectivos íons-fragmentos, energia de colisão $30 \mathrm{eV}$.

Podemos observar desta figura que o produto com tempo de retenção em 9.3 min possui a mesma relação $\mathrm{m} / \mathrm{z}$ que o produto com tempo de retenção em $8.9 \mathrm{~min}$ obtido na fração aquosa da eletrooxidação do DIP na primeira onda em acetonitrila (Figura 12). O seu íon molecular com m/z $472[\mathrm{M}+\mathrm{H}]^{+}$(Figura $17 \mathrm{~A}$ ) e o íonfragmento com $\mathrm{m} / \mathrm{z} 253[\mathrm{M}+\mathrm{H}]^{+}$(Figura $17 \mathrm{~B}$ ), indicam que estes produtos podem ser isômeros, visto que, possuem tempos de retenção diferentes nas mesmas condições de análise.

Esta mesma característica é observada com os produtos com tempos de retenção em 12.2 min (Figura 18) e 16.5 min (Figura 19). Desta forma, estes produtos são isômeros provavelmente dos produtos com tempo de retenção em 11.7 min (Figura 13) e em 16 min (Figura 14) respectivamente, obtidos e descritos anteriormente na eletrooxidação do DIP na primeira onda. 


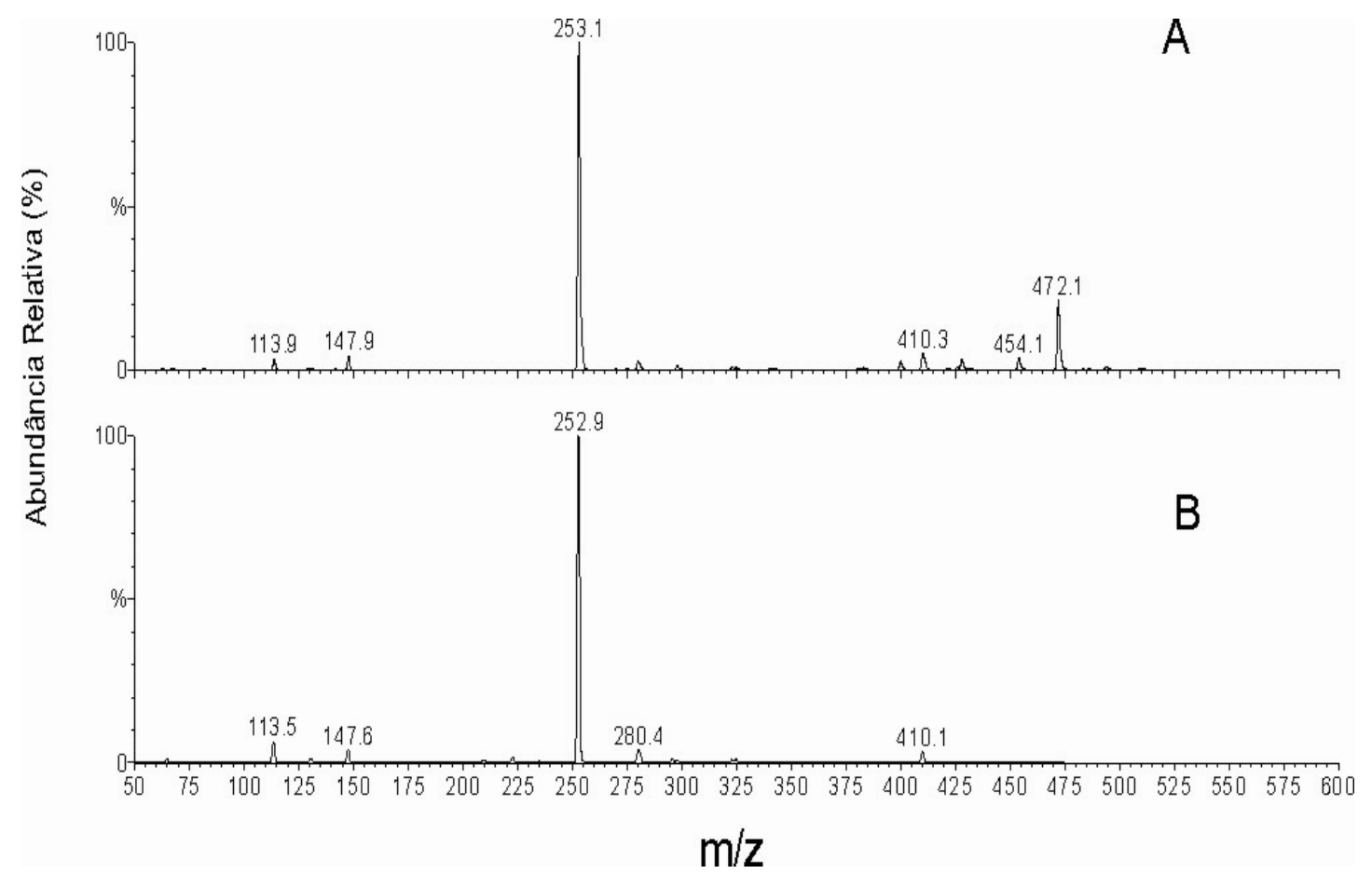

Figura 18: Espectros de massas do produto de $t_{r}=12.2 \mathrm{~min}$, fração aquosa da eletrooxidação na segunda onda (A) "fullscan" - ESI/MS no modo positivo, voltagem do cone $40 \mathrm{~V}$, voltagem do capilar $3,6 \mathrm{kV}$. (B) respectivos íons-fragmentos, energia de colisão $30 \mathrm{eV}$.

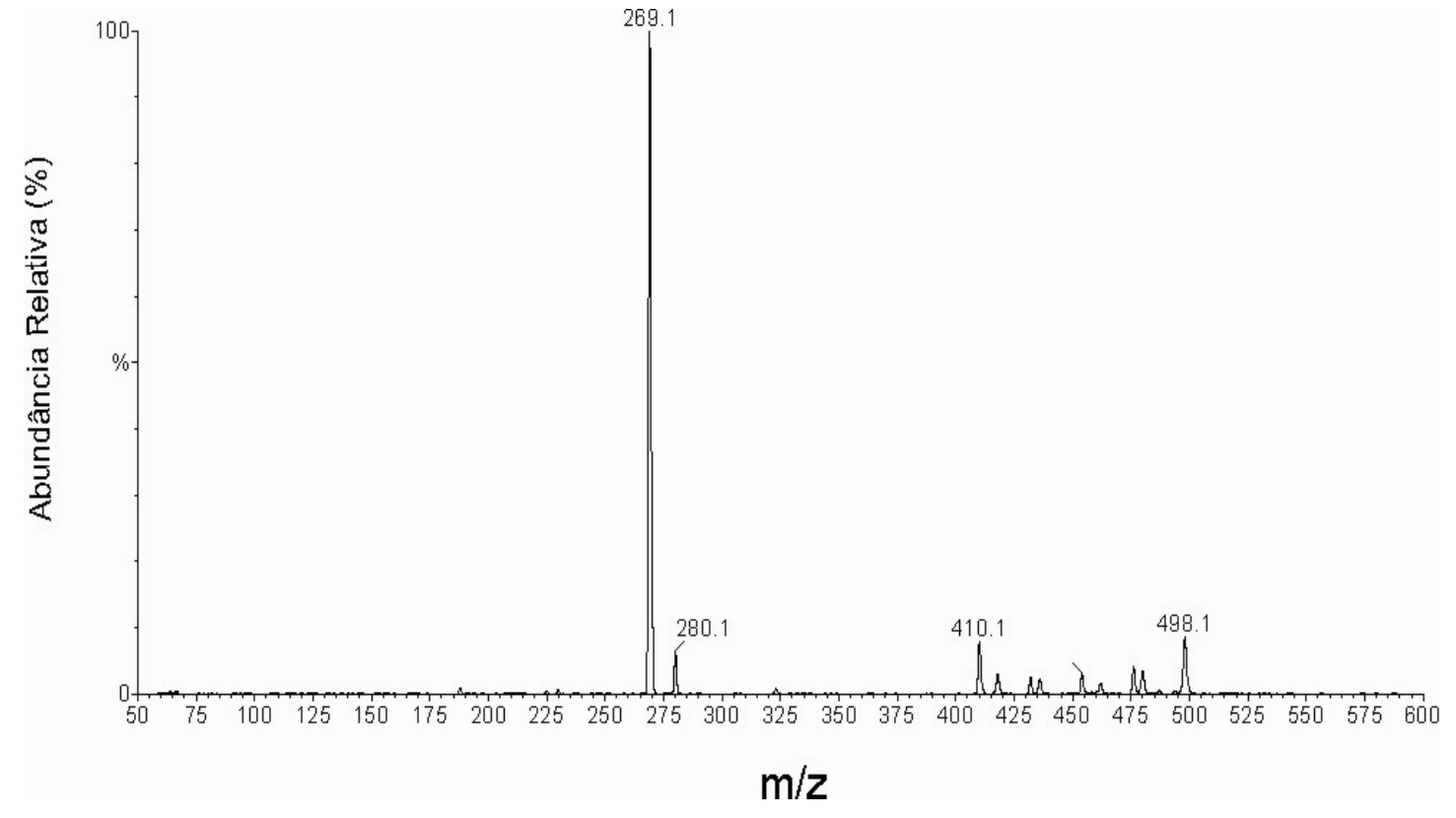

Figura 19: Espectros de massas "fullscan" - ESI/MS no modo positivo, do produto de $t_{r}=$ $16.5 \mathrm{~min}$, fração aquosa da eletrooxidação na segunda onda, voltagem do cone 40V, voltagem do capilar $3,6 \mathrm{kV}$. 


\section{IV.3.3 ANÁLISE DOS PRODUTOS DA FRAÇÃO METANÓLICA DAS ELETRÓLISES DO DIPIRIDAMOL EM ACETONITRILA NA PRIMEIRA ONDA.}

A Figura 20 apresenta os cromatogramas referentes à fração metanólica da eletrólise obtida em acetonitrila na primeira onda. O cromatograma obtido apresenta três picos majoritários como pode ser observado. O primeiro pico apresenta dois compostos que podem ser isômeros uma vez que, estão ligeiramente separados.

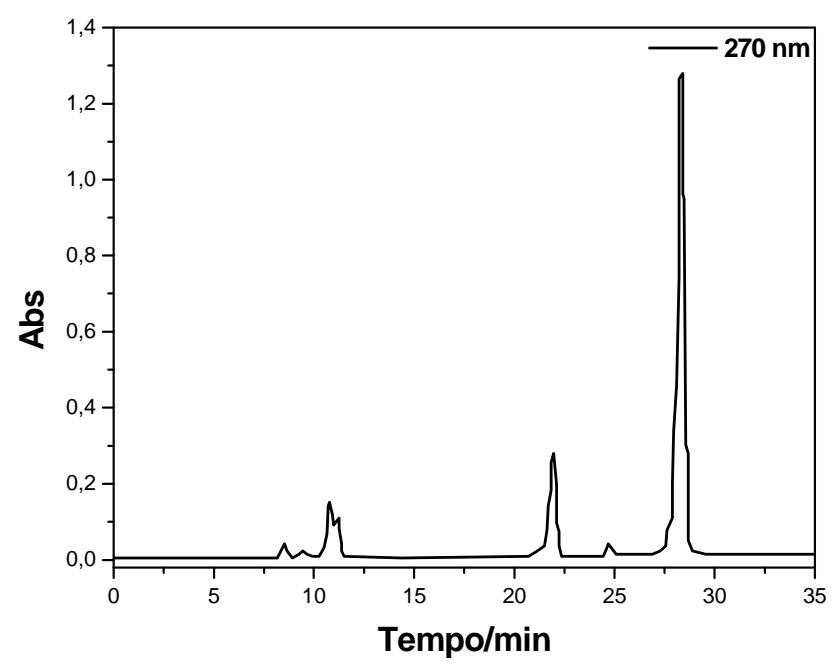

Figura 20: Cromatograma dos produtos da fração metanólica da eletrooxidação na primeira onda $(+350 \mathrm{mV})$ do DIP em acetonitrila. Fase móvel: $\mathrm{NH}_{4} \mathrm{COOH}[30 \mathrm{mM}] / \mathrm{MeOH}$. Gradiente: $30 \%$ a 97\% de $\mathrm{MeOH}$ em 30 min; Fase estacionária: C18; Volume de injeção: 100 $\mu \mathrm{L}$. Com fluxo de $1 \mathrm{~mL} / \mathrm{min}$.

Assim, verificamos a existência de um íon com $\mathrm{m} / \mathrm{z} 269[\mathrm{M}+\mathrm{H}]^{+}$com tempo de retenção em 11.9 min (Figura 21), outro íon com m/z $519[\mathrm{M}+\mathrm{H}]^{+}$com tempo de retenção em 22.0 min (Figura 22) e um terceiro pico com m/z $505[\mathrm{M}+\mathrm{H}]^{+} \mathrm{com}$ tempo de retenção em 29.1 min (Figura 23) correspondente à forma protonada do DIP $[\mathrm{M}+\mathrm{H}]^{+}$.

Pelo espectro de massas (fullscan) da Figura 21 observa-se o pico do íon 537 $[\mathrm{M}+2 \mathrm{H}]^{+}$e o pico $269[\mathrm{M}+\mathrm{H}]^{+}$com tempo de retenção em 11.9 min. Este mesmo íon foi detectado anteriormente na fração aquosa da eletrooxidação em acetonitrila 
(Figura 15). A presença deste composto nesta fração deve estar relacionada ao fato que na separação em SPE um pouco deste composto ficou nesta fração.

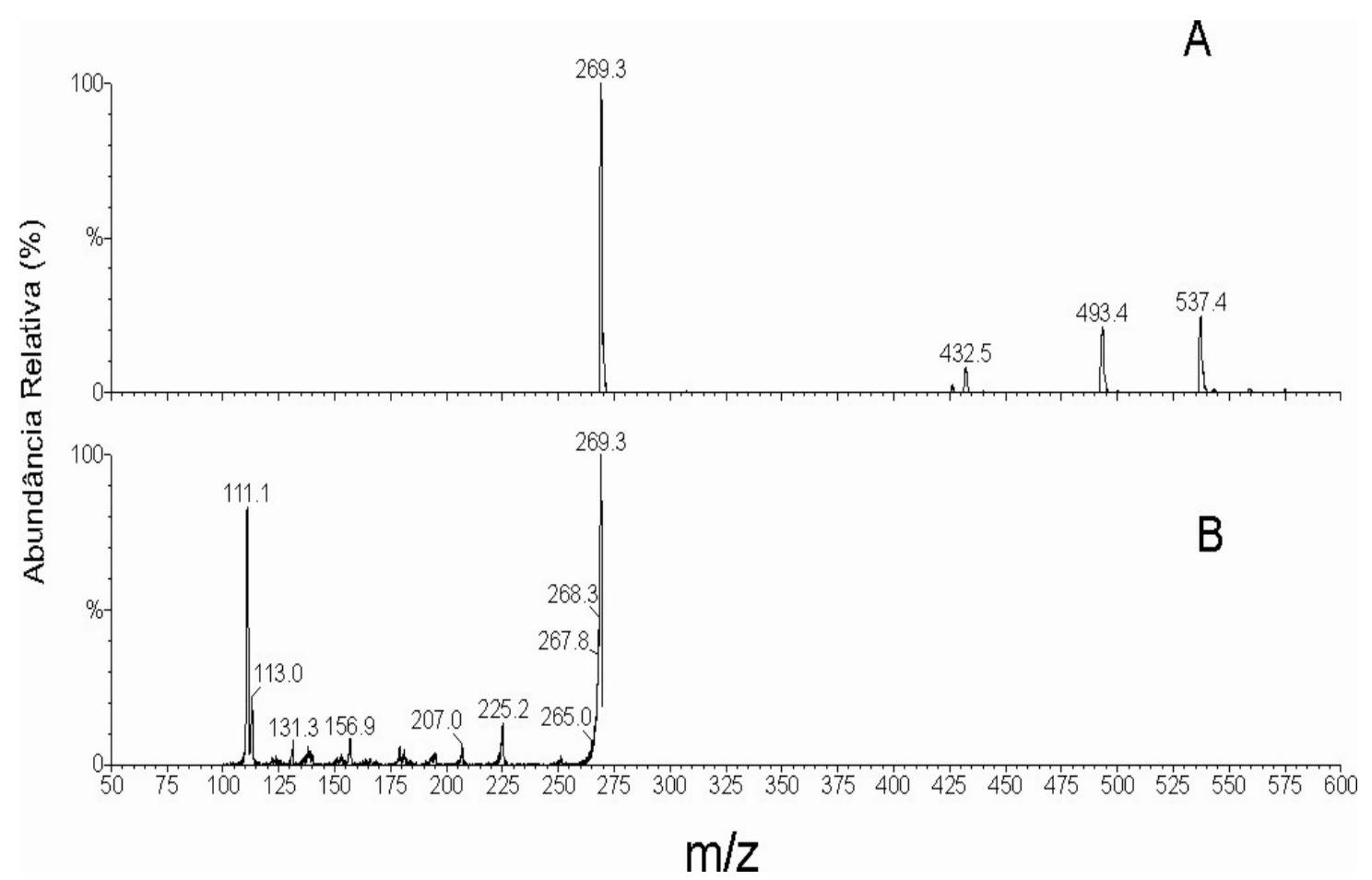

Figura 21: Espectros de massas do produto de $t_{r}=11.9$ min, fração metanólica da eletrooxidação na primeira onda (A) "fullscan" - ESI/MS no modo positivo, voltagem do cone $30 \mathrm{~V}$, voltagem do capilar 3,6 kV. (B) respectivos íons-fragmentos, energia de colisão $50 \mathrm{eV}$.

Pelo espectro de massas (fullscan) Figura 21 observa-se o pico do íon 519 $[\mathrm{M}+\mathrm{H}]^{+}$com tempo de retenção em $22.0 \mathrm{~min}$, sendo que neste caso o pico m/z 537 pode ser $\left[\mathrm{M}+\mathrm{NH}_{4}\right]^{+}$. Esta massa molecular pode estar associada à molécula do DIP com um átomo de oxigênio adicionado.

A Figura 23 apresenta uma proposta para este composto. Esta molécula é bem estável sendo necessário uma energia de colisão de $70 \mathrm{eV}$ para fragmentar este composto, mesmo com esta energia a fragmentação é bem pequena.

Este composto também é observado na eletrólise do DIP no potencial de segunda onda. 


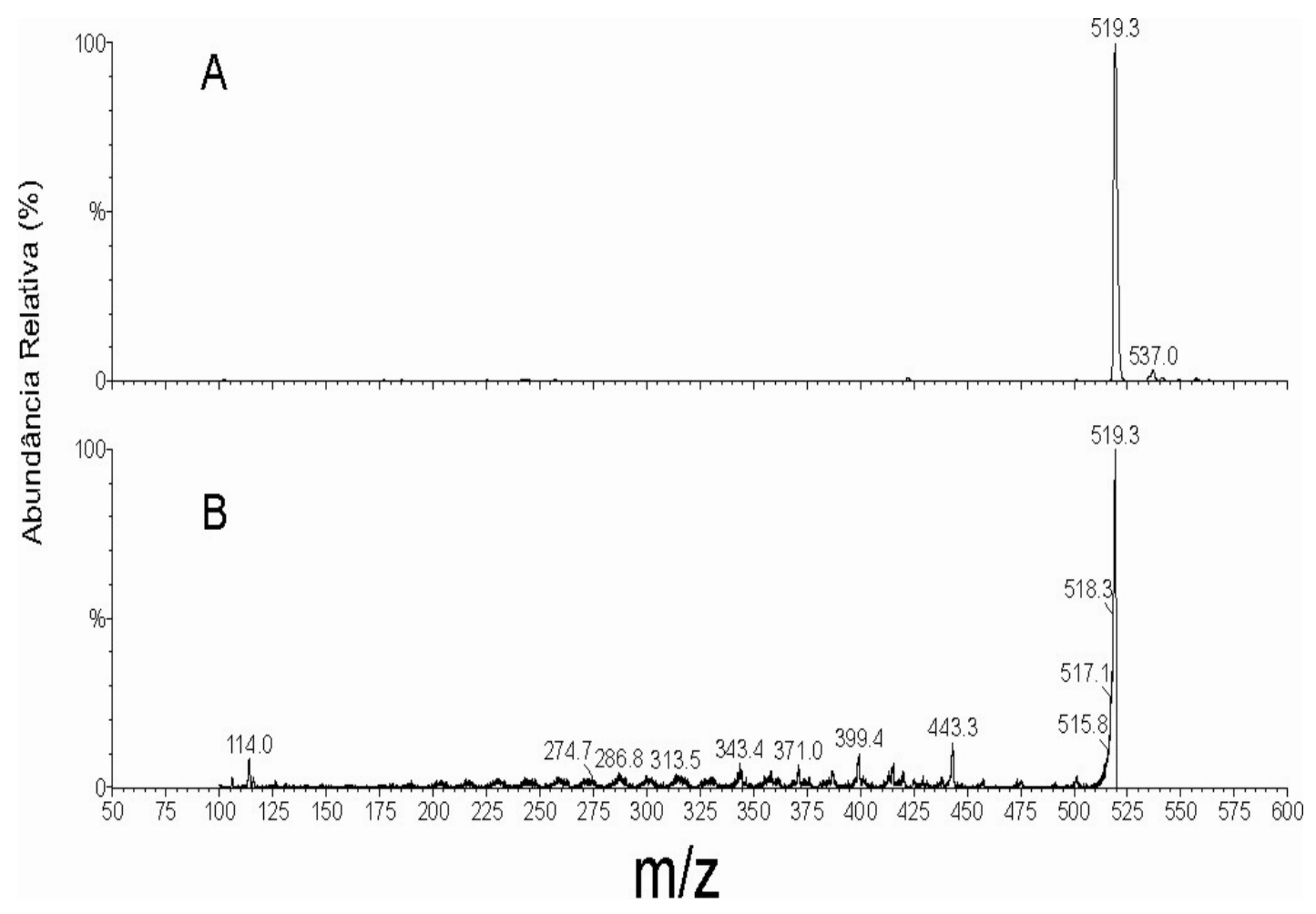

Figura 22: Espectros de massas do produto de $t_{r}=22.0 \mathrm{~min}$, fração metanólica da eletrooxidação na primeira onda (A) "fullscan" - ESI/MS no modo positivo, voltagem do cone $30 \mathrm{~V}$, voltagem do capilar $3,6 \mathrm{kV}$. (B) respectivos íons-fragmentos, energia de colisão $70 \mathrm{eV}$.

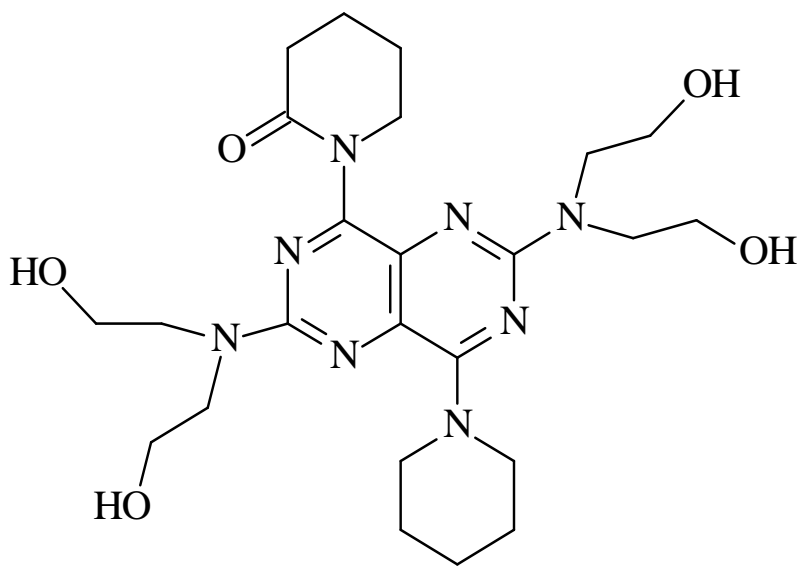

\section{$\mathrm{C}_{24} \mathrm{H}_{38} \mathrm{~N}_{8} \mathrm{O}_{5}$}

518.61

Figura 23: Proposta de mecanismo e estrutura final do produto da eletrooxidação (fração metanólica) na primeira e segunda onda em acetonitrila, $\mathrm{t}_{\mathrm{r}}=22.0 \mathrm{~min}$. 
O pico com tempo de retenção em 29.1 min (Figura 20) está associado ao DIP que pode ter sido regenerado em solução pela reação de desproporcionamento (Equação 13). O espectro de massas "fullscan" apresentado na Figura 24, mostra o íon do pico molecular do dipiridamol. Estudos sobre a fragmentação do DIP e alguns de seus derivados foram realizados e são apresentados na referência 33.

\section{DIP $^{\bullet+} \rightarrow$ DIP $^{2+}+$ DIP $\quad$ (Equação 13)}

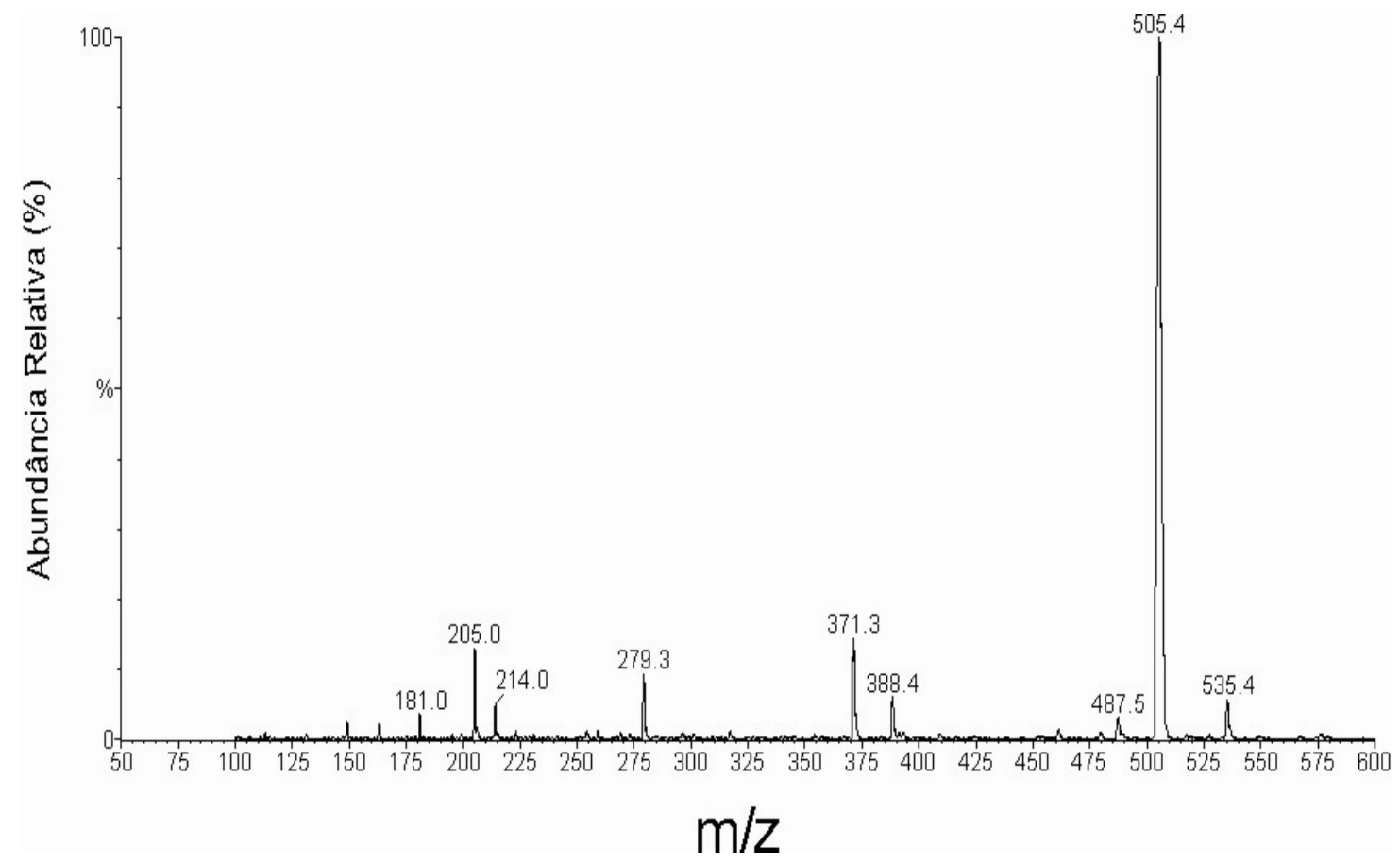

Figura 24: Espectro de massas do DIP regenerado em solução após a eletrooxidação na primeira onda $t_{r}=29.1 \mathrm{~min}$; "fullscan" - ESI/MS no modo positivo, voltagem do cone $40 \mathrm{~V}$, voltagem do capilar $3,6 \mathrm{kV}$. 


\section{IV.3.4 ANÁLISE DOS PRODUTOS DA FRAÇÃO METANÓLICA DAS ELETRÓLISES DO DIPIRIDAMOL EM ACETONITRILA NA SEGUNDA ONDA.}

A fração metanólica da eletrooxidação do DIP em acetonitrila na segunda onda é muito semelhante aos produtos obtidos na fração metanólica do DIP na primeira onda de oxidação como pode ser visto na Figura 25. Entretanto, os tempos de retenção estão diferentes por diminuir-se o tempo do gradiente de eluição para o melhor aproveitamento do tempo de máquina.

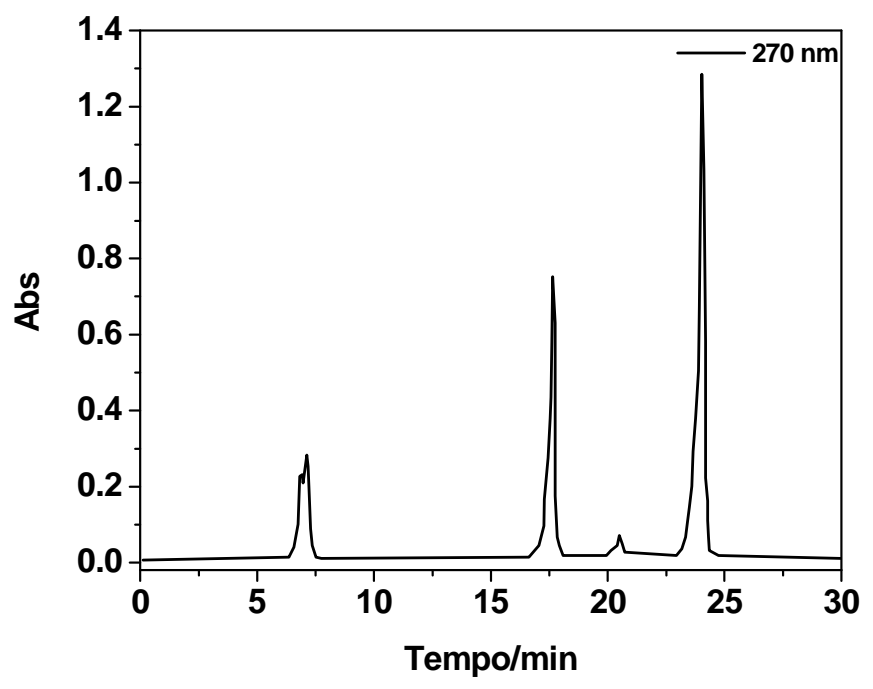

Figura 25: Cromatograma dos produtos da fração metanólica da eletrooxidação na segunda onda (+640 mV) do DIP em acetonitrila. Fase móvel: $\mathrm{NH}_{4} \mathrm{COOH}$ [30 mM] / MeOH. Gradiente: $30 \%$ a 97\% de $\mathrm{MeOH}$ em 25 min; Fase estacionária: C18; Volume de injeção: 100 $\mu \mathrm{L}$. Com fluxo de $1 \mathrm{~mL} / \mathrm{min}$.

Esta fração apresenta íons com m/z $269[\mathrm{M}+\mathrm{H}]^{+}$com tempo de retenção em $6.8 \mathrm{~min}$ Figura 26 (semelhante a Figura 21), outro íon com m/z $519[\mathrm{M}+\mathrm{H}]^{+} \mathrm{com}$ tempo de retenção em 17.6 min Figura 27 (semelhante a Figura 22) e o pico de m/z $505[\mathrm{M}+\mathrm{H}]^{+}$Figura 28 (semelhante a Figura 24) correspondente à forma protonada do DIP $[\mathrm{M}+\mathrm{H}]^{+}$com tempo de retenção em 24 min. 


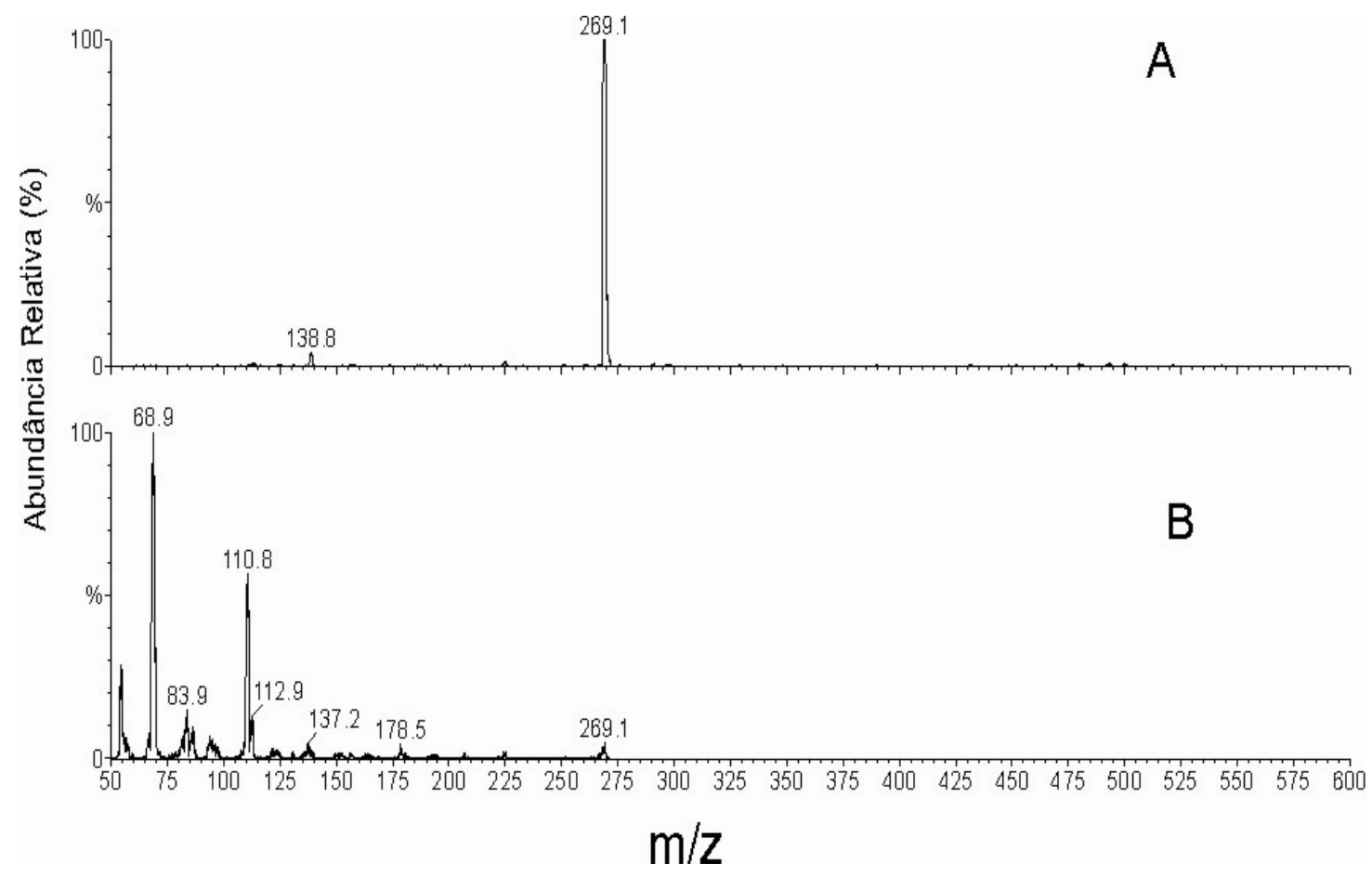

Figura 26: Espectros de massas do produto de $t_{r}=6.8 \mathrm{~min}$, fração metanólica da eletrooxidação na segunda onda (A) "fullscan" - ESI/MS no modo positivo, voltagem do cone $30 \mathrm{~V}$, voltagem do capilar $3,6 \mathrm{kV}$. (B) respectivos íons-fragmentos, energia de colisão $50 \mathrm{eV}$.

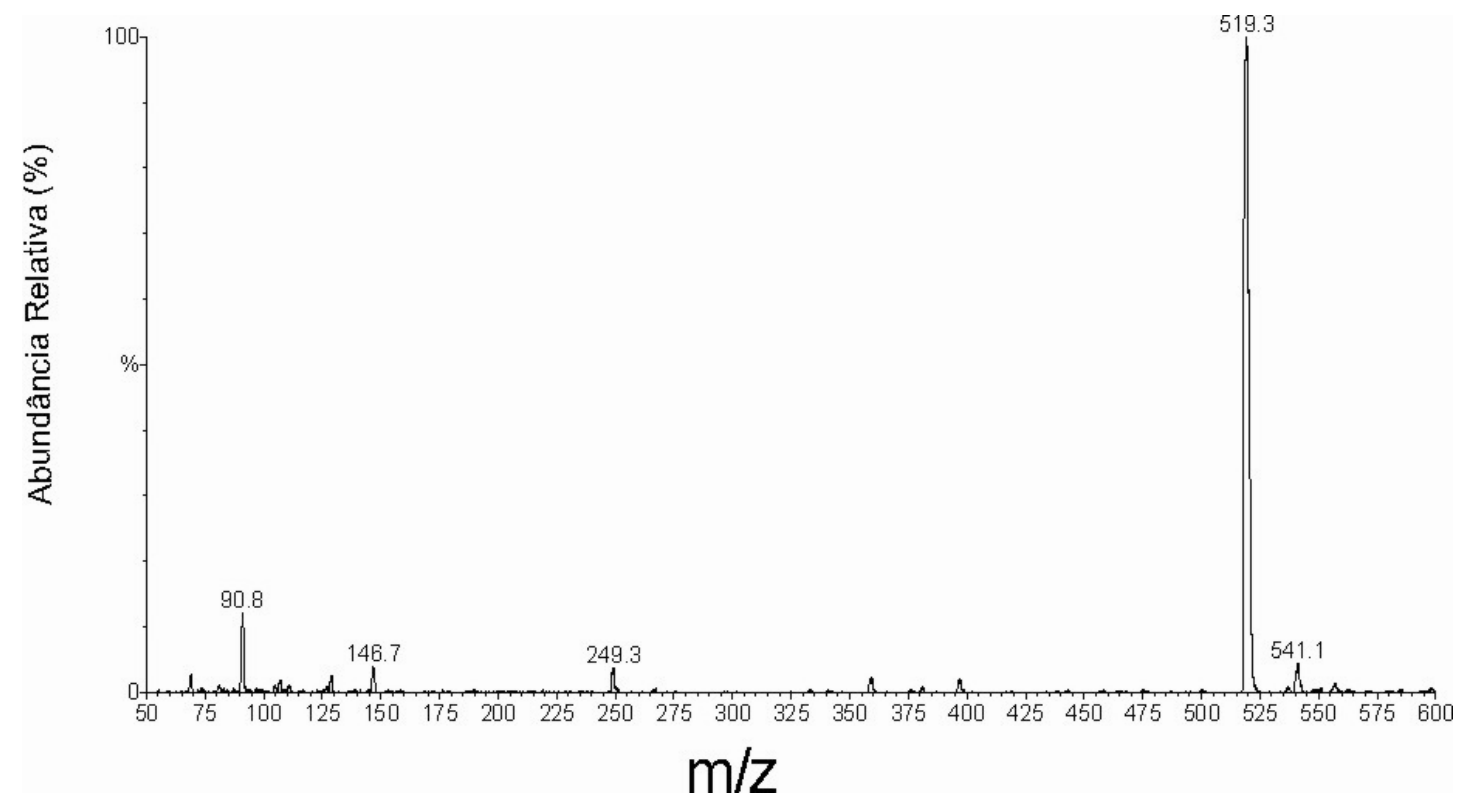

Figura 27: Espectros de massas do produto de $t_{r}=17.6$ min, fração metanólica da eletrooxidação na segunda onda (A) "fullscan" - ESI/MS no modo positivo, voltagem do cone $30 \mathrm{~V}$, voltagem do capilar $3,6 \mathrm{kV}$. (B) respectivos íons-fragmentos, energia de colisão $70 \mathrm{eV}$. 


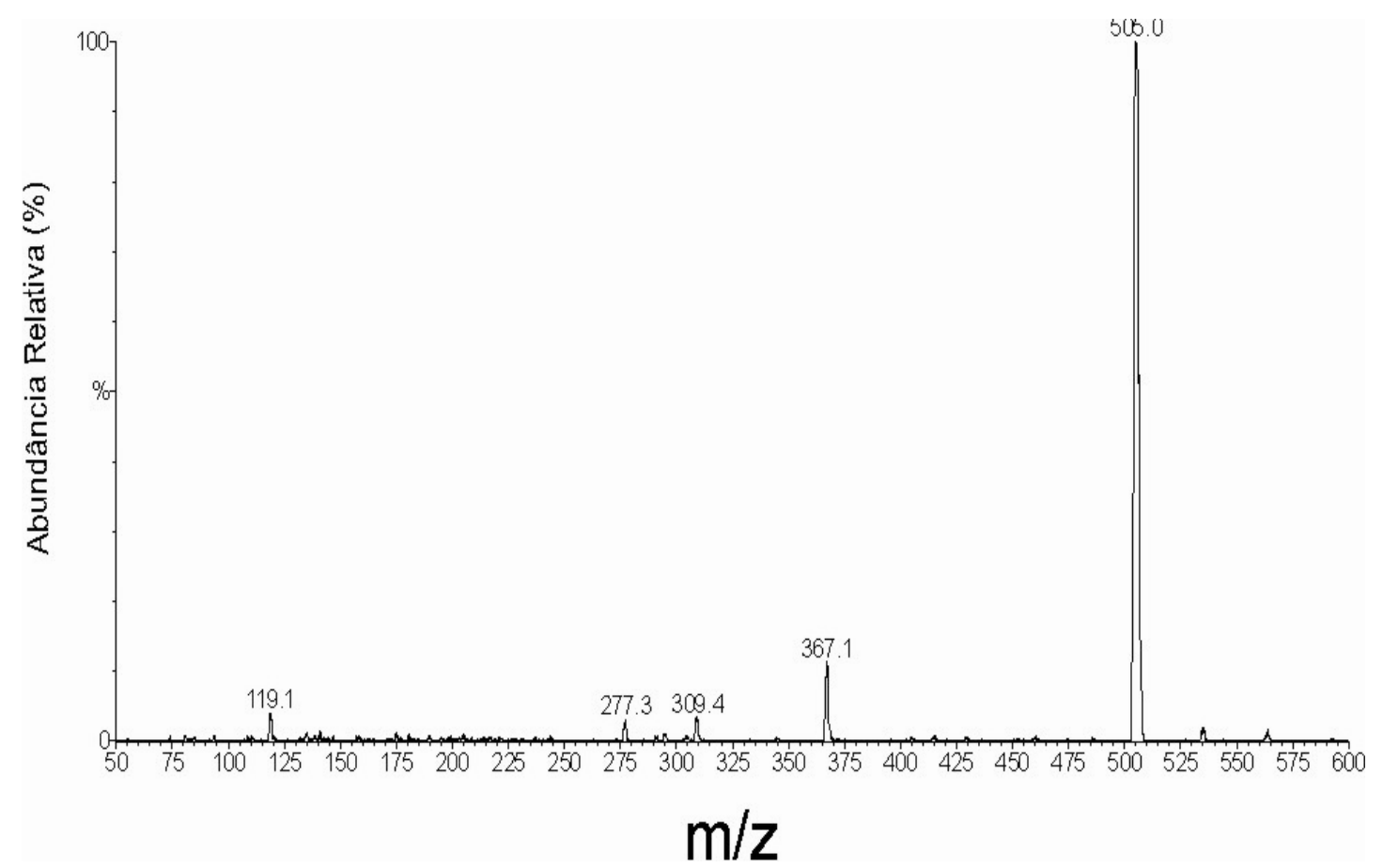

Figura 28: Espectro de massas do DIP regenerado em solução após a eletrooxidação na segunda onda; "fullscan" - ESI/MS no modo positivo, $t_{r}=24$ min voltagem do cone $40 \mathrm{~V}$, voltagem do capilar $3,6 \mathrm{kV}$.

\section{IV.3.5 ANÁLISE DOS PRODUTOS DAS ELETRÓLISES DO DIPIRIDAMOL EM MEIO AQUOSO ÁCIDO.}

Análises de LC-MS também foram realizadas para a eletrooxidação do DIP em meio aquoso ácido. A solução eletrolisada foi liofilizada e ressuspendida em 1 $\mathrm{mL}$ de água Milli-Q. O pH foi conferido e estava em torno de 2.0, sendo que esta solução foi injetada diretamente no HPLC e analisada por LC-MS.

A Figura 29 apresenta os cromatogramas obtidos para esta amostra. Observa-se a presença de vários picos, sendo que os picos majoritários possuem tempo de retenção em 8.9, 11.7, 14.4, 21.1 e 29.7 min. 

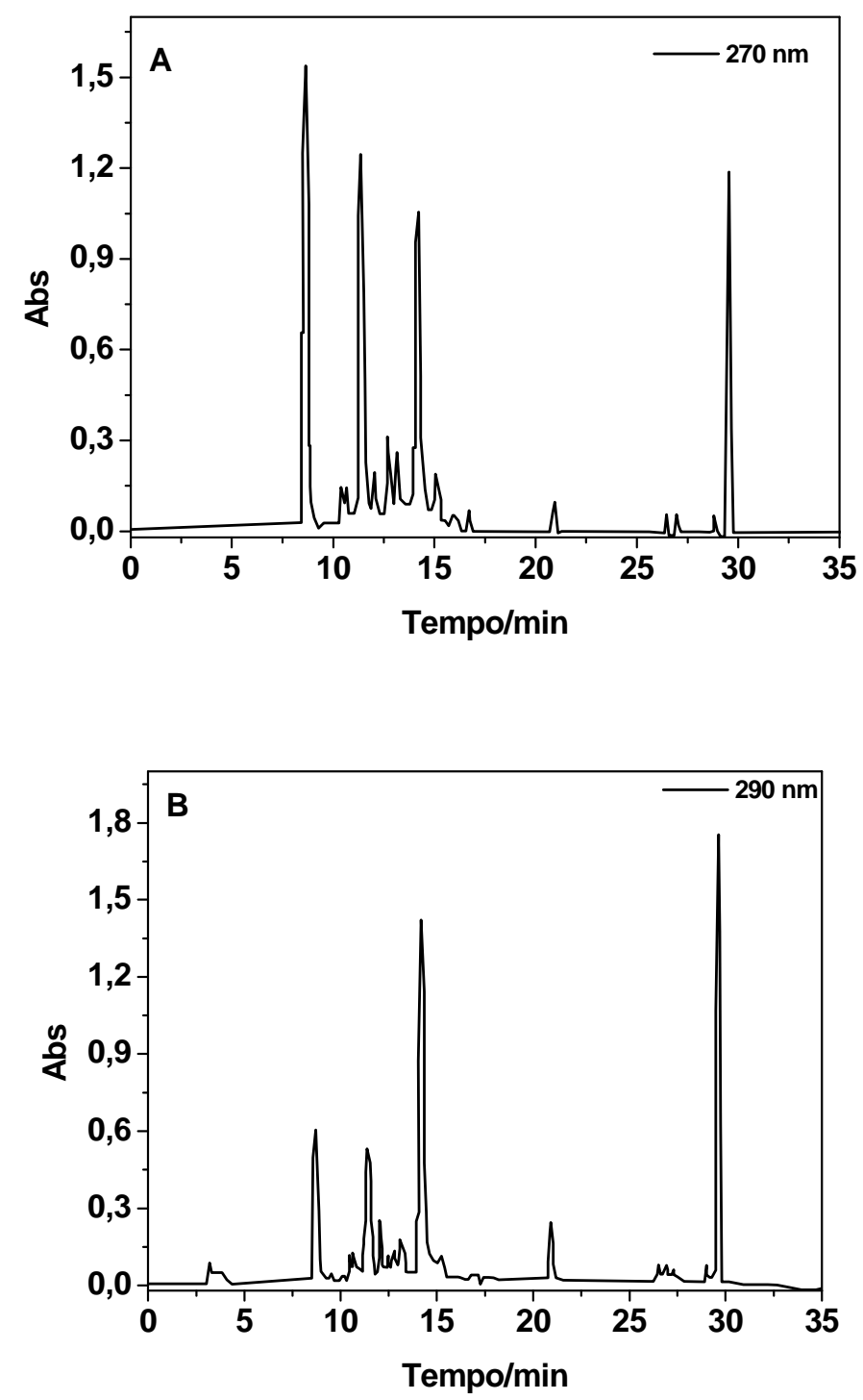

Figura 29: Cromatogramas dos produtos da eletrólise do DIP em meio ácido. Fase móvel $\mathrm{NH}_{4} \mathrm{COOH}[30 \mathrm{mM}$ / MeOH. Gradiente de eluição: 3-97\% de $\mathrm{MeOH}$ em $30 \mathrm{~min}$. Fase estacionária: C18; Volume de injeção: $100 \mu \mathrm{L}$. com fluxo de $1 \mathrm{~mL} / \mathrm{min}$.

A Figura. 30 apresenta o espectro de massas (fullscan) e os íons fragmentos para os compostos com tempos de retenção em 8.9 (Figura $30 \mathrm{~A}), 11.7$ (Figura $30 \mathrm{C}$ ) e 12 min (Figura 30 E). Pelo espectro de massas pode-se observar que estes três compostos com $\mathrm{m} / \mathrm{z} 472[\mathrm{M}+\mathrm{H}]^{+}$são isômeros, sendo importante comentar que o composto de tempo de retenção em 11 min apresenta uma fragmentação diferente: 
observa-se o íon com $\mathrm{m} / \mathrm{z}$ de $299[\mathrm{M}+\mathrm{H}]^{+}$(Figura $30 \mathrm{D}$ ), enquanto que, para os outros íons de $m / z 472[\mathrm{M}+\mathrm{H}]^{+}$, observa-se em sua fragmentação o íon fragmento de $m / z 253[\mathrm{M}+\mathrm{H}]^{+}$.

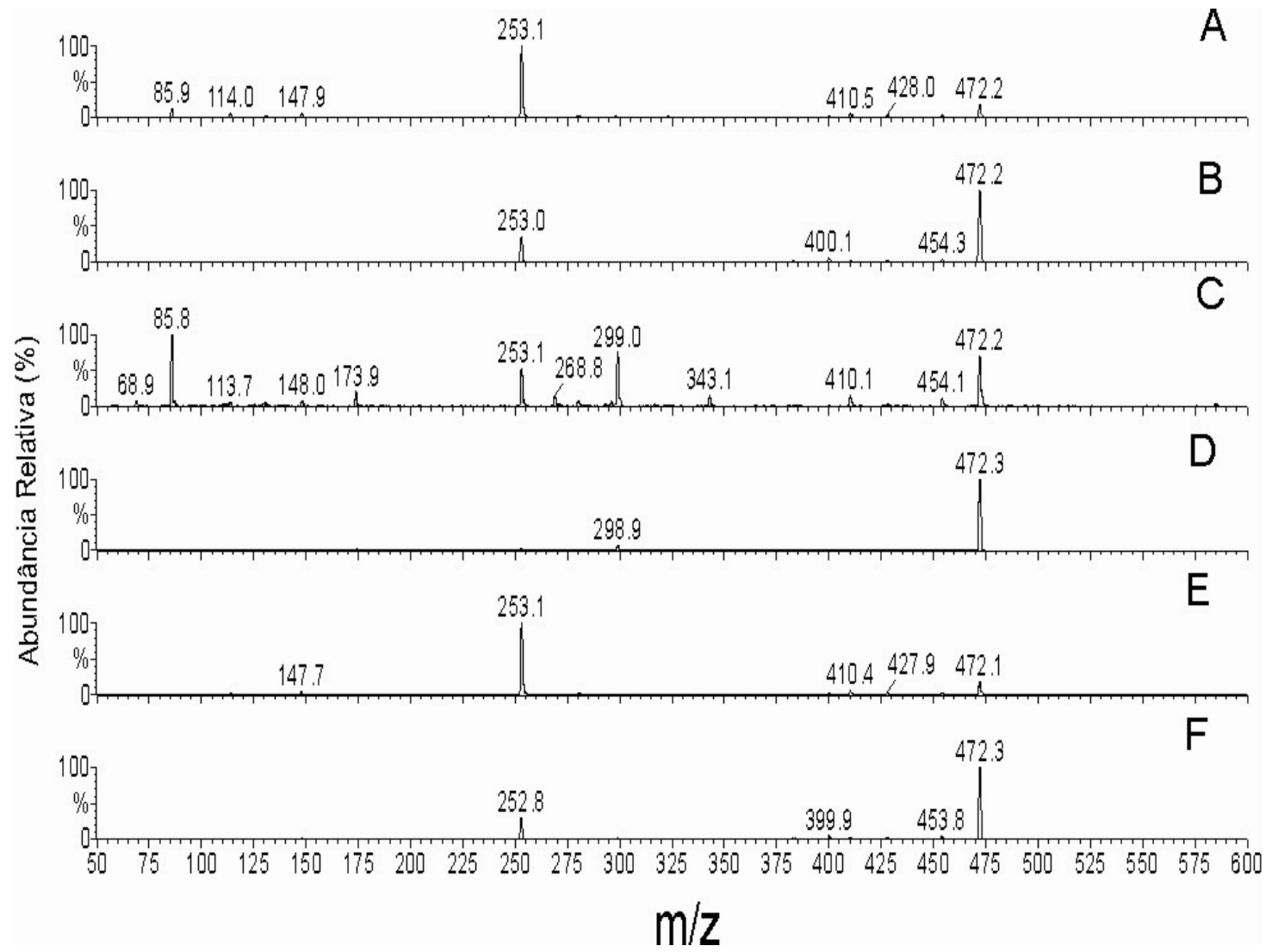

Figura 30: Espectros de massas do produto de $t_{r}=8.9 \mathrm{~min}(A), t_{r}=11.7 \mathrm{~min}(C), t_{r}=12.0 \mathrm{~min}(E)$, da eletrooxidação do Dipiridamol em meio aquoso ácido. "Fullscan" - ESI/MS no modo positivo, voltagem do cone $20 \mathrm{~V}$, voltagem do capilar $3,6 \mathrm{kV}$. (B, D, F) respectivos íons-fragmentos, energia de colisão $30 \mathrm{eV}$.

Este comportamento é um pouco diferente quando comparado à eletrooxidação do DIP em acetonitrila, onde somente dois isômeros com $\mathrm{m} / \mathrm{z} 472$ foram observados na fração aquosa.

Como mencionado anteriormente uma caracterização parcial e preliminar dos produtos da eletrooxidação em meio aquoso ácido foi realizada e descrita na tese de doutorado de Adaíla M. P. A. Brasileiro [31] onde é relatada a presença de compostos com m/z 473 e $m / z$ 253. Estrutura esta observada na Figura 12. 
A Figura 31 apresenta os espectro de massas para os íons de tempo de retenção em 29.7, 21.1 e 14.4 min.

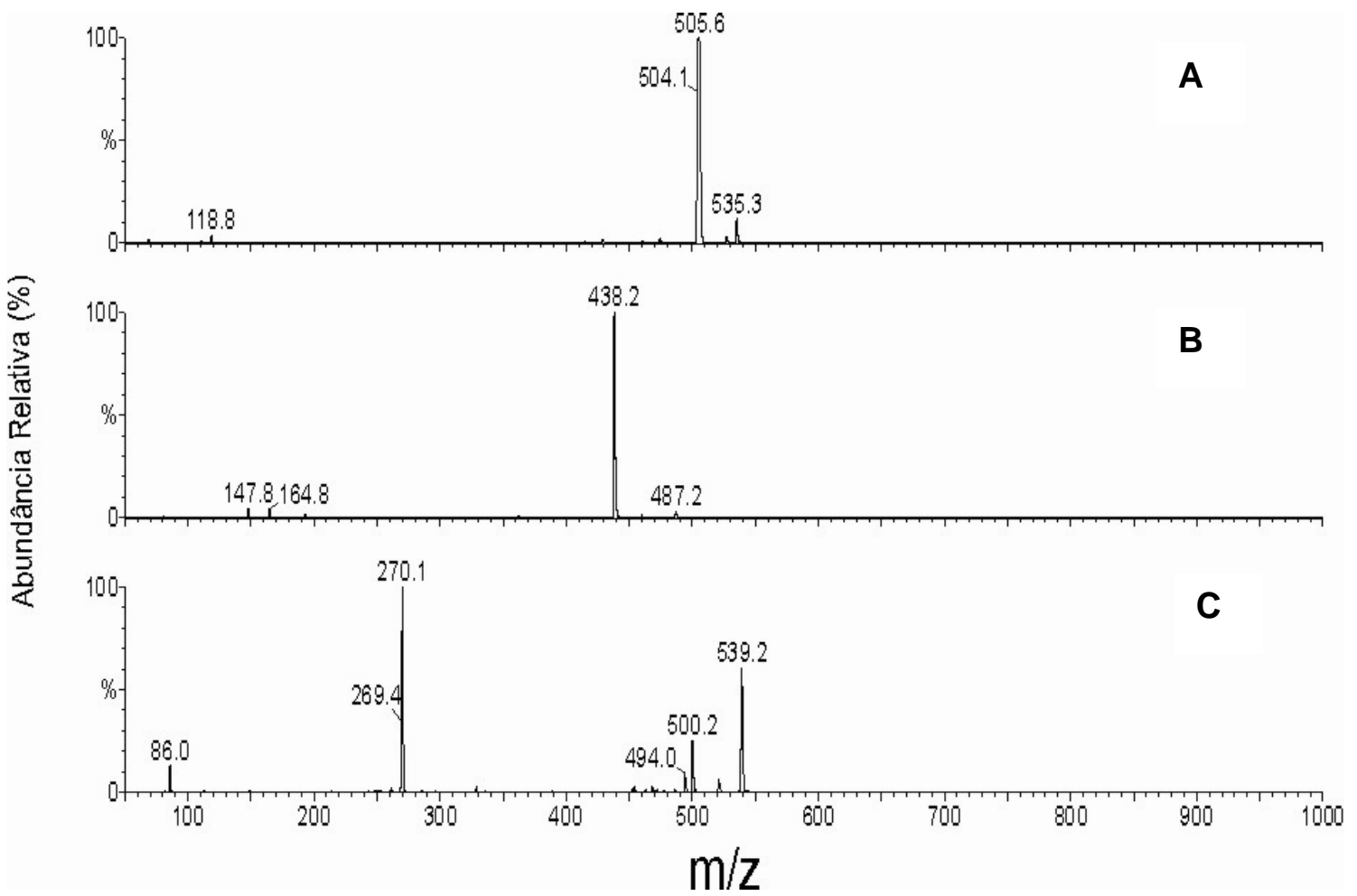

Figura 31: Espectros de massas dos produtos de $t_{r}=29.7$ (A), 21.0 (B) e $14.4 \mathrm{~min}(C)$, da eletrooxidação do Dipiridamol em meio aquoso ácido. "Fullscan" - ESI/MS no modo positivo, voltagem do cone $20 \mathrm{~V}$, voltagem do capilar $3,6 \mathrm{kV}$.

O íon com tempo de retenção de 29.7 min está relacionado ao DIP remanescente em solução não oxidado, como pode ser observado pelo espectro de massas da Figura 31 A. O íon com tempo de retenção em $21.0 \mathrm{~min}$ com m/z 438 $[\mathrm{M}+\mathrm{H}]^{+}$não está bem definido, neste caso a molécula do DIP tem a perda de massa de $67 \mathrm{Da}$. Este íon não foi detectado anteriormente na tese de Adaíla e precisa ser melhor analisado (Figura $31 \mathrm{~B}$ ).

O pico do cromatograma com tempo de retenção em 14.4 min apresenta íons de $m / z 539[\mathrm{M}+\mathrm{H}]^{+}$e $270[\mathrm{M}+\mathrm{H}]^{+}$(Figura $31 \mathrm{C}$ ). Na eletrooxidação em acetonitrila um íon de $\mathrm{m} / \mathrm{z} 269[\mathrm{M}+\mathrm{H}]^{+}$foi detectado e está relacionado à metade da molécula do DIP com um oxigênio (Figura 15). O íon detectado nestas condições poderia ser um 
dímero desse composto com $\mathrm{m} / \mathrm{z}$ de $539[\mathrm{M}+2 \mathrm{H}]^{+}$e o íon de $270[\mathrm{M}+\mathrm{H}]^{+}$, poderia ser o íon $\mathrm{m} / \mathrm{z}=269$ protonado.

Na eletrooxidação do DIP em meio aquoso ácido também se observa o pico de $m / z 269[\mathrm{M}+\mathrm{H}]^{+}$, como mostra a Figura 32 e o íon em 519 (Figura 33), os quais já foram discutidos anteriormente na eletrooxidação do DIP em acetonitrila (Figuras 20 e 21, respectivamente).Entretanto estes compostos na eletrooxidação do DIP em meio aquoso ácido são formados em pequenas quantidades.

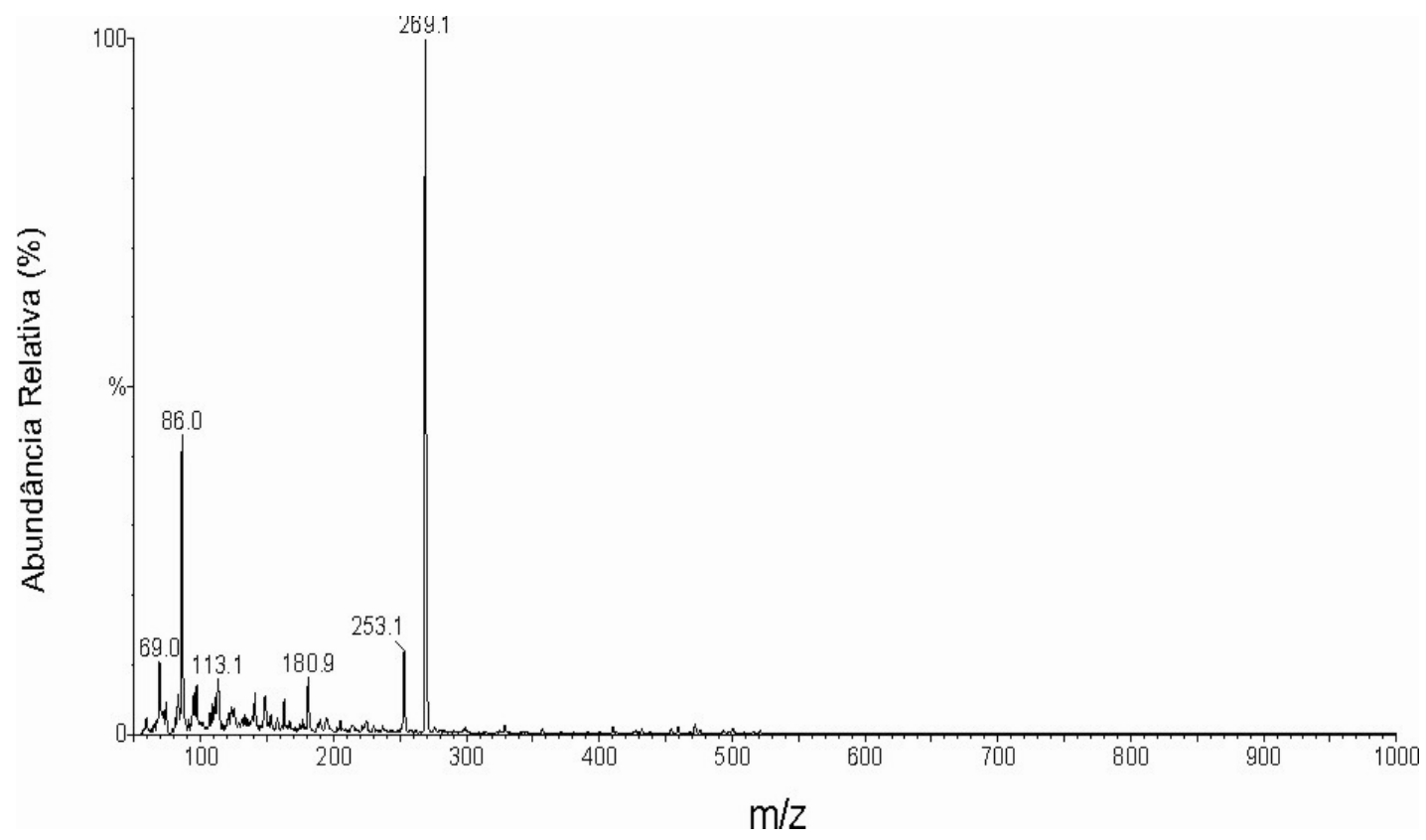

Figura 32: Espectros de massas dos produtos de $t_{r}=15.1 \mathrm{~min}$, da eletrooxidação do Dipiridamol em meio aquoso ácido. "fullscan" - ESI/MS no modo positivo, voltagem do cone $20 \mathrm{~V}$, voltagem do capilar $3,6 \mathrm{kV}$.

Um estudo mais detalhado dos produtos da eletrooxidação em meio aquoso ácido ainda se faz necessário, pois observam-se muitos picos minoritários com intensidades menores e que dificultam a análise dos picos majoritários no espectrômetro de massas. Entretanto, pode-se notar que em todas as eletrooxidações tanto em acetonitrila como no meio ácido ocorre a formação de alguns produtos com a mesma relação $\mathrm{m} / \mathrm{z}$ sendo que em meio ácido observa-se uma maior formação de isômeros do íon $472[\mathrm{M}+\mathrm{H}]^{+}$. 


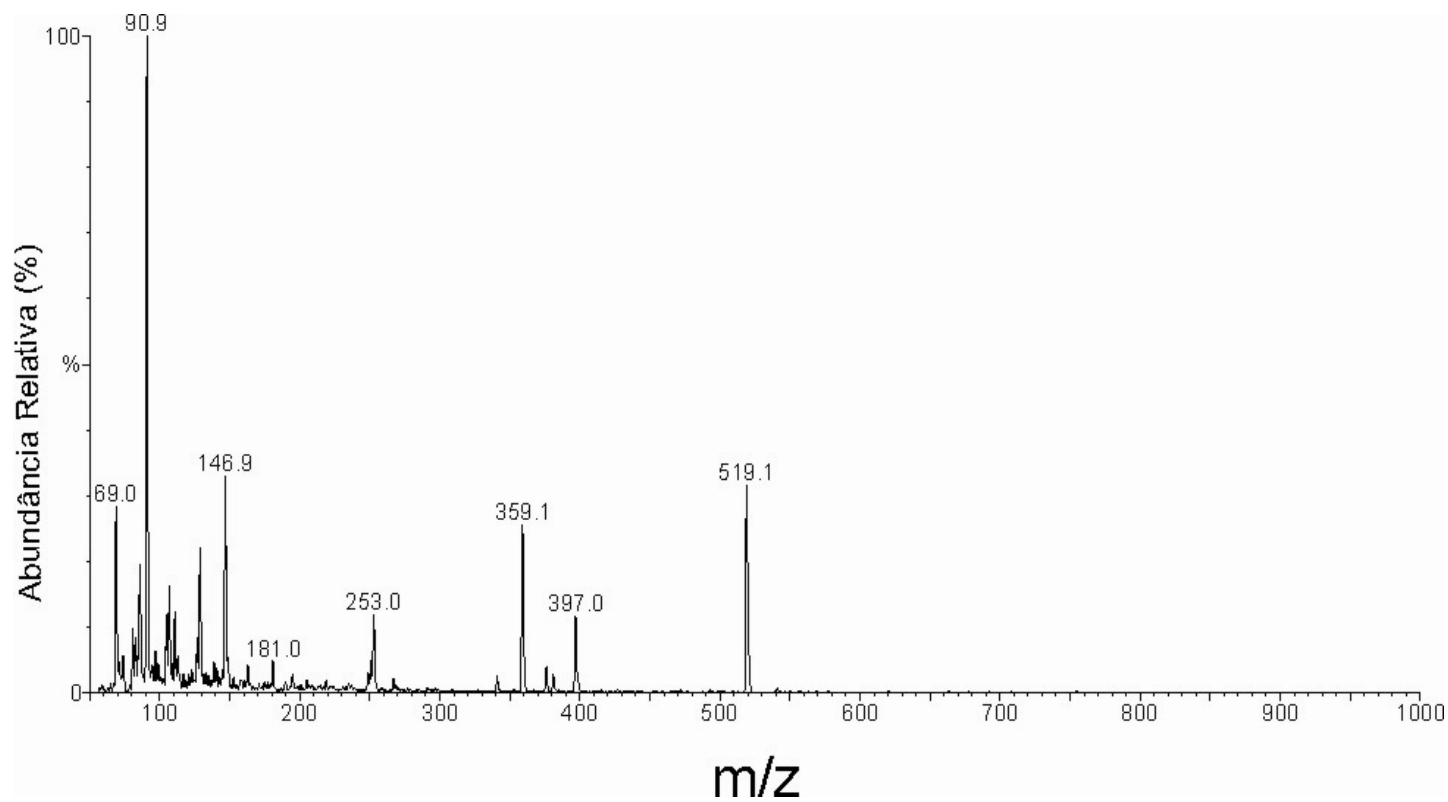

Figura 33: Espectros de massas dos produtos de $t_{r}=26.9 \mathrm{~min}$, da eletrooxidação do Dipiridamol em meio aquoso ácido. "fullscan" - ESI/MS no modo positivo, voltagem do cone $20 \mathrm{~V}$, voltagem do capilar $3,6 \mathrm{kV}$. 


\section{CAPÍTULO V - CONCLUSÕES}

Análises de LC-MS mostraram que a eletrooxidação do Dipiridamol em acetonitrila e em meio aquoso ácido leva à formação de produtos que possuem a mesma relação $\mathrm{m} / \mathrm{z}$. Todas as eletrólises levaram à formação de isômeros com $\mathrm{m} / \mathrm{z}$ de $472[\mathrm{M}+\mathrm{H}]^{+}, 269[\mathrm{M}+\mathrm{H}]^{+}, 519[\mathrm{M}+\mathrm{H}]^{+}$e $505[\mathrm{M}+\mathrm{H}]^{+}$. Estes produtos não são estáveis e há a necessidade de congelamento dos mesmos após o período de 24 horas depois da eletrólise e também, depois da extração em fase sólida para as análises posteriores. Os produtos gerados são mais polares que o DIP uma vez que seus tempos de retenção são menores que o seu precursor.

As análises mostraram que os produtos obtidos na fração aquosa da primeira e segunda ondas em acetonitrila são muito semelhantes. Nestas frações o produto majoritário são os isômeros de $\mathrm{m} / z 472[\mathrm{M}+\mathrm{H}]^{+}$sendo que, este produto aparentemente é formado em maior quantidade na eletrooxidação na segunda onda e possui maior absorção em $270 \mathrm{~nm}$. Este produto é consistente com a perda de 32 Da referente a perda do grupo $-\mathrm{CH}_{2} \mathrm{OH}$ do DIP. O produto com $\mathrm{m} / z 472[\mathrm{M}+\mathrm{H}]^{+}$que possui como íon-fragmento o $\mathrm{m} / \mathrm{z}=253[\mathrm{M}+\mathrm{H}]^{+}$, já havia sido relatado anteriormente na tese de doutorado de Adaíla M. P. A. Brasileiro como sendo produto gerado pela eletrooxidação do DIP em meio ácido. Entretanto foi constatado que esse produto também é produto da eletrooxidação do DIP em acetonitrila. Já o produto minoritário com $\mathrm{m} / \mathrm{z} 269[\mathrm{M}+\mathrm{H}]^{+}$absorve mais em $290 \mathrm{~nm}$, sendo que este aparentemente é

formado em maior quantidade na eletrooxidação na primeira onda. É consistente com a perda de metade da molécula do DIP com a adição de um oxigênio, ou ainda poderia estar relacionado à molécula do DIP com a incorporação de dois átomos de oxigênios e duplamente carregado $\mathrm{m} / \mathrm{z} 537[\mathrm{M}+2 \mathrm{H}]^{+}$. 
Pelos cromatogramas dos produtos obtidos nas frações metanólicas da eletrooxidação do DIP em acetonitrila pode-se observar que os produtos formados na primeira e na segunda ondas são isômeros, onde são observados três picos majoritários. O primeiro deles, o íon com $\mathrm{m} / \mathrm{z} 269[\mathrm{M}+\mathrm{H}]^{+}$, observado anteriormente na fração aquosa; o segundo íon com $\mathrm{m} / \mathrm{z}$ de $519[\mathrm{M}+\mathrm{H}]^{+}$poderia estar associado à molécula do DIP com a incorporação de um átomo de oxigênio. E o último, o íon com $\mathrm{m} / z 505[\mathrm{M}+\mathrm{H}]^{+}$, que está relacionado ao DIP remanescente ou regenerado pela reação de desproporcionamento, o que corrobora com os dados obtidos pelos espectros de fluorescência tanto na primeira quanto na segunda ondas.

Os cromatogramas da eletrólise do DIP em meio aquoso ácido apresentam vários picos, visto que, a amostra foi injetada diretamente no LC-MS. Entretanto pode ser observado pelos espectros de massa dos picos majoritários a formação dos mesmo compostos obtidos na eletrooxidação em acetonitrila. Como pode ser observado, o produto formado em maior quantidade é $0 \mathrm{~m} / \mathrm{z}=472[\mathrm{M}+\mathrm{H}]^{+}$, sendo que, entre os vários isômeros analisados do mesmo íon, um deles apresentou uma fragmentação diferente da observada anteriormente, com a presença do íonfragmento $m / z=299[\mathrm{M}+\mathrm{H}]^{+}$.

A Extração em Fase Sólida mostrou-se uma técnica bastante eficaz pois obteve-se cromatogramas e espectros bastante limpos quando comparados à injeção direta da solução eletrolisada em meio ácido. Ainda se faz necessário um estudo mais detalhado dos produtos da eletrooxidação em meio aquoso ácido, pois observam-se picos minoritários que podem dificultar a análise dos picos majoritários no espectrômetro de massas. A obtenção de um espectro de massas mais limpo é fundamental para a caracterização dos produtos majoritários. 
O eluente tampão Acetato/Metanol utilizado por Adaíla em sua tese de doutorado [31] durante suas análises cromatográficas não foi o melhor eluente para separação dos produtos da eletrólise do Dipiridamol deste trabalho, sendo que o melhor eluente para as devidas análises foi o Formiato de Amônio [30 mM]/Metanol.

Um fato importante a relatar, na caracterização dos produtos de eletrooxidação, é a dificuldade em realizar análises por RMN, devido à pequena quantidade de produto formado, sendo necessário realizar várias eletrólises seguidas, afim de obter quantidade de material adequada. Sendo que, para a caracterização definitiva dos produtos da eletrooxidação, ainda se fazem necessárias as análises por RMN, pois as caracterizações destes compostos darão a informação necessária para a definição das estruturas dos compostos. O conhecimento destas estruturas possibilitará um entendimento maior do mecanismo de oxidação, podendo assim contribuir para a elucidação do mecanismo de ação antioxidante deste composto. 


\section{CAPÍTULO VI - PERSPECTIVAS FUTURAS}

Para a continuidade deste projeto será necessário fazer análises de RMN dos produtos obtidos das eletrooxidações do DIP. Essas análises são primordiais para a completa elucidação estrutural destes compostos. Como a formação destes produtos é muito baixa, serão necessárias eletrólises em maiores quantidades de solução. 


\section{CAPÍTULO VII - REFERÊNCIAS BIBLIOGRÁFICAS}

[1] CASTRO, I. Cardiologia Princípios e Prática - $\mathbf{1}^{\text {a }}$ Ed. Porto Alegre: Artes Médicas, p. 235-308, 1999.

[2] KINDERMANN, M.; MEYER T.; KINDERMANN, W.; NICKENIG, G. Exercise training in heart failure. Herz, 28(2), p.153-165, 2003.

[3] SINGAL, P.K.; KHAPER, N.; PALACE, V.; KUMAR, D. The role of oxidative stress in genesis of heart disease. Cardiovascular Research, 40(3), p. 426-432,1998.

[4] OGA, S. Fundamentos de Toxicologia - 2ª Ed. São Paulo: Atheneu Editora, p. 3754, 2003.

[5] MELlo FilHo, A.C.; HOfFMAN, M.E.; MENEGHINI, R. Cell Killing and DNA damage by hydrogen peroxide are mediated by intracellular iron. Biochemical Journal, 218, p. 273-285, 1983.

[6] HERSHKO, C. Mechanism of iron toxicity and its possible role in red cell membrane damage. Seminairs in Hematology, 26, p. 277-285, 1989.

[7] SHAN, X.; AW, T.Y.; JONES, D.P. Glutathione-dependent protection against oxidative injury. Pharmacology \& Therapeutics, 47, p. 61-71, 1990. 
[8] ROSS, D.; MOLDEUS, P. Antioxidant defense systems and oxidative stress - 1th Ed. Boca Raton: CRC Press, p. 151-70, 1991.

[9] FERREIRA, A.L.A.; MATSUBARA, L. S. Radicais livres: conceitos, doenças relacionadas, sistema de defesa e estresse oxidativo. Revista da Associação Médica Brasileira, 43(1), p. 61-67, 1997.

[10] MINOTTI, G.; AUST, S.D. The requirement for iron (III) in the initiation of lipid peroxidation by iron (II) and hydrogen peroxide. Journal of Biological Chemistry, 262, p.1.098-1104, 1987.

[11] HUSAIN, S.R.; CILLARD, J.; CILLARD, P. Phytochemistry. Oxford : Pergamon Press, p. 2489-2491, 1987.

[12] HALLIWELL, B.; GUTTERIDGE, J.M.C. Free Radicals in Biology and Medicine. Oxford: Clarendon Press, p. 543- 598, 1991.

[13] STEIMBERG, D. Antioxidants in the prevention of human artherosclerosis. Circulation, 85, p. 2338-2343, 1992.

[14] FITZGERALD, G.A. Dipyridamole. New England Journal of Medicine, 316, p.1247-1257, 1987. 
[15] KLEM, I.; HEITNER, J.F.; SHAH, D.J. Improved detection of coronary artery disease by stress perfusion cardiovascular magnetic resonance with the use of delayed enhancement infarction imaging. Journal of American Cardiology, 47, p. 1630-1638, 2006.

[16] UDELSON, J.E.; DILSIZIAN, V.; BONOW, R.O. Cardiologia nuclear - Tratado de doenças cardiovasculares. Revista de Radiologia Brasileira, 40(5), p. 287-333, 2007.

[17] KIM, R.J.; FIENO, D.S.; PARRISH, T.B.; et al. Relationship of MRI delayed contrast enhancement to irreversible injury, infarct age, and contractile function. Circulation, 100, p. 1992-2002, 1999.

[18] I Diretriz da Sociedade Brasileira de Cardiologia Sobre Cardiologia Nuclear. Arquivo Brasileiro de Cardiologia, volume 78, (suplemento III), p. 5-42, 2002.

[19] IULIANO, L.; VIOLI, F.; GHISELLI, A.; ALESSANDRI, C.; BALSANO, F. Dipyridamole inhibits lipid peroxidation and scavengers oxygen free radicals. Lipids, 24 , p. $430-433,1989$.

[20] PEDULLI, G.F.; LUCARINI, M.; MARCHESI, E.; PAOLUCCI, F.; ROFFIA, S.; FIORENTINI, D.; LANDI, L. Medium effects on the antioxidant activity of dipyridamole. Free Radicals in Biology and Medicine, 26 (33/4), p. 295-302, 1999. 
[21] HEYOB, M.B.; MERLIN, J.L.; PONS, L.; CALCO, M.; WEBER, B.A. A sensitive isocratic liquid chromatography assay for the determination of dipyridamole in plasma with electrochemical detection. Journal of Liquid Chromatography, 17(8), p. 18371848, 1994.

[22] ZENG, X.; LIN, S.; HU, N. Trace measurement of dipyridamole by adsorptive stripping voltammetry. Talanta, 40 (8), p. 1183-1187, 1993.

[23] TUNCEL, M.; YAZAN, Y.; DOGRUKOL, D.; ATROSAR, Z. A polarographic study on dipyridamole and its determination in commercial tablets. Analytical Letters, 24(10), p. 1837-1846, 1991.

[24] ALMEIDA, L.E.; CASTILHO, M.; MAZO, L.H.; TABAK, M. Voltammetric and spectroscopic of the oxidation of the antioxidante drug dipyridamole in acetonitrile and ethanol. Analytica Chimica Acta, 375, p. 223-231, 1998.

[25] CASTILHO, M.; ALMEIDA, L.E.; TABAK, M.; MAZO, L.H.; Voltammetric oxidation od dipyridamole in aqueous acid solutions. Journal of the Brazilian Chemical Society, 11(2), p. 148-153, 2000.

[26] CASTILHO, M.; ALMEIDA, L.E.; TABAK, M.; MAZO, L.H. The electrochemical oxidation of the antioxidant drug dipyridamole at glassy carbon and graphite electrodes in micellar solutions. Electrochimica Acta, 46, p. 67-75, 2000. 
[27] NEPOMUCENO, M.F.; ALONSO, A.; SILVA, L.P.; TABAK, M. Inhibitory effect of dipyridamole and its derivatives on lipid peroxidation in mitochondria. Free Radicals in Biology and Medicine, 23(7), p. 1046-1054, 1997.

[28] BORISSEVITCH, I.E.; BORGES, C.P.F.; BORISSEVITCH, G.P.; YUSHMANOV, V.E.; LOURO, S.R.W.; TABAK, M. Binding and Location of Dipyridamole Derivatives in micelles: The Role of Drug Molecular Structure and Charge. Zeitschrift fuer Naturforschung, 51C, p. 578-590, 1996.

[29] RUGGIERO, A.C.; NEPOMUCENO, M.F.; JACOB, R.F.; DORTA, D.J.; TABAK, M. Antioxidant effect of dipyridamole (DIP) and its derivative RA25 upon lipid peroxidation and hemolysis in red blood cells. Physiological Chemistry \& Physics \& Medical NMR, 32, p. $35-48,2000$.

[30] IULIANO, L.; PICCHERI, C.; COPPOLA, I.; PRATICO, D.; MICELETTA, F.; VIOLI, F. Fluorescence quenching of dipyridamole associated to peroxyl radical scavenging: a versatile probe to measure the chain breaking antioxidant. Biochimica et Biophysica Acta, 1474(2), p. 177-182, 2000.

[31] BRASILEIRO A.M.P.A., tese de doutorado, IQSC, USP, São Carlos, agosto de 2001. 
[32] CASTILHO, M.; ALMEIDA, A.M.P.; TABAK, M.; MAZO, L.H. The electrooxidation of dipyridamole derivatives in acetonitrile solution. Journal of Electroanalytical Chemistry, 528, p. 175-183, 2002.

[33] FILHO, E.R.; ALMEIDA, A.M.P.; TABAK, M. Fragmentation of dipyridamole and related dipyrimidines by electrospray ionization collisional actived decomposition mass spectrometry. Journal of Mass Spectrometry, 38, 540-547, 2003.

[34] BORISSEVITCH, I.E.; BORGES, C.P.F.; YUSHMANOV, V.E.; TABAK, M. Localization of Dipyridamole in ionic micelles - Effect of micelle and drug charge. Biochimica et Biophysica Acta, 1238, p. 57-62, 1995.

[35] BORISSEVITCH, I.E.; TABAK, M. Electronic absorption and fluorescence spectroscopic studies of Dipyridamole - Effect of solution composition. Journal of Luminescence, 51, p. 315-322, 1992.

[36] CASTILHO, M., tese de doutorado, IQSC, USP, São Carlos, abril de 2001.

[37] ALVES, C.N.; CASTILHO, M.; MAZO, L.H.; TABAK, M.; SILVA, A.B.F. Theorical calculations on dipyridamole structure allow to explain experimental properties associated to electrochemical oxidation and protonation. Chemical Physics Letters, 349, p. 146-152, 2001. 
[38] BARD, A.J.; FAULKER L.R. Electrochemical Methods Fundamentals and Applications $-\mathbf{2}^{\text {nd }}$ Ed. New York:.JOHN WILEY \& SONS, INC., p. 417-418, 2001. 